Final Report

FHWA/IN/JTRP-2005/17

\title{
PROCEDURES FOR THE ESTIMATION OF PAVEMENT AND BRIDGE PRESERVATION COSTS FOR FISCAL PLANNING
}

\author{
By \\ Kumares C. Sinha \\ Olson Distinguished Professor \\ Samuel Labi \\ Visiting Assistant Professor \\ Marcela Rodriguez \\ Gabriel Tine \\ Rucci Dutta \\ Graduate Research Assistants \\ School of Civil Engineering \\ Purdue University \\ Joint Transportation Research Program \\ Project No. C-36-73W \\ File No.: 3-4-23 \\ SPR-2810 \\ Prepared in Cooperation with the \\ Indiana Department of Transportation and \\ The U.S. Department of Transportation \\ Federal Highway Administration
}

The contents of this report reflect the views of the authors who are responsible for the facts and the accuracy of the data presented herein. The contents do not necessarily reflect the official views of the Federal Highway Administration and the Indiana Department of Transportation. The report does not constitute a standard, a specification, or a regulation.

Purdue University

West Lafayette, Indiana, 47907

July 2005 


\section{TECHNICAL Summary}

INDOT Research

Technology Transfer and Project Implementation Information

TRB Subject Code: 14-3 Financial Programming

Publication No.: FHWA/IN/JTRP-200517, SPR-2810

July 2005

Final Report

\section{Procedures for the Estimation of Pavement and Bridge Preservation Costs for Fiscal Planning}

\section{Introduction}

Facility preservation generally refers to the set of activities that are carried out to keep a facility in usable condition until the next reconstruction activity. For fiscal planning and programming, it is necessary to know the expected costs of preservation projects and how long they would last. Such information, coupled with minimum standards and facility inventory data, enables estimation of overall monetary needs for bridge and pavement preservation, and can assist INDOT in undertaking appropriate programming and attendant financial planning over the long term. However, detailed engineering analyses are not possible every year because of the time and effort involved; therefore, simple procedures to broadly estimate annual pavement and bridge preservation needs are useful for long-term fiscal planning.

\section{Findings}

The study methodology consisted of first undertaking a full analysis based on engineering principles and detailed work in order to determine pavement and bridge needs for a period of time. Then simple procedures to estimate yearly pavement and bridge preservation costs were developed and the results were compared to the detailed engineering needs. Deterioration and cost models to establish engineering needs were developed using an array of statistical techniques including analysis of variance and regression analysis. Using the deterioration models, system inventory and minimum standards, the level of physical needs was determined for the entire pavement and bridge network over the analysis period. Finally, using the identified physical needs and developed cost models, the monetary needs were estimated. An age-based approach (that considers fixed time intervals instead of deterioration trends and minimum standards) was used for the bridge preservation needs. Based on the historical expenditure records and the amount of work performed in the past, simple regression models were developed to estimate future annual pavement and bridge preservation needs. The results obtained proved to be consistent with the engineering analysis.

\section{Implementation}

The study results are useful for longterm planning and budgeting as INDOT's Divisions of Policy and Fiscal Management and Planning will be able to schedule and monitor its pavement and bridge preservation cash flows in a more effective manner than what is possible at present. 


\section{Contacts}

For more information:

Prof. Kumares C. Sinha

Principal Investigator

School of Civil Engineering

Purdue University

West Lafayette, IN 47907-2051

Phone: (765) 494-2211

Fax: (765) 496-7996

E-mail: sinha@ecn.purdue.edu
Indiana Department of Transportation

Division of Research

1205 Montgomery Street

P.O. Box 2279

West Lafayette, IN 47906

Phone: (765) 463-1521

Fax: (765) 497-1665

\section{Purdue University}

Joint Transportation Research Program

School of Civil Engineering

West Lafayette, IN 47907-1284

Phone: (765) 494-9310

Fax: (765) 496-7996

E:mail: jtrp@ecn.purdue.edu

http://www.purdue.edu/jtrp 
TECHNICAL REPORT STANDARD TITLE PAGE

\begin{tabular}{|c|c|c|c|c|}
\hline $\begin{array}{l}\text { 1. Report No. } \\
\text { FHWA/IN/JTRP-2005/17 }\end{array}$ & \multicolumn{2}{|c|}{ 2. Government Accession No. } & \multicolumn{2}{|l|}{ 3. Recipient's Catalog No. } \\
\hline \multirow{2}{*}{\multicolumn{3}{|c|}{$\begin{array}{l}\text { 4. Title and Subtitle: Procedures for the Estimation of Pavement \& Bridge } \\
\text { preservation Costs for Fiscal Planning and Programming }\end{array}$}} & \multicolumn{2}{|l|}{$\begin{array}{l}\text { Report Date: } \\
\text { July } 2005\end{array}$} \\
\hline & & & \multicolumn{2}{|l|}{ 6. Performing Organization Code } \\
\hline \multicolumn{3}{|c|}{$\begin{array}{l}\text { 7. Author(s) } \\
\text { Kumares C. Sinha, Samuel Labi, Marcela Rodriguez, Gabriel Tine, Rucci Dutta }\end{array}$} & \multicolumn{2}{|c|}{$\begin{array}{l}\text { 8. Performing Organization Report No. } \\
\text { FHWA/IN/JTRP-2005/17 }\end{array}$} \\
\hline \multirow{2}{*}{\multicolumn{3}{|c|}{$\begin{array}{l}\text { 9. Performing Organization Name and Address } \\
\text { Joint Transportation Research Program } \\
550 \text { Stadium Mall Drive, Purdue University, West Lafayette, IN 47907-1284 }\end{array}$}} & \multicolumn{2}{|c|}{ 10. Work Unit No. } \\
\hline & & & \multicolumn{2}{|l|}{$\begin{array}{l}\text { 11. Contract or Grant No. } \\
\text { SPR-2810 }\end{array}$} \\
\hline \multirow{2}{*}{\multicolumn{3}{|c|}{$\begin{array}{l}\text { 12. Sponsoring Agency Name and Address } \\
\text { Indiana Department of Transportation, State Office Building, } 100 \text { N. Senate Ave. } \\
\text { Indianapolis, IN } 46204\end{array}$}} & \multicolumn{2}{|c|}{$\begin{array}{l}\text { 13. Type of Report and Period Covered } \\
\text { Final Report }\end{array}$} \\
\hline & & & \multicolumn{2}{|l|}{ 14. Sponsoring Agency Code } \\
\hline \multicolumn{5}{|c|}{$\begin{array}{l}\text { 15. Supplementary Notes } \\
\text { Prepared in cooperation with the Indiana Department of Transportation and Federal Highway Administration. }\end{array}$} \\
\hline \multicolumn{5}{|c|}{$\begin{array}{l}\text { 16. Abstract } \\
\text { Facility preservation generally refers to the set of activities that are carried out to keep a facility in usable condition until the next } \\
\text { reconstruction activity. For fiscal planning and programming, it is necessary to know the expected costs of preservation projects } \\
\text { and how long they would last. Such information, coupled with minimum standards and facility inventory data enable estimation } \\
\text { of overall monetary needs for bridge and pavement preservation, and would assist INDOT in undertaking appropriate } \\
\text { programming and attendant financial planning over the long term. However, detailed engineering analyses are not possible every } \\
\text { year because of the time and effort involved, therefore simple procedures to help estimate annual pavement and bridge } \\
\text { preservation needs are useful for long-term fiscal planning. } \\
\text { The study methodology consisted of first undertaking a full analysis based on engineering principles and detailed work in order to } \\
\text { determine pavement and bridge needs for a period of time. Then simple procedures to estimate yearly pavement and bridge } \\
\text { preservation costs were developed and the results were compared to the detailed engineering needs. Deterioration and cost models } \\
\text { to establish engineering needs were developed using an array of statistical techniques including analysis of variance and } \\
\text { regression analysis. Using the deterioration models, system inventory and minimum standards, the level of physical needs was } \\
\text { determined for the entire pavement and bridge network over the analysis period. Finally, using the identified physical needs and } \\
\text { developed cost models, the monetary needs were estimated. An age-based approach (that considers fixed time intervals instead of } \\
\text { deterioration trends and minimum standards) was used for the bridge preservation needs. Based on the historical expenditure } \\
\text { records and the amount of work performed in the past, simple regression models were developed to estimate future annual } \\
\text { pavement and bridge preservation needs. The results obtained proved to be consistent with the engineering analysis. }\end{array}$} \\
\hline $\begin{array}{l}\text { 17. Key Words } \\
\text { Bridge Preservation, Pavemen } \\
\text { Life, Preservation Cost, Rehal }\end{array}$ & $\begin{array}{l}\text { rvice } \\
\text { ance }\end{array}$ & $\begin{array}{l}\text { 18. Distribution Stat } \\
\text { No restrictions. This } \\
\text { National Technical Inf }\end{array}$ & $\begin{array}{l}\text { ment } \\
\text { cument is available to the pr } \\
\text { rmation Service, Springfield }\end{array}$ & $\begin{array}{l}\text { hrough the } \\
22161\end{array}$ \\
\hline $\begin{array}{l}\text { 19. Security Classif. (of this report) } \\
\text { Unclassified }\end{array}$ & & $\begin{array}{l}\text { rity Classif. (of this page) } \\
\text { Unclassified }\end{array}$ & $\begin{array}{c}\text { 21. No. of Pages } \\
111 \\
\end{array}$ & 22. Price \\
\hline
\end{tabular}




\section{ACKNOWLEDGEMENTS}

The authors wish to acknowledge the assistance provided by Messrs. Samy Noureldin, Gary Eaton, David Holtz, Jaffar Golkhajeh, (all of INDOT) and Keith Hoernschemeyer (of FHWA), who served on the Study Advisory Committee and provided valuable information at various stages of the study. For the acquisition of bridge data, we appreciate the assistance provided by Messrs. Ron Scott, Mike Jenkins, Dauda Ishola, and Bill Dittrich, all of INDOT. Regarding pavement data collection, we acknowledge the efforts of Messrs. William Flora and Mike Yamin. The assistance of Dr. Bob McCullouch and Aldy Haryopratomo are also acknowledged. We are also grateful to Dr. Barry Partridge, Chief of INDOT Research Division, and Karen Hatke, JTRP Coordinator, for their assistance in this research effort. 


\section{TABLE OF CONTENTS}

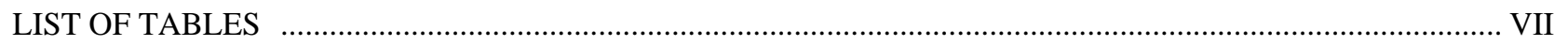

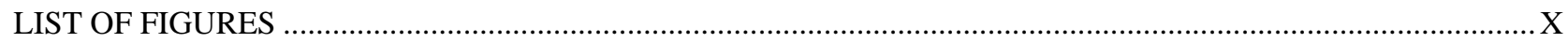

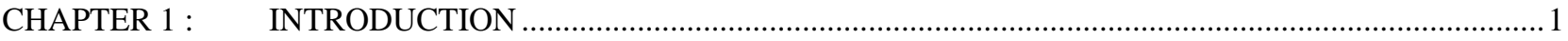

$\begin{array}{lll}1.1 & \text { Background and Problem Statement } & 1\end{array}$

1.2 Objectives of the Study 2

1.3 Study Overview 3

1.4 Scope of the Study 3

1.5 Alternative Methodologies for Estimating Service Lives of Preservation Treatments 4

1.5.1 Estimation of Preservation Treatment Service Life Based on Time Interval 4

1.5.2 Estimation of Preservation Treatment Service Life Based on Facility erformance/Condition 5

CHAPTER 2: LITERATURE REVIEW FOR PAVEMENT PRESERVATION NEEDS

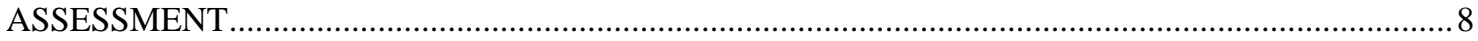

2.1 Needs Assessment Methodologies $\quad 8$

2.2 Review of Pavement Performance Models 9

$2.3 \quad$ Pavement Rehabilitation Costs 10

CHAPTER 3 : STUDY METHODOLOGY FOR PAVEMENT NEEDS ASSESSMENT....................................12

3.1 Study Framework 12

3.2 Methodology 13

3.2.1 Defining the Jorizon Period 13

3.2.2 Establishment of Minimum Standards 13

3.2.3 Development of Pavement Deterioration Curves 13

3.2.4 Development of Preservation Cost Models 15

CHAPTER 4： PAVEMENT SERVICE LIVES AND COST MODELS ..........................................................

4.1 Pavement Design Life 16

4.2 Pavement Condition 16

4.2.1 Pavement Deterioration Rates 17

4.2.2 Pavement Treatments 19

4.3 Pavement Preservation Cost Models 21

4.4 Unit Costs of Highway Routine Maintenance 22 
CHAPTER 5 : $\quad$ PAVEMENT PRESERVATION NEEDS ANALYSIS ..........................................................24

5.1 Collection and Processing of Data 24

5.2 Methodology 25

5.3 Interstate Initial Pavement Condition and Treatment 27

5.4 Non-Interstate NHS Pavement Condition and Initial Treatment 32

5.5 Non-Interstate Non-NHS Pavement Condition and Initial Treatment 34

5.6 Network Analysis Results 38

CHAPTER 6 : $\quad$ PROCEDURE FOR EVALUATING ANNUAL PAVEMENT PRESERVATION COST ...........40

6.1 Total System Size Prediction 41

6.2 Percentage of system to be treated 42

6.3 Estimation of total preservation cost using unit cost per lane mile 43

6.4 Rehabilitation and Non rehabilitation cost 45

6.5 Preservation cost by Highway Class 47

CHAPTER 7 : $\quad$ DEVELOPMENT OF BRIDGE PRESERVATION COST MODELS.....................................49

7.1 Introduction 49

7.2 Cost Estimation of Bridge Replacement 50

7.2.1 Slab Bridge Replacement Cost Models 50

7.2.1 Slab Bridge Replacement Cost Models 51

7.2.2 Pre-stressed Beam Bridge Replacement Cost Models 54

7.2.3 Steel Bridge Replacement Cost 58

7.2.4 Summary and Conclusions for Bridge Replacement Cost Modeling 59

7.3 Cost Estimation for Bridge Rehabilitation Activities 61

7.3.1 Deck Rehabilitation Cost Model

7.3.2 Deck and Superstructure Rehabilitation Cost Model 64

7.3.3 Deck Replacement Cost Model 65

7.3.4 Deck Replacement + Superstructure Rehabilitation Cost Model 67

7.3.5 Superstructure Replacement Cost Model 69

7.3.6 Superstructure Replacement + Substructure Rehabilitation Cost Models 71

7.3.7 Bridge Widening Cost Model 73

7.3.8 Summary and Conclusions for Bridge Rehabilitation Cost Models 76

7.4 Overall Summary and Conclusions for Bridge Preservation Cost Models 78

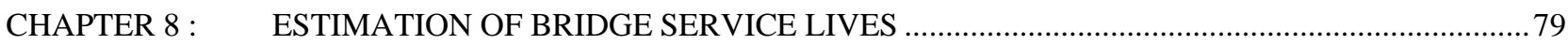


CHAPTER 9 : $\quad$ BRIDGE PRESERVATION EXPENDITURES ..............................................................83

9.1 Age-Based Needs 83

9.2 Estimated Needs Based on Historical Bridge Expenditures 87

9.2.1 Historical Expenditures 87

9.2.2 Projected Expenditure on the Basis of Historical Trends 88

9.3 Comparison of Age-Based Needs and Needs Based on Past Expenditure 89

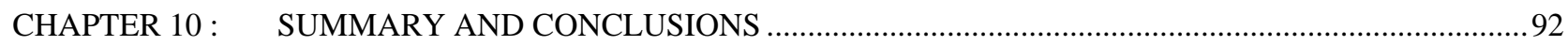

10.1 Summary of Estimation Procedures 92

10.2 Conclusions 93

REFERENCES

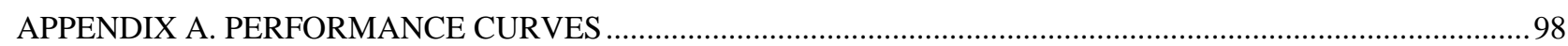

APPENDIX B. COST MODELS FOR ASPHALTIC CONCRETE PAVEMENTS ............................................101

APPENDIX C. INDOT CONTRACTS UNIT PAVEMENT TREATMENT COSTS ............................................103

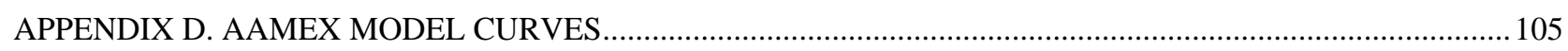

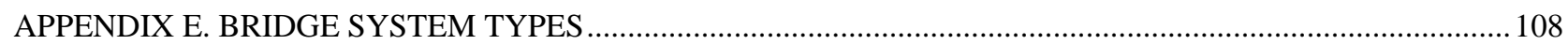




\section{LIST OF TABLES}

Table 4-1 Design Life of Pavement Treatments.................................................................................... 16

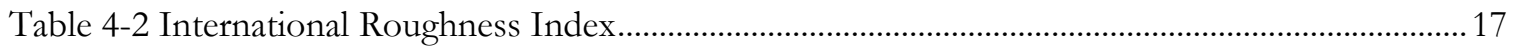

Table 4-3 Terminal Pavement Serviceability Ratings ...............................................................................17

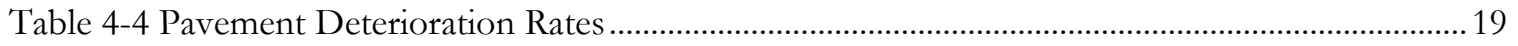

Table 4-5 Input Variables for Pavement Preservation Cost Models .......................................................... 22

Table 4-6 Average Pavement Treatment Costs per Lane-Mile ................................................................2 22

Table 4-7 Average Annual Maintenance Costs per Lane-Mile..................................................................... 23

Table 5-1 Network Analysis Pavement Resurfacing Deficiency Levels ....................................................25

Table 5-2 Network Analysis Pavement Reconstruction Deficiency Levels .............................................26

Table 5-3 Pavement Performance (IRI) Jumps after Treatment ..............................................................2 27

Table 5-4 Interstate HMA Pavement Treatment Thresholds......................................................................28

Table 5-5 Interstate PCC Pavement Treatment Thresholds........................................................................2

Table 5-6 Interstate COMP Pavement Treatment Thresholds ................................................................... 30

Table 5-7 Non-Interstate NHS HMA Pavement Treatment Thresholds................................................ 33

Table 5-8 Non-Interstate NHS PCC Pavement Treatment Thresholds................................................... 33

Table 5-9 Non-Interstate NHS COMP Pavement Treatment Thresholds ............................................... 34

Table 5-10 Non-Interstate, Non-NHS, HMA Pavement Treatment Thresholds...................................35

Table 5-11 Non-Interstate Non-NHS PCC Pavement Treatment Thresholds......................................... 36

Table 5-12 Non-Interstate Non-NHS COMP Pavement Treatment Thresholds ..................................36

Table 5-13 Fifteen-year Pavement Condition Preservation Needs Scenario A ........................................38

Table 5-14 Fifteen-year Pavement Condition Preservation Needs Scenario B ....................................... 39

Table 6-1 Comparison of actual and predicted pavement preservation costs for 2002 and 2003........ 44

Table 6-2 Percentage of money spent on different highway classes (2000 and 2001) ........................ 47

Table 6-3 2008 Pavement Preservation Costs by Highway class ..............................................................48

Table 7-1 Summary of Superstructure Replacement Cost Models for Slab Bridges ............................... 52

Table 7-2 Details of Best Superstructure Replacement Cost Model for Slab Bridges..............................52

Table 7-3 Summary of the Substructure Replacement Cost Models for Slab Bridges ............................. 53

Table 7-4 Details of Best Substructure Replacement Cost Model for Slab Bridges ................................. 53 
Table 7-5 Summary of Superstructure Replacement Cost Models for Pre-stressed Beam Bridges ..... 55

Table 7-6 Details of Best Model for Superstructure Replacement Cost of Pre-stressed Beam Bridges

Table 7-7 Summary of Substructure Replacement Cost Models for Pre-stressed Beam Bridges......... 56

Table 7-8 Details of Best Substructure Replacement Cost Model for Pre-stressed Beam Bridges...... 56

Table 7-9 Summary of the Approach Cost Models for Pre-stressed Beam Bridge Replacement ......... 57

Table 7-10 Details of Best Approach Cost Model for Pre-stressed Beam Bridge Replacement ...........57

Table 7-11 Summary of the "Other Cost" Models for Pre-stressed Beam Bridge Replacement .......... 58

Table 7-12 Details of Best "Other Cost” Model for Beam Bridge Replacement..................................... 58

Table 7-13 Descriptive Statistics of Replacement Unit Cost: for Steel Structure ....................................59

Table 7-14 Summary of Bridge Replacement Cost for Concrete Bridges ................................................. 60

Table 7-15 Summary of Deck Rehabilitation Primary Cost Models for all Bridge Types .....................62

Table 7-16 Summary of "Other Cost" Models for Deck Rehabilitation Contracts................................ 62

Table 7-17 Details of Best Deck Rehabilitation Primary Cost Model for all Bridge Types ..................63

Table 7-18 Details of Best Unit "Other Cost” Model for Deck Rehabilitation, all Bridge Types .......63

Table 7-19 Summary of Primary Cost Models for Deck + Superstructure Rehabilitation for all Bridge Types.

Table 7-20 Details of the Best Primary Cost Model for Deck + Superstructure Rehabilitation for all Bridge Types.

Table 7-21 Descriptive Statistics for Deck Replacement Total Cost .66

Table 7-22 Descriptive Statistics for Deck Replacement Unit Cost.. .66

Table 7-23 Descriptive Statistics for Deck Replacement + Superstructure + Substructure Rehabilitation Cost.

Table 7-24 Descriptive Statistics for Deck Replacement + Superstructure + Substructure Rehabilitation Cost

Table 7-25 Summary of Deck Replacement + Superstructure Rehabilitation Primary Cost Models for all Bridge Types. .68

Table 7-26 Best Deck Replacement + Superstructure Rehabilitation Primary Cost Model for all Bridge Types. .68

Table 7-27 Summary of Deck Replacement + Super Rehabilitation "Other Cost" Models for all Bridge Types. .68

Table 7-28 Details of Best Deck Replacement + Super Rehabilitation "Other Cost" Model for all Bridge Types. .69 
Table 7-29 Summary of Superstructure Replacement Primary Cost Models for all Bridge Types ......69

Table 7-30 Details of Best Superstructure Replacement Primary Cost Model for all Bridge Types.... 70

Table 7-31 Summary of Superstructure Replacement "Other Cost" Models for all Bridge Types.......70

Table 7-32 Details of Best Superstructure Replacement “Other Cost” Model for all Bridge Types... 70

Table 7-33 Summary of Superstructure Replacement + Substructure Rehabilitation Primary Cost

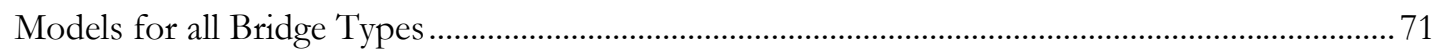

Table 7-34 Details of Best Superstructure Replacement + Substructure Rehabilitation Primary Cost

Model for all Bridge Types................................................................................................................ 71

Table 7-35 Summary of Superstructure Replacement + Substructure Rehabilitation "Other Cost"

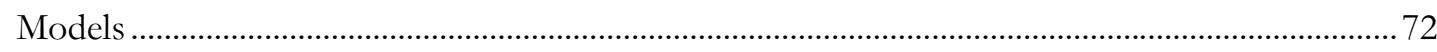

Table 7-36 Details of Best Superstructure Replacement + Substructure Rehabilitation "Other Cost"

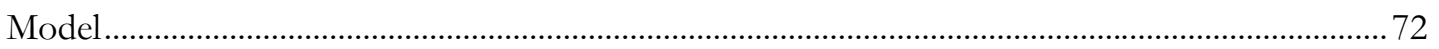

Table 7-37 Summary of Bridge Widening Primary Cost Models............................................................. 74

Table 7-38 Details of Best Bridge Widening Primary Cost Model for all Bridge Types ..........................74

Table 7-39 Summary of Bridge Widening “Other Cost” Models for all Bridge Types........................... 75

Table 7-40 Details of Best Bridge Widening “Other Cost” Model for all Bridge Types ........................75

Table 7-41 Summary of Rehabilitation Activity Cost Models ...................................................................... 77

Table 8-1 Results of Age-Based Physical Needs Assessment of Concrete Bridges, 2004-2015 ...........81

Table 8-2 Results of Age-Based Physical Needs Assessment of Steel Bridges, 2004-2015 ................... 82

Table 9-1 Age-Based Monetary Needs for Bridge Replacement, by Year and Structure Material....... 84

Table 9-2 Annual Deck Rehabilitation Needs by Structure Material .......................................................... 85

Table 9-3 Historical Bridge Expenditure from (1996-2003) .................................................................... 87

Table 9-4 Projected Bridge Expenditure from 2005 to 2015 .................................................................... 89

Table 9-5 Comparison of Needs Based on Past Expenditures and Needs Based on Age .................... 90

Table C.0-1 Unit Pavement Treatment Costs .............................................................................................103

Table C.0-2 Unit Costs of Pavement Treatments (Continued) ..................................................................104 


\section{LIST OF FIGURES}

Figure 1-1 Alternative Methodologies for Service Life Determination ..................................................... 4

Figure 1-2 Estimation of Preservation Treatment Service Life based on Time Interval ......................... 5

Figure 1-3 Estimation of Preservation Treatment Service Life Based on Time-Series ............................ 6

Figure 1-4 Estimation of Preservation Treatment Service Life Based on Cross-Sectional Condition

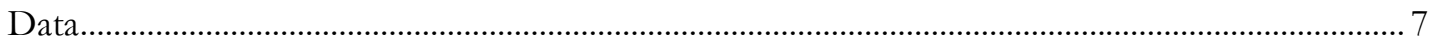

Figure 3-1 Framework Used for Pavement Preservation Needs Assessment ........................................ 12

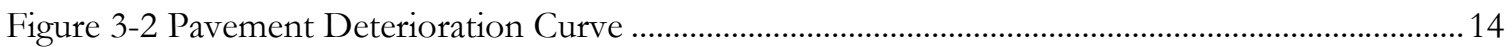

Figure 5-1 Distribution of Interstate Pavement as of Year 2001 ............................................................28

Figure 5-2 Methodology used for Excellent, Good and Good-To-Fair Pavements .............................. 31

Figure 5-3 Distribution of Non-Interstate NHS by Pavement Condition as of Year 2001 .................. 32

Figure 5-4 Distribution of Non-Interstate Non-NHS by Pavement Condition as of Year 2001 ......... 35

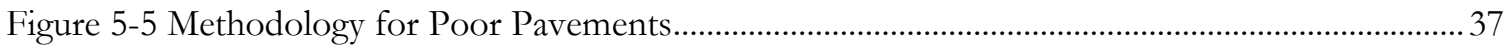

Figure 6-1 Indiana’s highway system size versus time .............................................................................. 41

Figure 6-2 Percentage of system preserved versus time ............................................................................42

Figure 6-3 Percentage of system rehabilitated versus time ……………………………...............................4 45

Figure 7-1 Schematic Illustration of Typical Concrete Slab Bridge Types ............................................... 51

Figure 7-2 Schematic Illustration of Typical Pre-stressed Concrete Bridge Sections ..............................54

Figure 7-3 Comparison of Unit Cost of Bridge Replacement between Steel and Concrete Bridges ... 59

Figure 7-4 Classification of Rehabilitation Cost Models Developed in Present Study ...........................61

Figure 7-5 Predicted and Actual Cost for Superstructure Replacement + Substructure Rehabilitation

Figure 8-1 Delineation of Bridge Age .............................................................................................. 79

Figure 9-1: Bridge Replacement Monetary Needs...................................................................................... 85

Figure 9-2 Bridge Rehabilitation Monetary Needs ................................................................................... 86

Figure 9-3 Modeling Bridge Preservation Expenditure ............................................................................ 88

Figure 9-4 Needs Based on Age and Historical Trends ............................................................................91 


\section{CHAPTER 1 : INTRODUCTION}

\subsection{Background and Problem Statement}

Facility preservation generally refers to the set of activities that are carried out to keep a facility in usable condition until the next reconstruction activity. For fiscal planning and programming, it is necessary to know the expected costs of preservation projects and how long they would last. Knowledge of such costs and service lives of preservation treatments, coupled with established minimum standards and facility inventory data (such as type, material, size, stage of deterioration and other characteristics) enable estimation of overall physical and monetary needs for preserving the state highway pavements and bridges. Such assessed needs would enable INDOT to undertake appropriate programming and attendant financial planning over the long term. The long-range financial plans would entail a projected cash flow schedule that indicates how much is needed and at what time it is needed. As these estimates are to be made at planning stage, expected input data can only include broad specification of project types along with data on unit costs, traffic characteristics, climatic features, and other data related to highway pavement and bridge condition and usage.

The current version of pavement and bridge management software packages used by INDOT incorporate several distinct types of preservation treatments. At the present time, it is not certain that there exists a direct and comprehensive analysis of the costs and service lives of facility preservation projects in a manner that would be consistent with INDOT's financial planners, particularly for the bridge projects. The cost and service life values currently in use may not properly reflect current conditions, because technological (preservation techniques) and economic changes in the transportation environment necessitate the re-estimation of highway facility preservation costs. It is therefore necessary to collect and analyze detailed post-construction data from recent years to develop appropriate models for pavement and bridge preservation. The development of such models is the focal point of the present study.

The present study investigated the information needs for programming and fiscal planning on project costs and service lives vis-à-vis the types of available information from the pavement and bridge management systems as well as from other sources. The study developed models to 
estimate/predict the cost and service life of various pavement and bridge preservation activity types, given facility characteristics such as functional class, material type, climatic region, and other variables.

It is important to note that within each preservation life-cycle, any of several alternative repair (maintenance and rehabilitation) strategies can be carried out. Therefore, the length of any preservation life-cycle is not fixed, but depends on the maintenance strategy within that cycle: generally, higher maintenance is associated with longer preservation life-cycles and vice versa. However, beyond a certain point, increasing maintenance leads to decreasing cost-effectiveness, therefore, for any given preservation type, there exists some optimal level of maintenance that should be carried out within the preservation life-cycle. The present study utilizes results from an earlier JTRP studies (Hodge et al., 2004; Rodriguez, 2004) that determined the preservation life-cycles corresponding to different levels of life cycle repair effort.

The study product will help INDOT to schedule and monitor its preservation cash flows in a more effective manner than what is possible at present. Also, the study provides a reliable and simple set of procedures for estimating annual preservation costs for pavement and bridge projects. It is expected that the study results will complement existing efforts by INDOT's pavement and bridge management systems in the provision of information related to preservation costs and service lives.

\subsection{Objectives of the Study}

The objectives of the study were as follows:

1) To collect and collate historical records of costs and service lives of pavement preservation and bridge replacement and rehabilitation projects,

2) To develop models for estimating service lives and costs of pavement preservation and bridge related activities.

3) To establish a simple procedure for INDOT's policy and fiscal management and programming divisions for estimating annual pavement and bridge preservation costs. 


\subsection{Study Overview}

The study is divided into two parts: first for pavements, and second for bridges. For each of these two facility types, the study investigated current service lives of pavements and bridges in the Indiana state highway system. Updated cost models were also developed to assess the financial needs for pavement and bridge over the 2005-2020 analysis period. This was carried out on the basis of: system size, minimum standards, deterioration trends for pavement, age for bridges and cost models. Simple procedures to estimate annual bridge and pavement expenditure were also developed. A comparison was made of the predicted expenditure with the estimated needs over the analysis period.

\subsection{Scope of the Study}

Spatial: Only pavements and bridges on the state highway system were considered. As much as possible, pavement sections and bridges at geographically diverse locations on the state network were included to capture any possible regional/climatic differences.

Temporal: Historical data for pavement and bridge cost and service life modeling was taken from projects executed between the years 1990-2003. This time period provided adequate time to evaluate the service lives of such projects. Due regard was given to the effect of changes in interest rate or construction price indices (CPI) within this period.

Project Types: Project types and their definitions were drawn from the planning and programming divisions and conformed to the need of the policy and fiscal management division.

Facility Material Type and Other Considerations: The study developed cost and service models for the types of bridges found on the state highway network, such as steel and reinforced-concrete bridges, and the types of pavements such as full-depth asphalt, rigid, and composite pavements. Also, all major functional classes of road on the network were considered. 
1.5 Alternative Methodologies for Estimating Service Lives of Preservation Treatments

There are several approaches that can be used to estimate the service life of pavement and bridge preservation treatments, as shown in Figure 1-1.

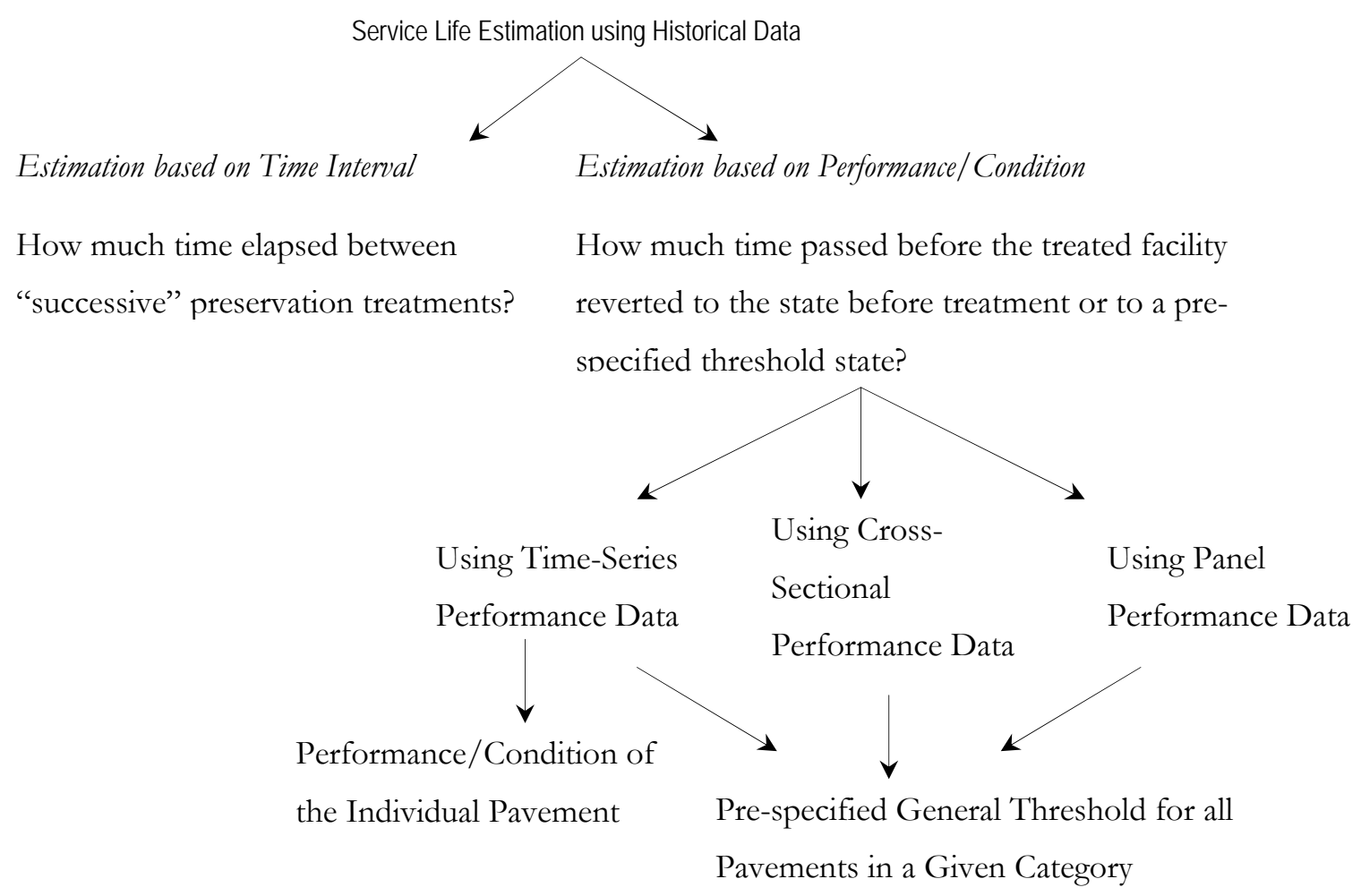

Figure 1-1 Alternative Methodologies for Service Life Determination

\subsubsection{Estimation of Preservation Treatment Service Life Based on Time Interval}

This approach simply involves measurement of the time interval that passes between a preservation treatment and the next similar or higher preservation treatment (Figure 1-2). 


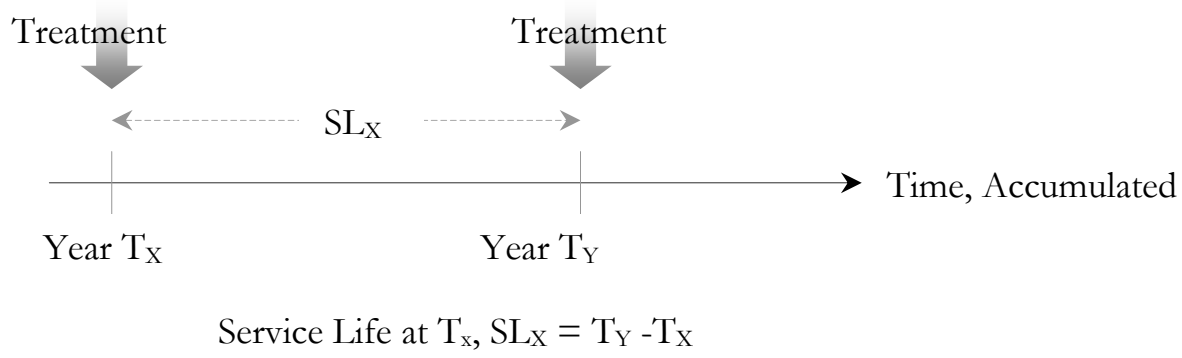

Figure 1-2 Estimation of Preservation Treatment Service Life Based on Time Interval

For each of several pavement sections or bridges that received the given preservation treatment, the service life can thus be determined, and expressed as an average value or as a function of facility type, traffic and weather characteristics. The advantage of this approach lies in its economy: no pavement performance/condition data is needed to establish service lives in this manner. However, for this approach to work, preservation treatment contract records spanning a considerable span of time should be available for each pavement or bridge. This is generally not the case at INDOT even though the Research Team has made earnest efforts in obtaining data of this sort.

\subsubsection{Estimation of Preservation Treatment Service Life Based on Facility Performance/Condition}

In this approach, service life of a preservation treatment can be determined by estimating the amount of time that passed before the treated facility reverted to the state before treatment or to a prespecified threshold state. Three separate approaches can be followed as discussed below.

Time Series. In this approach, the performance/condition of each individual facility (pavement section or bridge) that has received a specific preservation treatment is monitored over time. The time interval between the time of treatment and the time at which condition falls below the condition before treatment (Figure 1-3(a)) or a pre-specified condition (Figure 1-3(b)), is measured as the service life of the preservation treatment. If a pre-specified condition is used, the facility condition at time of treatment may be lower than that threshold (as shown in the illustration) or may be higher than the threshold. This approach is data intensive: facility performance/condition data is needed over a considerable span of time for each facility. 


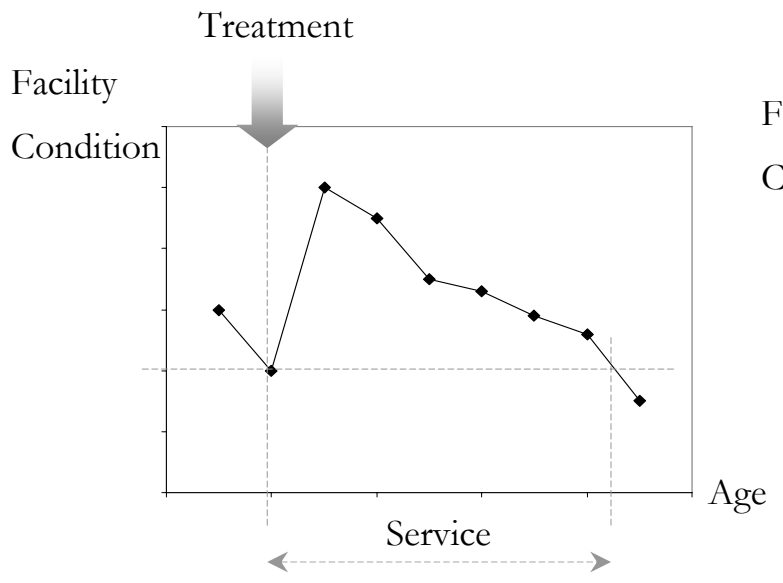

(a)
Treatment

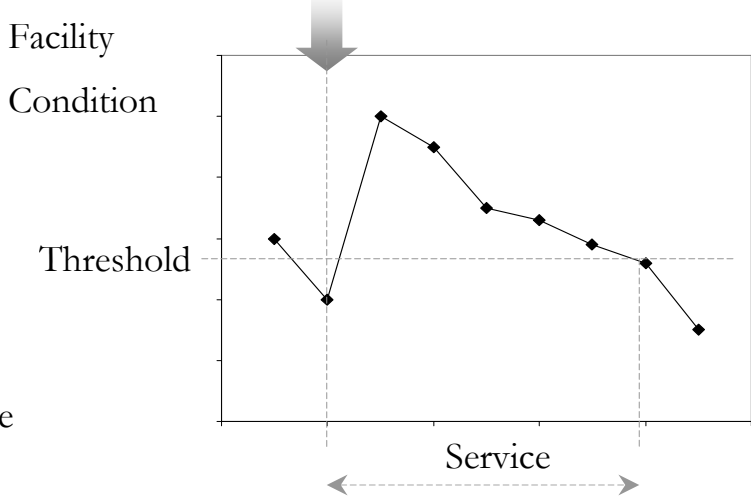

(b)

Figure 1-3 Estimation of Preservation Treatment Service Life Based on Time-Series

This may be repeated for several facilities that received the treatment in question, and the service lives thus obtained can simply be processed to give an average service life for that treatment, or may be expressed as a function of facility type, traffic, weather and other attributes, for that preservation treatment.

Cross Sectional: In this approach, the performance/condition (at any single given year only) of several facilities that received a specific treatment is used. As such facilities typically have a wide range of ages at the year in question, it is possible to obtain performance models that relate facility condition to facility age. Using such functions, it is possible to determine the average service life associated with the preservation treatment under investigation. 
Treatment

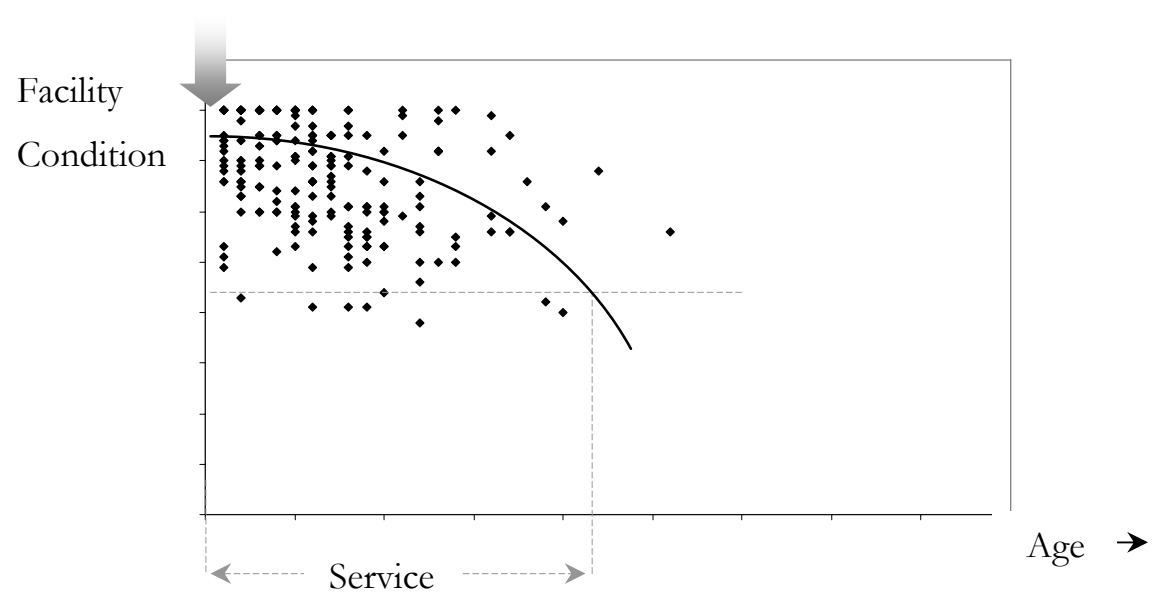

Figure 1-4 Estimation of Preservation Treatment Service Life Based on Cross-Sectional Condition Data

Panel Data: This approach, consistent with the pooling of data across years, is similar to that for cross-sectional data, with the exception that performance data for more than one year, rather than just one year, are used for developing performance models for facilities that received a specific treatment. Such analysis is susceptible to problems of auto-correlation, and it is important that appropriate statistical and econometric tools are employed to detect and correct for any such problems. 


\section{CHAPTER 2 : LITERATURE REVIEW FOR PAVEMENT PRESERVATION NEEDS ASSESSMENT}

\subsection{Needs Assessment Methodologies}

Need can generally be attributed to investment targeted to address an identified deficiency or maintain/operate existing facilities or transportation systems. (Hartgen, 1986). Need could be backlog or current need and accruing or future need. This need could be physical (need to maintain the physical condition) or monetary (cost associated with carrying out the physical needs). Physical need arises when a pavement's level of service falls below minimum tolerable conditions and thus indicating a deficiency. The state and local agencies accountable for maintaining millions of miles of the roadway pavements constantly seek tools to help them make cost-effective pavement repair decisions. Many agencies have implemented a pavement management systems (PMS) that help them assess and prioritize needs, and to optimize the use of available funds. From INDOT 2000-2025 Long Range Plan, it can be noted that INDOT places high priority on the preservation of the existing road system as demonstrated by the policy planning of 1995 statewide plan (INDOT, 1999). System preservation strategies can be developed, implemented and evaluated using the pavement management system (PMS). INDOT's Pavement Management System performs a pavement performance analysis which includes an estimate of present and predicted performance for specific pavement types and an estimation of the remaining service life of all pavements on the network. It also carries out a network level analysis that estimates total costs to correct present and future conditions of pavements across the network, and appropriate time periods, as determined by the state, for these investment analyses. Thus, the PMS system at INDOT conducts pavement condition analysis, pavement performance analysis and investment analysis to determine the needs for the pavement network. Thus, the PMS system at INDOT conducts pavement condition analysis, pavement performance analysis and investment analysis to determine the needs for the pavement network. To manage this pavement system effectively, it is important to determine existing pavement conditions and to predict remaining service life. These two aspects are some of the challenges facing transportation agencies like INDOT. 
The needs assessment study conducted by the Oregon Department of Transportation (ODOT) is a recent example of such efforts (Griffith et al., 2002). In this study, the pavement preservation methodology was based on extrapolation of historical data. In order to create the pavement preservation projection model, some basic assumptions were made. The pavement preservation forecast was based on the use of asphalt concrete (AC) overlays/inlays on all highways and the use of chip seals on low volume highways. Only three existing pavement types were considered, namely Asphalt Concrete (AC), Jointed Concrete pavement (JCP) and Continuously Reinforced Concrete Pavement (CRCP). Different preservation options were applied based on the existing type of pavement, traffic volumes, and urban or rural location. Preservation options, such as overlay, chip sealing, rubblizing were identified based on the existing surface type and functional class of the road and a predetermined value of treatment thickness was used in the model to estimate aggregate needs. The length of each highway segment in the ODOT system, as well as corresponding paved surface width was entered into a spreadsheet and thus by multiplying both, the surface area was determined. Knowing the surface area and thickness of the treatment, volumetric calculations of required paving were made for each highway segment. Thus the aggregate physical needs for pavement preservation was determined which was converted into monetary value by multiplying the aggregate volume for a treatment with the standard unit cost associated with each treatment. The preservation forecast model assumed a stable paving cycle in the 15-year period and did not consider fluctuations in funding levels from year to year. The major limitation of such approach is that needs are based on historical expenditure data which may not reflect actual requirements to maintain a certain level of condition.

\subsection{Review of Pavement Performance Models}

Pavement performance models are generally represented by condition versus age relationships. They reflect the deterioration patterns of the pavement section and thus help assess its present and future condition. Such models can be used to estimate the time when a pavement will reach a specified threshold condition and thus will require a preservation activity. The year in which a pavement section deteriorates to unacceptable levels is determined by extrapolating pavement deterioration curves for each type of pavement to be rehabilitated. As the concept of pavement performance curve to predict deterioration and forecast service life has been widely employed (NCHRP Synthesis 223), it was also utilized in the present study. 
The rationale for using the performance curve approach is simple: a consistently well maintained pavement (a gently sloping performance curve, yielding a large area under that curve) provides the user greater benefits than a poorly maintained pavement (a steep performance curve having a small underlying area). Because the benefits of a well-maintained pavement are numerous and difficult to quantify in monetary terms, the area under the performance curve could be used as a surrogate for user benefits. Another way of measuring benefit is to estimate the extended remaining service life by carrying out that improvement, i.e., time taken for the pavement to deteriorate to a certain threshold level (Geoffroy, 1996; Collura, 1993; Corvi et al, 1970).

\subsection{Pavement Rehabilitation Costs}

Rehabilitation policies are comprised of strategies that are simply a "collection" of one or more maintenance treatment types carried out at various points in time on a given pavement. The costs of the treatments are a necessary input to cost-effectiveness modeling, and they provide a quantitative measure of the cost aspect of any strategy. Rehabilitation treatment cost models are different from rehabilitation expenditure models in that the former are treatment specific, while the latter are specific to a pavement section. Rehabilitation treatment cost models are therefore more appropriate for assessing the costs of treatment strategies. Typically, factors that affect rehabilitation expenditure belong to two groups: pavement attributes (such as type, functional class, location, condition, etc.) and work source (in-house or by-contract) (Ben Akiva et al., 1990; Carnahan et al., 1987).

Also, it has been observed that preservation treatment unit accomplishment cost (UAC) models typically express the cost of a treatment in terms of dollars per unit output (tons, lane-miles, linear miles, etc.) (Feighan and Sinha, 1987). For a given rehabilitation treatment, the variation in unit accomplishment costs are typically due to variations in pavement attributes (such as location, condition, etc) on one hand, and treatment attributes such as type (alternative material or process), work source (in-house or by-contract) on the other hand. Using treatment levels and annualized cost data for various rehabilitation treatments received by pavements within a study period, models are usually developed to estimate the unit costs of various treatments. All costs indicated are in constant dollar of the present year but can be updated to current values using the Highway Construction and Maintenance Cost Indices.

The present study focused on estimating the agency costs associated with pavement preservation. Cost estimates for replacement, rehabilitation and maintenance activities are vital not 
only for life-cycle cost analysis and ultimately for pavement repair project prioritization and selection, but also for fiscal planning and budgeting.

In order to determine the costs for pavement preservation, equations can be developed that model the cost of the preservation activity as a function of significant variables. Agency costs can be obtained from historical data, either as an average value, or in the form of a model that estimates costs as a function of the pavement type, functional class, length, width and thickness of the preservation activity and other explanatory variables. For the identification of cost-effective pavement projects, cost models should be developed using explanatory variables. However, for the purpose of long range fiscal planning, procedures based on historical data may provide satisfactory results. 


\section{CHAPTER 3 : STUDY METHODOLOGY FOR PAVEMENT NEEDS ASSESSMENT}

\subsection{Study Framework}

For estimating the pavement preservation needs on actual requirements, the following methodology, as shown in Figure 3-1, was used.

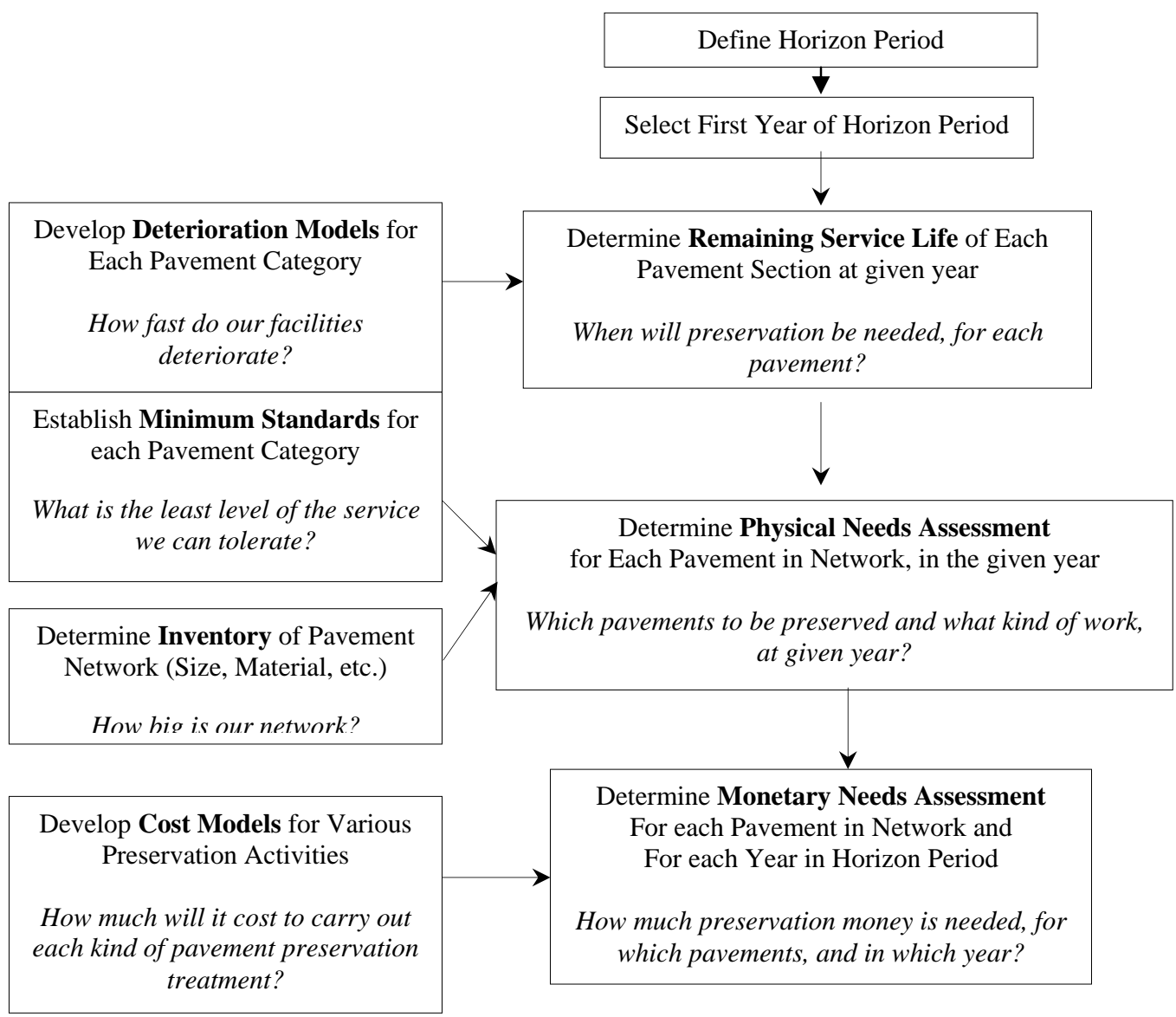

Figure 3-1 Framework Used for Pavement Preservation Needs Assessment 


\subsection{Methodology}

\subsubsection{Defining the Jorizon Period}

INDOT's 2000-2025 long-range plan calls for the implementation of hundreds of capacity expansion projects, with a total price tag of approximately $\$ 6.5$ billion [INDOT, 1999]. This needs assessment study can provide the information necessary to make cost-effective decisions about the rehabilitation of the pavement network in the long term. This long term period of needs assessment was defined in conjunction with INDOT's long range plan, and hence the horizon period of 15 years, i.e. 2006-2020 was considered for the analysis. 2002 was considered as the base year for the study.

\subsubsection{Establishment of Minimum Standards}

The use of condition triggers based on aggregate measures seems to be popular with many agencies including INDOT. In such formulations, maintenance and rehabilitation treatments are carried out any time the aggregate measure fall below certain thresholds or "trigger values". An advantage of using trigger values lies in their economy. There is no need to carry out field monitoring of each indicator of pavement distresses. However, a disadvantage is that the aggregate measures only give an indication of the overall pavement performance and fail to provide the distribution of various distresses which can be used to determine the treatment types.

\subsubsection{Development of Pavement Deterioration Curves}

The current or most recent condition of pavement sections is reported for the Indiana state highway system in terms of IRI and PSR. In the present study, based on the current and future conditions, the network pavement performance trend was developed in terms of needs distribution. The current age of the pavements was calculated by subtracting the base year from the year it was last rehabilitated. This analysis was performed using trigger or minimum acceptable index (IRI) values. Pavement sections with performance indices below the trigger level were identified as needs and were recommended for rehabilitation treatments. The current age was identified on pavement performance curve and thus the year when the pavement section would reach the minimum threshold limit was estimated on the curve. Such determined year was an indicator of the service life of the pavement. Thus, subtracting the current age from the service life provided the remaining service life values. Remaining service life provided the time frame when the next rehabilitation 
activity was due. All the forecasted preservation sections were summed up for a particular year, which helped determine the total number of miles that need to be rehabilitated for each year for the horizon period. This concept is explained in Figure 3-2.

The results of the analysis provide a useful tool to understand the current and future conditions of the highway network. The remaining service lives of the pavements were also determined by subtracting the current age of the pavements from the service (design) life values for rehabilitated pavements given as default service life values in the Indiana Design Manual (IDM). This method is not very reliable because it gives a preset interval when the rehabilitation work needs to be carried out in the future, irrespective of the condition of the pavement at that particular time period. The pavements could deteriorate more or less depending upon the traffic and environmental conditions. Hence the method based on conditions should be a better estimate of the remaining service life of the rehabilitated pavements.

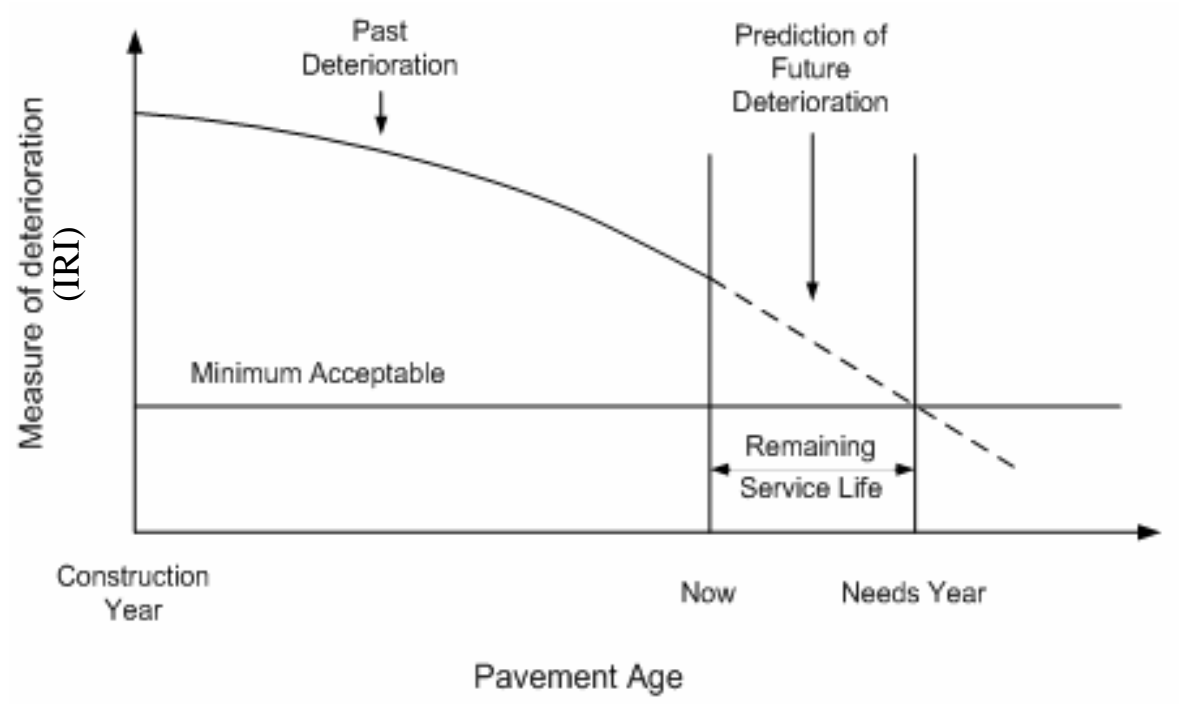

Figure 3-2 Pavement Deterioration Curve 


\subsubsection{Development of Preservation Cost Models}

Once the pavement sections that needed preservation were identified, or in other words the total miles to be preserved each year were calculated, cost models were used for the assessment of the monetary needs involved. The cost models were developed using unit preservation cost as the dependent variable, as a function of various pavement preservation treatment attributes (such as road width, new pavement thickness) and physical characteristics of the pavements (such as functional class, age, resurfacing year, location) and other explanatory variables.. 


\section{CHAPTER 4 : PAVEMENT SERVICE LIVES AND COST MODELS}

\subsection{Pavement Design Life}

Pavements are typically designed for 15 to 30-year design lives (INDOT, 1998). Table 4-1 presents the typical design life of various pavement treatments as provided by INDOT.

Table 4-1 Design Life of Pavement Treatments

\begin{tabular}{lc}
\hline \multicolumn{1}{c}{ Pavement Treatment } & Design Life (years) \\
\hline New PCCP & 30 \\
Concrete Pavement over Existing Pavement & 25 \\
New Full Depth HMA & 20 \\
HMA Overlay over Rubblized PCCP & 20 \\
HMA Overlay over Asphalt Pavement & 15 \\
HMA Overlay over Cracked and Seated PCCP & 15 \\
HMA Overlay over CRC Pavement & 15 \\
HMA Overlay over Jointed Concrete, Sawed and Sealed Joints & 15 \\
HMA Overlay over Jointed Concrete & 12 \\
PCCP Joint Sealing & 8 \\
Thin Mill and Resurface of Existing Asphalt & 8 \\
Concrete Pavement Rehabilitation (CPR) Techniques & 7 \\
Microsurface Overlay & 6 \\
Chip Seal & 4 \\
Asphalt Crack Sealing & 3 \\
\hline Sorce Inat &
\end{tabular}

Source: Indiana Design Manual, Chapter 52, 1998

\subsection{Pavement Condition}

Pavement condition influences user costs, such as vehicle operating costs, safety, and travel time. Two measures of pavement condition were used in this research, the Pavement Serviceability Rating (PSR) and the International Roughness Index (IRI). The Pavement Serviceability Rating (PSR) is a subjective rating of pavement ride quality which requires visual inspection of the pavement. According to the INDOT Design Manual (IDM) Chapter 52, the pavement is rated from 
0 to 5 , where 0 is totally impassable or failed pavement and 5 is a pavement in excellent condition. The manual assumes an initial serviceability index of 4.2 .

IRI is a physical measure of the pavement ride quality and captures the "bumpiness" of the pavement in terms of inches per mile. The higher the IRI value, the rougher is the ride. A review of a set of sample data collected from INDOT suggests that a new flexible pavement would have an initial IRI of 60 and typical new rigid pavement would have an initial IRI of 70. A summary of the IRI index as provided by the Pavement Management Section of the Program Development Division of INDOT is illustrated in Table 4-2.

Table 4-2 International Roughness Index

\begin{tabular}{cc}
\hline Pavement Condition & IRI Range \\
\hline Excellent & $60-100$ \\
Good & $100-150$ \\
Fair & $150-200$ \\
Poor & $>200$ \\
\hline
\end{tabular}

INDOT, 2000

Over time, new pavements deteriorate due to traffic loads and weather effects, and the PSR value decreases. A pavement is considered to have reached its terminal serviceability between a PSR of 2.5 to 2.0 , depending on its functional classification. A summary of terminal serviceability ratings for pavements is shown in Table 4-3.

Table 4-3 Terminal Pavement Serviceability Ratings

\begin{tabular}{cc}
\hline Pavement Classification & PSR \\
\hline Rural major collector and above & 2.5 \\
Rural minor collector and below & 2.0 \\
Urban arterials & 2.5 \\
Urban collectors and below & 2.0 \\
\hline Source: INDOT Design Manual, Chapter 52,1998
\end{tabular}

\subsubsection{Pavement Deterioration Rates}

Rehabilitation based on trigger values implies that a specific rehabilitation activity is carried out anytime a selected measure of pavement condition reaches a certain threshold value. For the measure of pavement performance, the pavement IRI values as of 2002 were considered. A deterioration curve that depicts the rate of deterioration of pavements over time was plotted for nine 
families of pavements, thus providing a tool with which the effective remaining service life of a particular pavement could be predicted. The deterioration curves were plotted with age as the Xvariable and IRI as the Y-variable. The current age of the pavement was estimated by subtracting the year when last work was done from the current year. With the knowledge of the current age of the pavement, and the deterioration curve, the year when the pavement would reach the threshold value could be established by extrapolating the curve. The performance curve showed IRI values varied linearly with age. Statistical equations for the performance curves were obtained using a spreadsheet. The trigger values for the pavement families were put in the equation and the corresponding age, when the pavement would reach that trigger value, was obtained. This was referred as the needs year. Thus, the current age was subtracted from the needs year to obtain the remaining service life of the pavements. Details of the models are presented in Appendix A.

Pavement deterioration curves based on PSR (Pavement Serviceability Rating) were also developed (Lamptey et al., 2004). The curves indicated that the average rate of deterioration for Indiana pavements can be taken as 0.2 PSR per year. To determine the corresponding change in IRI associated with a 0.2 PSR/year deterioration rate, Equation 4-1 (Gulen et al., 1994 and INDOT, 2000) relating IRI to PSR was used.

$$
P S R=9.0 \times \varepsilon^{(-0.008747 \times I R I)}
$$

Eq. 4-1

Using this equation, a new pavement with an initial PSR of 4.2 and a pavement deterioration rate of $0.2 \mathrm{PSR} /$ year has an equivalent change in IRI due to pavement deterioration of $6 \mathrm{IRI} /$ year. Using this method, a new pavement with a PSR of 4.2 would have a condition rating of 4.0 PSR after one year. The pavement needs analysis for the network method is based on deterioration rates of 0.2 PSR/year and 0.3 PSR/year, which correspond to deterioration rates of 6 IRI/year and 8 IRI/year respectively, using a PSR pf 4.2 as the starting condition. Table 4-4 illustrates the pavement deterioration rates in terms of IRI and PSR. 
Table 4-4 Pavement Deterioration Rates

\begin{tabular}{ccccc}
\hline Initial & \multicolumn{2}{c}{ Deterioration Rate } & \multicolumn{2}{c}{ Condition After 1 Year } \\
\cline { 2 - 5 } $\begin{array}{c}\text { Condition } \\
\text { Rating (PSR) }\end{array}$ & $\Delta$ PSR/Year & $\Delta$ IRI/Year & PSR & IRI \\
\hline \multirow{3}{*}{ 4.2 PSR } & 0.2 & 6 & 4.00 & 93 \\
& 0.25 & 7 & 3.95 & 94 \\
& 0.3 & 8 & 3.90 & 96 \\
& 0.4 & 11 & 3.80 & 99 \\
\hline
\end{tabular}

\subsubsection{Pavement Treatments}

There are many types of treatments that can be selected to improve the condition of pavements as illustrated in Table 4-1. Descriptions of common pavement treatments as outlined in the IDM and the April 2003 INDOT Memorandum entitled "FY-2004 Pavement Preservation Guidance (Draft)," are discussed in the sections that follow. The terms "3R" and "4R," when used in a pavement treatment context, imply the following:

- $\quad 3 \mathrm{R}$ projects are used for rehabilitating the pavement. This is major pavement work that will include pavement rehabilitation or reconstruction; shoulder work such as patching and/or replacement; and limited pipe work and safety work. Work may include curb or sidewalk work and minor realignment of the road centerline at specific spot locations. No right-of-way acquisition is needed (INDOT, 2003).

- $4 \mathrm{R}$ projects are intended to replace the entire pavement structure. This is major pavement work that generally requires the correction of all safety defects and reconstruction of items outside the pavement structure. Work includes bringing the road up to current geometric standards, upgrading all safety features, and upgrading all drainage features. Work may include added travel lanes if authorized by the INDOT LRP. 


\subsubsection{Preventive Maintenance Treatments}

NCHRP Report 223 provides two convenient criteria for maintenance activities: urgency of the activity and the effect of the activity. Geoffroy (1996) provided the following descriptions for maintenance activities:

- Routine Maintenance: Day-to-day activities that are scheduled and whose timing is within the control of maintenance personnel, such as moving and ditch cleaning. "Routine maintenance" is a broad term often used to describe any activity that is carried out on a routine basis, such as routine preventive maintenance, i.e., crack sealing; routine corrective maintenance, i.e., patching; and non-pavement routine maintenance, i.e., mowing and underdrain maintenance.

- Demand Maintenance: Urgent activities that must be done in response to an event beyond the control of maintenance personnel, i.e., any emergency repair of a pavement.

- Corrective Maintenance: Planned activities to repair deficiencies, i.e., shallow patching to increase the structural capacity at a localized area.

- Preventive Maintenance: Planned activities that correct minor defects, slow down future deterioration, and maintain and improve the functional condition of the system while not substantially increasing the structural capacity.

Preventive Maintenance (PM) is intended to extend the life of the pavement by arresting light deterioration, retarding progressive damage, and reducing the need for routine maintenance. The proper time for PM is before the pavement experiences severe distress, structural problems, and moisture or aging-related damage.

The commonly used PM treatments on asphalt surfaces include: chip sealing, crack sealing, micro-surfacing, sand sealing, and thin hot-mix asphalt (HMA) overlays with or without milling. Thin HMA overlays may involve a single course of $40 \mathrm{~mm}$ HMA. For concrete pavements, the pavement could receive Concrete Pavement Rehabilitation (CPR) techniques, such as joint sealant replacement, contract crack sealing, minor patching, and retrofit joint load transfer. Cleaning and sealing of joints for PCC pavement includes inspecting contraction and longitudinal joints for loose, missing, or depressed sealant. Defective sealants are removed and replaced. This prevents dirt and moisture from entering the joints. 


\subsubsection{Pavement Rehabilitation Partial 3-R}

This treatment includes a new surface placed on the existing road to improve service. The project is not constructed to the current $3 \mathrm{R} / 4 \mathrm{R}$ standards (which could include alignment work). The primary intent is to restore the surface of the road by several methods. Incidental work such as curbs, drains, shoulders, guardrail or other facility improvements also may be included. This type of work does not widen, modernize, or significantly upgrade the facility.

\subsubsection{Pavement Replacement/Reconstruction}

This treatment replaces existing mainline pavement with new pavement. The new pavement may be wider than the existing or have a number of lanes that is different from the original. Incidental work, such as grading, drains, shoulders, or guard rails, for the purpose of modernizing the facility and enhancing safety may be included.

\subsection{Pavement Preservation Cost Models}

Cost models were developed from contract data provided by INDOT. Preservation project costs were converted into unit costs (dollars/square-feet). Statistical regression technique (SPSS software) was used to develop models for estimating preservation costs, as a function of the physical characteristics of the pavement, such as the length and width of the pavement rehabilitation section, thickness of repair work, functional class, pavement type, and location of the pavement: north or south, PSI, surface milling and the year of the last rehabilitation work. Three types of cost models were developed depending upon the type of pavement, i.e., Asphaltic Concrete, Portland Cement Concrete and Composite. The NHS and Non-NHS classification was not found to be significant since unit rehabilitation costs were almost the same for these two categories. Table 4-5 shows the variables included in the models and as they were found to be significant or otherwise. 
Table 4-5 Input Variables for Pavement Preservation Cost Models

\begin{tabular}{|c|c|}
\hline Significant & Non-Significant \\
\hline Length & Functional Class \\
\hline Width & Year of Rehab \\
\hline Thickness & PSI \\
\hline North Factor & \\
\hline South Factor & \\
\hline Surface Milling & \\
\hline
\end{tabular}

T-Statistics of each variable was used to determine the effect of each of the significant variable. The details of the models are presented in Appendix B

Several sources were also investigated for Indiana-specific pavement treatment costs. Average costs per lane-mile for treatments by pavement type were obtained from the JTRP project entitled, "Life Cycle Cost Analysis for Pavement Design Procedures" (Lamptey et al., 2004). A list of common pavement treatments and their costs per lane-mile is provided in Table 4-6. A complete description of all of the pavement treatment costs is shown in Table C1 and Table C2 in Appendix C.

Table 4-6 Average Pavement Treatment Costs per Lane-Mile

\begin{tabular}{|c|c|c|c|}
\hline Treatment & $\begin{array}{c}\text { Flexible } \\
\text { Pavement } \\
\text { (HMA) }\end{array}$ & $\begin{array}{l}\text { Rigid } \\
\text { (PCC) }\end{array}$ & $\begin{array}{c}\text { Composite } \\
\text { (COMP) }\end{array}$ \\
\hline Joint and Crack Sealing & - & $\$ 539 \mathrm{a}$ & - \\
\hline Preventive Maintenance & $\$ 72,689 \mathrm{~b}$ & - & $\$ 72,689^{b}$ \\
\hline Resurfacing Partial 3-R Standards & $\$ 297,263^{b}$ & $\$ 297,263 c$ & $\$ 297,263^{b}$ \\
\hline Reconstruction/Replacement & $\$ 1,394,329^{\mathrm{b}}$ & $\$ 1,454,117^{b}$ & $\$ 1,394,329^{b}$ \\
\hline
\end{tabular}

4.4 Unit Costs of Highway Routine Maintenance

Average maintenance costs were obtained from models developed by Labi and Sinha (2003). The average annual maintenance expenditure (AAMEX) models were developed for interstate and non-interstate pavements as functions of pavement age, functional class, surface type, and other 
pavement attributes. The models include all categories of maintenance. The expenditures were reported in 1995 dollars per lane-mile and the average values are listed here:

- Interstate PCC $-\$ 1,093$

- $\quad$ Interstates HMA $-\$ 1,100$

- $\quad$ Non-Interstate HMA - $\$ 500$

- $\quad$ Interstates COMP $-\$ 410$

- $\quad$ Non-Interstate COMP - $\$ 590$

Where two curves are provided for one road classification, the higher cost curve was used. The average costs reflect the average of all pavement ages. The AAMEX models are illustrated in Appendix D. The AAMEX values were adjusted to year 2002 dollars and are listed in Table 4-7.

Table 4-7 Average Annual Maintenance Costs per Lane-Mile

\begin{tabular}{cccc}
\hline Facility Type & $\begin{array}{c}\text { Flexible Pavement } \\
(\text { HMA) }\end{array}$ & $\begin{array}{c}\text { Rigid } \\
(\text { PCC) }\end{array}$ & $\begin{array}{c}\text { Composite } \\
(\text { COMP) }\end{array}$ \\
\hline $\begin{array}{c}\text { Interstate } \\
\text { Non Interstate }\end{array}$ & $\$ 1,335$ & $\$ 1,326$ & $\$ 497$ \\
$\$ 607$ & $\$ 1,326$ & $\$ 716$ \\
\hline
\end{tabular}

Labi and Sinha (2003).

Costs are expressed in Year 2002 dollars.

Maintenance costs were estimated in dollars per lane-mile as a function of PSI rather than age. Unit costs are based on parameters associated with the amount of damage to the pavement at each PSI level and the maintenance activities included crack sealing, surface patching and deep patching. 


\section{CHAPTER 5 : PAVEMENT PRESERVATION NEEDS ANALYSIS}

The network needs analysis method was used to establish pavement resurfacing and reconstruction needs. This chapter describes the data and methodology used for the network condition analysis approach. The unit pavement treatment costs developed by Lamptey et al. (2004), as shown in Table 4-6, and the average annual maintenance expenditure costs (Labi and Sinha, 2003), given in Table 4-7, were used for this analysis.

Two pavement deterioration rates were used in the analysis: 6 IRI and 8 IRI per year. The analysis used IRI pavement condition levels as a trigger to initiate specific pavement treatments based on the pavement condition ranges established by INDOT. All lane-miles were treated with regular annual maintenance, using the AAMEX curves developed by Labi and Sinha (2003).

The data used in the manual method did not include information on shoulders, capacity, or alignment deficiencies, and the need estimates therefore are based solely on improvements to the mainline pavement and do not include costs for improvements in alignments, shoulder, or capacity. Capacity improvement needs, such as pavement widening, are based on those identified in the INDOT LRP. Safety needs in this manual method are based on an estimate of 9.4 million dollars per year, in year 2002 constant dollars, for road segments only (excluding intersections) as identified in the research project by Lamptey et al. (2004), which utilized the Indiana Safety and Congestion Management Systems Software. For the present study, the safety improvement need at intersections was based on improvements identified in the LRP.

\subsection{Collection and Processing of Data}

The 2001 pavement contracts database used in t he research by Lamptey et al. (2004) was obtained for use as a source of pavement condition data. The contracts database was sorted to group the pavements into three main categories: HMA, PCC, and Composite (HMA over PCC). The pavements were then separated by location: Interstate, Non-Interstate NHS (on the National Highway System), and Non-Interstate Non-NHS. The needs analysis was conducted on the pavements based on these categories of pavement type and location. 


\subsection{Methodology}

The same pavement condition threshold levels used in HERS-ST analysis were used to trigger pavement treatments. Tables 5-1 and 5-2 illustrate the equivalent IRI deficiency thresholds used for resurfacing and reconstruction treatments in the manual analysis method based on the equivalent deficiency thresholds used for HERS-ST.

Table 5-1 Network Analysis Pavement Resurfacing Deficiency Levels

\begin{tabular}{ccc}
\hline Location & $\begin{array}{c}\text { INDOT IRI } \\
\text { Equivalent }\end{array}$ & $\begin{array}{c}\text { HERS Deficiency } \\
\text { Level }\end{array}$ \\
\hline Interstate & 118 & 3.2 \\
\hline Principal Arterial AADT $>6000$ & 118 & 3.2 \\
\hline Principal Arterial AADT $<6000$ & 126 & 3.0 \\
\hline Minor Arterial AADT $>2000$ & 142 & 2.6 \\
\hline Minor Arterial AADT $<2000$ & 142 & 2.6 \\
\hline Major Collector AADT $>1000$ & 151 & 2.4 \\
\hline Major Collector AADT $>400$ & 151 & 2.4 \\
\hline Major Collector AADT $<400$ & 161 & 2.2 \\
\hline Urban Interstate & 111 & 3.4 \\
\hline Urban Freeway & 118 & 3.2 \\
\hline Urban Principal Arterial & 126 & 3.0 \\
\hline Urban Minor Arterial & 142 & 2.6 \\
\hline Urban Collectors & 151 & 2.4 \\
\hline
\end{tabular}

a. Calculated using Gulen (1994).

b. Default values from HERS-ST.

According to Table 5-1, a 3.2 PSR for a principal arterial is equivalent to 118 IRI, which means that if a pavement condition falls below 118 IRI, then resurfacing is implemented. For urban minor arterials, if the IRI falls below 142, then the pavement is resurfaced. Similarly, in Table 5-2, if an urban interstate has an IRI of less than 161, it receives pavement reconstruction. 
Table 5-2 Network Analysis Pavement Reconstruction Deficiency Levels

\begin{tabular}{ccc}
\hline Location & $\begin{array}{c}\text { INDOT IRI } \\
\text { Equivalent }\end{array}$ & $\begin{array}{c}\text { HERS Deficiency } \\
\text { Level (PSR) }\end{array}$ \\
\hline Interstate & 172 & 2 \\
\hline Principal Arterial AADT $>6000$ & 172 & 2 \\
\hline Principal Arterial AADT $<6000$ & 172 & 2 \\
\hline Minor Arterial AADT $>2000$ & 205 & 1.5 \\
\hline Minor Arterial AADT $<2000$ & 205 & 1.5 \\
\hline Major Collector AADT $>1000$ & 221 & 1.3 \\
\hline Major Collector AADT $>400$ & 221 & 1.3 \\
\hline Major Collector AADT $<400$ & 240 & 1.1 \\
\hline Urban Interstate & 161 & 2.2 \\
\hline Urban Freeway & 172 & 2 \\
\hline Urban Principal Arterial & 184 & 1.8 \\
\hline Urban Minor Arterial & 221 & 1.3 \\
\hline Urban Collector & 240 &
\end{tabular}

After sorting the pavement data by location and pavement material type, the data was analyzed to determine the number of lane-miles that fell within the INDOT-specified IRI ranges from excellent to poor. The good-to-excellent category was split into an upper and lower range of good condition to create the option for additional pavement treatments for pavements in the goodto-excellent range. The treatment IRI ranges were:

- Excellent - Good, IRI $=60-100$

- Good, IRI=101 --125

- Good - Fair, IRI = $126--150$

- $\quad$ Fair, IRI $=151-200$

- $\quad$ Poor, $\mathrm{IRI}=>200$

The initial IRI is the condition of the pavement at the time of the pavement condition survey in year 2001. The initial pavement IRI was compared to the established trigger values that would indicate the need for a resurfacing project, a reconstruction project, or a "do nothing" option. Annual maintenance was applied each year to all pavements. The research by Lamptey et al. (2004) determined the average increase in pavement condition or "performance jump" after specific treatments were applied based on historical data from the contracts database. Two treatments used in the network analysis utilized the performance jumps identified by Lamptey et al., specifically, thin overlays and cleaning and sealing of joints on portland cement concrete pavement (PCCP). The average pavement performance jump associated with these treatments is illustrated in Table 5-3. 
Forty-two pavement sections were used in the analysis of the pavement jump associated with HMA overlays and 18 sections of pavement data were used to determine the pavement performance jumps associated with cleaning and sealing of joints on concrete pavement. Based on the performance jump information provided by Lamptey et al. (2004), the condition of the pavement should improve by 53.3 IRI after an HMA overlay and improve by 22.7 IRI after cleaning and sealing of joints on PCC pavement.

Table 5-3 Pavement Performance (IRI) Jumps after Treatment

\begin{tabular}{ccc}
\hline Treatment Type & $\begin{array}{c}\text { Average } \\
\text { Jump }\end{array}$ & $\begin{array}{c}\text { No. of } \\
\text { Sections }\end{array}$ \\
\hline HMA Overlay, Preventive Maintenance & 53.5 & 42 \\
PCCP Cleaning and Sealing Joints & 22.7 & 18 \\
\hline
\end{tabular}

Lamptey et al. (2004).

Pavements with less than 126 IRI at the start of the analysis were treated so as keep all of them in that condition over the 15-year analysis period. In essence, any pavements in excellent condition at the start of the analysis therefore would be maintained in that excellent condition category. The trigger value for work on pavements with initial IRI of $<126$ was 118 IRI. Specific treatments were selected to represent the typical treatments to be applied to pavements based on their IRI. Flexible pavements (HMA) in good to fair condition (IRI 126 to 150) would be treated with preventive maintenance or a thin HMA overlay specifically, while PCC pavements in good to fair condition would be treated with joint and crack sealing. The typical treatment for pavements in fair condition (IRI 151-200) was the Resurfacing Partial 3-R standards, while those in poor condition would be replaced or reconstructed. Any pavement that received a Resurfacing Partial 3-R standards or Reconstruction as the initial treatment was assumed to be returned to excellent condition, specifically 60 IRI for HMA pavements and 70 IRI for concrete pavements, which are the accepted IRI conditions for new pavements of those material types.

\subsection{Interstate Initial Pavement Condition and Treatment}

A total of 4,143 lane-miles of interstate were included in the analysis. A summary of the initial pavement conditions, as well as the initial treatment chosen for the interstate pavement data, are provided in Table 5-4. Approximately, 92 percent of the interstate system was in excellent condition; 97 percent was in excellent or good condition; and there were no lane-miles on the interstate in poor condition. Figure 5-1 illustrates the interstate pavement condition in year 2001. 


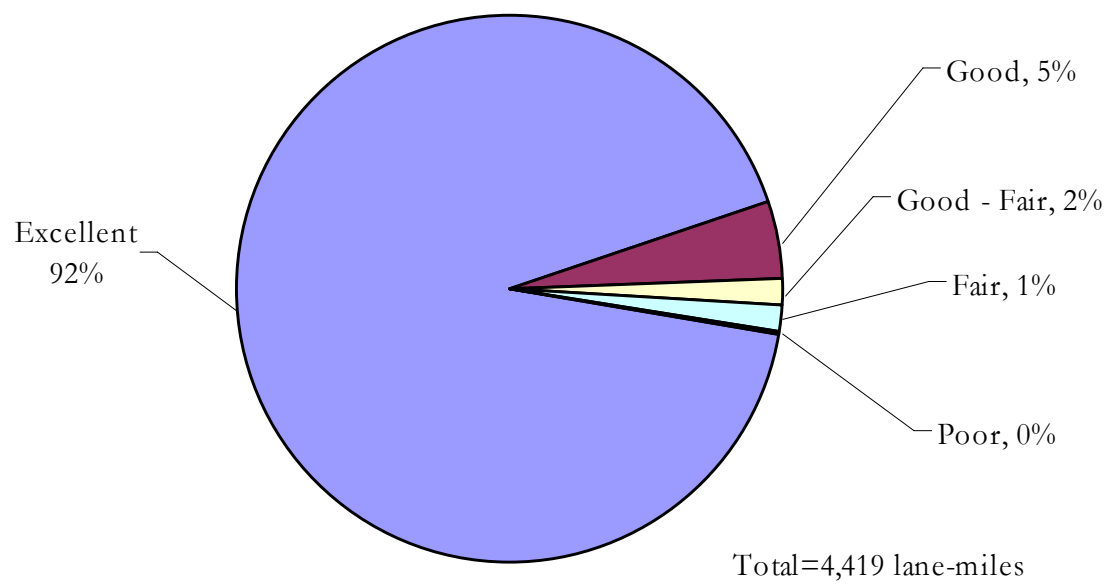

Figure 5-1 Distribution of Interstate Pavement as of Year 2001

Table 5-4 Interstate HMA Pavement Treatment Thresholds

\begin{tabular}{|c|c|c|c|c|}
\hline Condition (IRI) & $\begin{array}{c}\text { Deficiency } \\
\text { Level IRI }\end{array}$ & $\begin{array}{c}\text { Existing } \\
\text { Average IRI }\end{array}$ & $\begin{array}{c}\text { Lane- } \\
\text { miles }\end{array}$ & $\begin{array}{c}\text { "Initial" Treatment } \\
\text { (Year 2001) }\end{array}$ \\
\hline $\begin{array}{c}\text { Excellent-Good } \\
\text { (IRI= 60 - 100) }\end{array}$ & Trigger $>118$ & 71 & 658 & Do Nothing \\
\hline $\begin{array}{c}\text { Good } \\
\text { (IRI=101 -125) }\end{array}$ & Trigger $>118$ & 106 & 11 & Do Nothing \\
\hline $\begin{array}{c}\text { Good - Fair } \\
\text { (IRI = 126 -150) }\end{array}$ & Trigger $>134$ & 145 & 11 & $\begin{array}{c}\text { Preventive } \\
\text { Maintenance }\end{array}$ \\
\hline $\begin{array}{c}\text { Fair } \\
\text { (IRI = 151 - 200) }\end{array}$ & Trigger $>151$ & 155 & 1 & $\begin{array}{c}\text { Resurfacing Partial 3-R } \\
\text { Standards }\end{array}$ \\
\hline $\begin{array}{c}\text { Poor } \\
(\text { IRI = }>200)\end{array}$ & Trigger $>200$ & - & 0 & $\begin{array}{c}\text { Reconstruction } \\
\text { All Conditions }\end{array}$ \\
$\mathrm{n} / \mathrm{a}$ & $\mathrm{n} / \mathrm{a}$ & 681 & $\begin{array}{c}\text { Maintenance } \\
\text { (AAMEX) }\end{array}$ \\
\hline
\end{tabular}


In year 2001, there were no treatments applied to 669 lane-miles of highway because their initial IRI exceeded 118 IRI (the trigger value). Eleven lane-miles in the good-fair pavement condition range met the criteria for treatment as their average IRI was 145 with the trigger value for treatment was an IRI greater than 134. A thin overlay preventive maintenance treatment was applied to these sections in year 2001, thereby decreasing their IRI by 53.5 units. In separate scenarios the pavements were simulated to deteriorate by six or eight IRI and when they again reached a condition that exceeded 134 IRI another treatment of thin overlay was simulated, thereby keeping the pavements in good-to-fair condition at the start of the analysis from deteriorating to the lower condition levels such as fair or poor.

Tables 5-5 and 5-6 illustrate the initial treatments applied to the PCC and COMP interstate pavements. The methodology used for the treatment of pavements that were initially in excellent condition, such as the interstate pavements, as well as for the good to fair pavements is illustrated in Figure 5-2.

Table 5-5 Interstate PCC Pavement Treatment Thresholds

\begin{tabular}{|c|c|c|c|c|}
\hline Condition (IRI) & $\begin{array}{c}\text { Deficiency } \\
\text { Level IRI }\end{array}$ & $\begin{array}{c}\text { Existing } \\
\text { Average IRI }\end{array}$ & $\begin{array}{c}\text { Lane- } \\
\text { miles }\end{array}$ & $\begin{array}{c}\text { "Initial" Treatment } \\
\text { (Year 2001) }\end{array}$ \\
\hline $\begin{array}{c}\text { Excellent-Good } \\
\text { (IRI }=60-100)\end{array}$ & Trigger $>118$ & 82 & 645 & Do Nothing \\
\hline $\begin{array}{c}\text { Good } \\
\text { IRI }=101-125)\end{array}$ & Trigger $>118$ & 112 & 149 & Do Nothing \\
\hline $\begin{array}{c}\text { Good - Fair } \\
\text { IRI = 126 -150) }\end{array}$ & Trigger $>134$ & 135 & 37 & Joint and Crack Sealing \\
\hline $\begin{array}{c}\text { Fair } \\
(\text { IRI }=151-200)\end{array}$ & Trigger $>151$ & 167 & 55 & $\begin{array}{c}\text { Resurfacing Partial 3-R } \\
\text { Standards }\end{array}$ \\
\hline $\begin{array}{c}\text { Poor } \\
\text { (IRI = }>200)\end{array}$ & Trigger $>200$ & 201 & 5 & Reconstruction \\
\hline All Conditions & $\mathrm{n} / \mathrm{a}$ & $\mathrm{n} / \mathrm{a}$ & 892 & Maintenance (AAMEX) \\
\hline
\end{tabular}


Table 5-6 Interstate COMP Pavement Treatment Thresholds

\begin{tabular}{|c|c|c|c|c|}
\hline Condition (IRI) & $\begin{array}{c}\text { Deficiency } \\
\text { Level IRI }\end{array}$ & $\begin{array}{c}\text { Existing } \\
\text { Average IRI }\end{array}$ & Lane-miles & $\begin{array}{c}\text { "Initial" Treatment } \\
\text { (Year 2001) }\end{array}$ \\
\hline $\begin{array}{c}\text { Excellent-Good } \\
\text { (IRI= } 60-100)\end{array}$ & Trigger $>118$ & 73 & 2771 & Do Nothing \\
\hline $\begin{array}{c}\text { Good } \\
(\text { IRI }=101-125)\end{array}$ & Trigger $>118$ & 114 & 41 & Do Nothing \\
\hline $\begin{array}{c}\text { Good - Fair } \\
\text { (IRI }=126-150)\end{array}$ & Trigger $>134$ & 132 & 27 & $\begin{array}{c}\text { Preventive } \\
\text { Maintenance }\end{array}$ \\
\hline $\begin{array}{c}\text { Fair } \\
\text { IRI }=151-200)\end{array}$ & Trigger $>151$ & 163 & 5 & $\begin{array}{c}\text { Resurfacing Partial } \\
\text { 3-R Standards }\end{array}$ \\
\hline $\begin{array}{c}\text { Poor } \\
(\text { IRI }=>200)\end{array}$ & Trigger $>200$ & 218 & 2 & $\begin{array}{c}\text { Reconstruction } \\
\text { Maintenance } \\
\text { (AAMEX) }\end{array}$ \\
\hline All Conditions & $\mathrm{n} / \mathrm{a}$ & $\mathrm{n} / \mathrm{a}$ & 2846 & \\
\hline
\end{tabular}




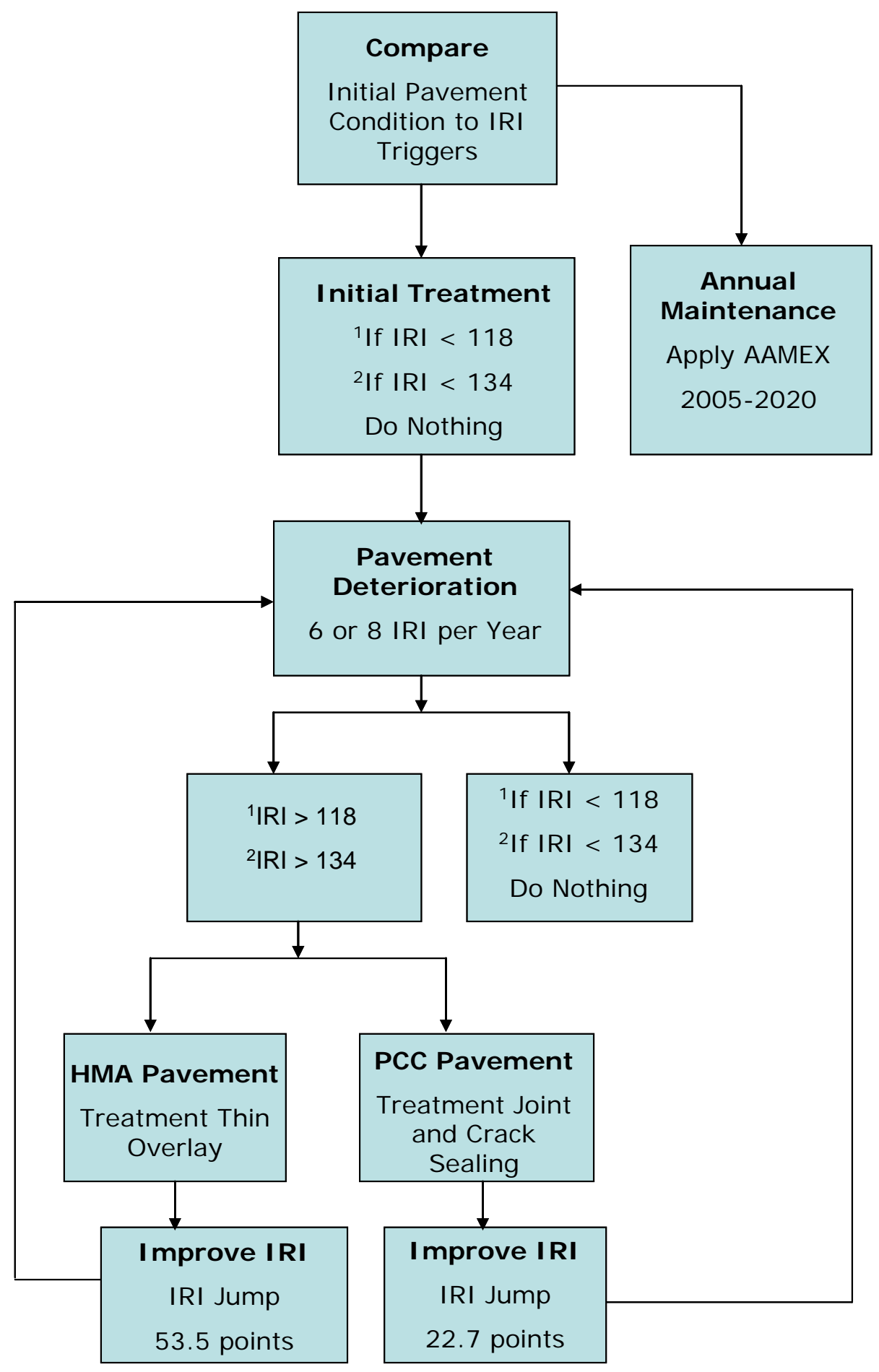

Figure 5-2 Methodology used for Excellent, Good and Good-To-Fair Pavements

${ }^{1}$ Excellent and Good Pavement

${ }^{2}$ Good-To-Fair Pavements 


\subsection{Non-Interstate NHS Pavement Condition and Initial Treatment}

This group of pavements represents 4,814 lane-miles of highway. Approximately 76 percent of non-interstate NHS pavements were in excellent condition and there were no sections in poor condition. A summary of the pavement conditions is illustrated in Figure 5-3, and the "initial" treatments applied to the pavements are described in Tables 5-7, 5-8, and 5-9 for HMA, PCC and COMP pavement "initial" treatment respectively. "Initial" treatment is not a treatment at year 0 , but rather the assumed treatment at the start of the year 2001.

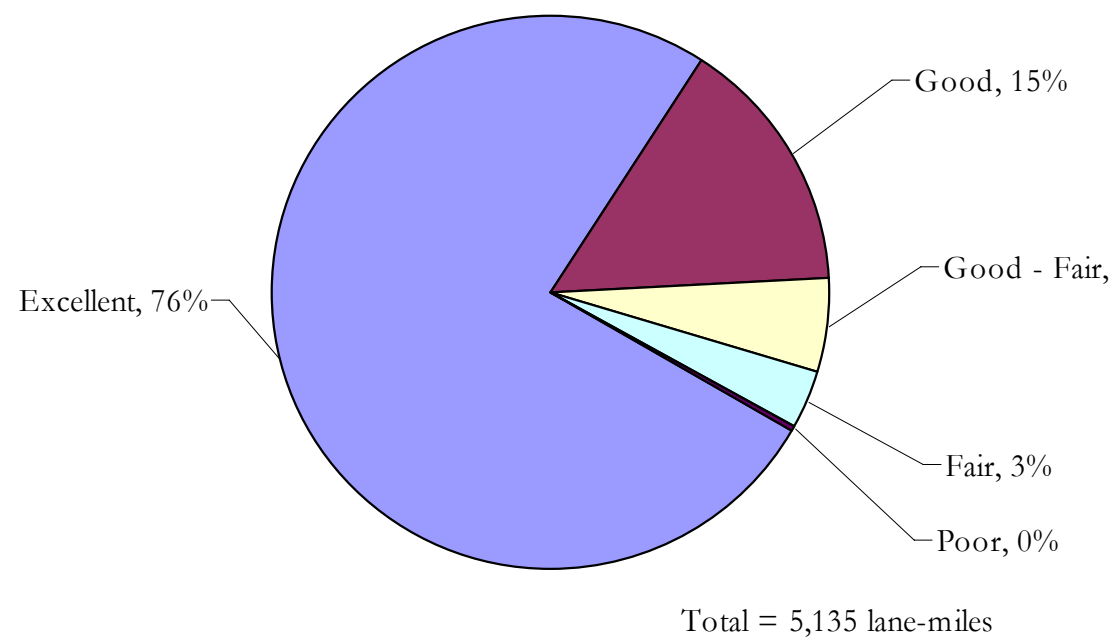

Figure 5-3 Distribution of Non-Interstate NHS by Pavement Condition as of Year 2001 
Table 5-7 Non-Interstate NHS HMA Pavement Treatment Thresholds

\begin{tabular}{|c|c|c|c|c|}
\hline Condition (IRI) & $\begin{array}{l}\text { Deficiency } \\
\text { Level IRI }\end{array}$ & $\begin{array}{c}\text { Existing } \\
\text { Average IRI }\end{array}$ & Lane-miles & $\begin{array}{c}\text { "Initial" Treatment } \\
\text { (Year 2001) }\end{array}$ \\
\hline $\begin{array}{l}\text { Excellent-Good } \\
(\text { IRI }=60-100)\end{array}$ & Trigger $>118$ & 76 & 3267 & Do Nothing \\
\hline $\begin{array}{c}\text { Good } \\
\text { (IRI=101 -125) }\end{array}$ & Trigger $>118$ & 111 & 596 & Do Nothing \\
\hline $\begin{array}{c}\text { Good - Fair } \\
(\text { IRI }=126-150)\end{array}$ & Trigger $>134$ & 135 & 180 & $\begin{array}{c}\text { Preventive } \\
\text { Maintenance }\end{array}$ \\
\hline $\begin{array}{c}\text { Fair } \\
(\text { IRI }=151-200)\end{array}$ & Trigger $>151$ & 167 & 135 & $\begin{array}{c}\text { Resurfacing Partial } \\
\text { 3-R Standards }\end{array}$ \\
\hline $\begin{array}{c}\text { Poor } \\
(\text { IRI }=>200)\end{array}$ & Trigger $>200$ & 230 & 8 & Reconstruction \\
\hline All Conditions & $\mathrm{n} / \mathrm{a}$ & $\mathrm{n} / \mathrm{a}$ & 4186 & $\begin{array}{l}\text { Maintenance } \\
\text { (AAMEX) }\end{array}$ \\
\hline
\end{tabular}

Table 5-8 Non-Interstate NHS PCC Pavement Treatment Thresholds

\begin{tabular}{ccccc}
\hline Condition (IRI) & $\begin{array}{c}\text { Deficiency } \\
\text { Level IRI }\end{array}$ & $\begin{array}{c}\text { Existing } \\
\text { Average IRI }\end{array}$ & $\begin{array}{c}\text { Lane- } \\
\text { miles }\end{array}$ & $\begin{array}{c}\text { "Initial" Treatment } \\
\text { (Year 2001) }\end{array}$ \\
\hline $\begin{array}{c}\text { Excellent-Good } \\
\text { IRI }=60-100)\end{array}$ & Trigger $>118$ & 76 & 511 & Do Nothing \\
\hline $\begin{array}{c}\text { Good } \\
\text { (IRI }=101-125)\end{array}$ & Trigger $>118$ & 112 & 170 & Do Nothing \\
\hline $\begin{array}{c}\text { Good }- \text { Fair } \\
(\text { IRI }=126-150)\end{array}$ & Trigger $>134$ & 139 & 108 & $\begin{array}{c}\text { Joint and Crack } \\
\text { Sealing }\end{array}$ \\
\hline $\begin{array}{c}\text { Fair } \\
(\text { IRI }=151-200)\end{array}$ & Trigger $>151$ & 162 & 35 & $\begin{array}{c}\text { Resurfacing Partial } \\
\text { 3-R Standards }\end{array}$ \\
\hline $\begin{array}{c}\text { Poor } \\
\text { (IRI }=>200)\end{array}$ & Trigger $>200$ & $\mathrm{n} / \mathrm{a}$ & 0 & $\begin{array}{c}\text { Reconstruction } \\
\text { All Conditions }\end{array}$ \\
$\mathrm{n} / \mathrm{a}$ & $\mathrm{n} / \mathrm{a}$ & 825 & $\begin{array}{c}\text { Maintenance } \\
\text { (AAMEX) }\end{array}$ \\
\hline
\end{tabular}


Table 5-9 Non-Interstate NHS COMP Pavement Treatment Thresholds

\begin{tabular}{|c|c|c|c|c|}
\hline Condition (IRI) & $\begin{array}{l}\text { Deficiency } \\
\text { Level IRI }\end{array}$ & $\begin{array}{c}\text { Existing } \\
\text { Average IRI }\end{array}$ & Lane-miles & $\begin{array}{l}\text { "Initial" Treatment } \\
\text { (Year 2001) }\end{array}$ \\
\hline $\begin{array}{l}\text { Excellent-Good } \\
(I R I=60-100)\end{array}$ & Trigger $>118$ & 73 & 115 & Do Nothing \\
\hline $\begin{array}{c}\text { Good } \\
\text { (IRI=101 -125) }\end{array}$ & Trigger $>118$ & 112 & 2 & Do Nothing \\
\hline $\begin{array}{c}\text { Good - Fair } \\
(\text { IRI = } 126-150)\end{array}$ & Trigger $>134$ & $\mathrm{n} / \mathrm{a}$ & 0 & $\begin{array}{c}\text { Preventive } \\
\text { Maintenance }\end{array}$ \\
\hline $\begin{array}{c}\text { Fair } \\
(\text { IRI }=151-200) \\
\end{array}$ & Trigger $>151$ & 159 & 6 & $\begin{array}{c}\text { Resurfacing Partial } \\
\text { 3-R Standards }\end{array}$ \\
\hline $\begin{array}{c}\text { Poor } \\
(\mathrm{IRI}=>200)\end{array}$ & Trigger $>200$ & $\mathrm{n} / \mathrm{a}$ & 0 & Reconstruction \\
\hline All Conditions & $\mathrm{n} / \mathrm{a}$ & $\mathrm{n} / \mathrm{a}$ & 124 & $\begin{array}{l}\text { Maintenance } \\
\text { (AAMEX) }\end{array}$ \\
\hline
\end{tabular}

\subsection{Non-Interstate Non-NHS Pavement Condition and Initial Treatment}

With 19,170 lane-miles, this pavement family represents the largest category in the analysis. Sixty-six percent of pavements in this family were in excellent condition and one percent were in poor condition. Tables 5-10, 5-11 and 5-12 present the initial conditions and initial treatments to HMA, PCC, and COMP pavements respectively. 


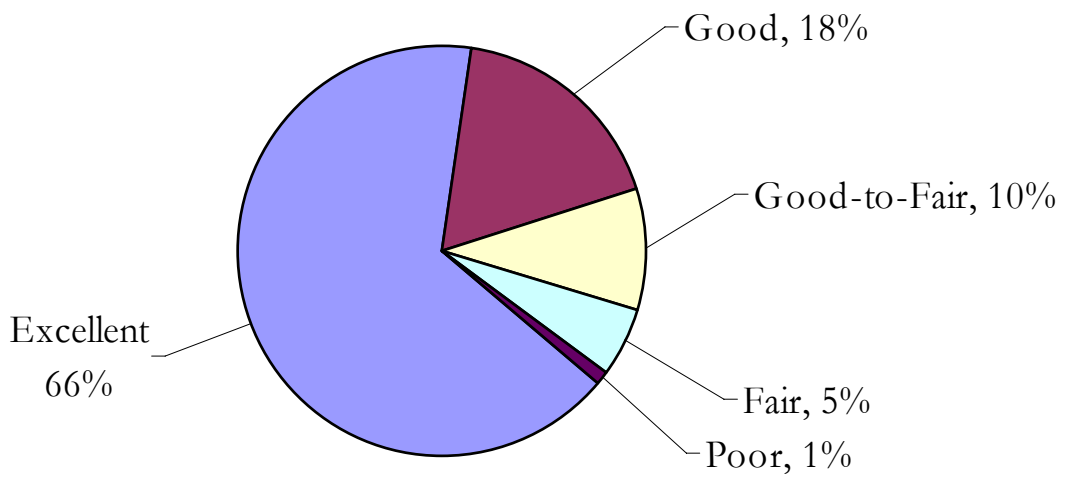

Total $=19,170$ lane-miles

Figure 5-4 Distribution of Non-Interstate Non-NHS by Pavement Condition as of Year 2001

Table 5-10 Non-Interstate, Non-NHS, HMA Pavement Treatment Thresholds

\begin{tabular}{|c|c|c|c|c|}
\hline Condition (IRI) & $\begin{array}{c}\text { Deficiency } \\
\text { Level IRI }\end{array}$ & $\begin{array}{c}\text { Existing } \\
\text { Average IRI }\end{array}$ & $\begin{array}{c}\text { Lane- } \\
\text { miles }\end{array}$ & $\begin{array}{c}\text { "Initial" Treatment } \\
\text { (Year 2001) }\end{array}$ \\
\hline $\begin{array}{c}\text { Excellent-Good } \\
\text { IRI }=60-100)\end{array}$ & Trigger $>118$ & 78 & 12222 & Do Nothing \\
\hline $\begin{array}{c}\text { Good } \\
\text { IRI =101 -125) }\end{array}$ & Trigger $>118$ & 112 & 3218 & Do Nothing \\
\hline $\begin{array}{c}\text { Good - Fair } \\
\text { (IRI = 126 -150) }\end{array}$ & Trigger $>134$ & 136 & 1771 & Preventive Maintenance \\
\hline $\begin{array}{c}\text { Fair } \\
\text { IRI = 151 - 200) }\end{array}$ & Trigger $>151$ & 169 & 961 & $\begin{array}{c}\text { Resurfacing Partial 3-R } \\
\text { Standards }\end{array}$ \\
\hline $\begin{array}{c}\text { Poor } \\
\text { (IRI = }>200)\end{array}$ & Trigger $>200$ & 222 & 184 & Reconstruction \\
\hline All Conditions & $\mathrm{n} / \mathrm{a}$ & $\mathrm{n} / \mathrm{a}$ & 18356 & Maintenance (AAMEX) \\
\hline
\end{tabular}


Table 5-11 Non-Interstate Non-NHS PCC Pavement Treatment Thresholds

\begin{tabular}{|c|c|c|c|c|}
\hline Condition (IRI) & $\begin{array}{l}\text { Deficiency } \\
\text { Level IRI }\end{array}$ & $\begin{array}{c}\text { Existing } \\
\text { Average IRI }\end{array}$ & $\begin{array}{l}\text { Lane- } \\
\text { miles }\end{array}$ & $\begin{array}{c}\text { "Initial" Treatment } \\
\text { (Year 2001) }\end{array}$ \\
\hline $\begin{array}{l}\text { Excellent-Good } \\
(\text { IRI }=60-100)\end{array}$ & Trigger $>118$ & 79 & 341 & Do Nothing \\
\hline $\begin{array}{c}\text { Good } \\
(\text { IRI }=101-125)\end{array}$ & Trigger $>118$ & 107 & 157 & Do Nothing \\
\hline $\begin{array}{c}\text { Good }- \text { Fair } \\
(\text { IRI = } 126-150)\end{array}$ & Trigger $>134$ & 135 & 76 & $\begin{array}{c}\text { Joint and Crack } \\
\text { Sealing }\end{array}$ \\
\hline $\begin{array}{c}\text { Fair } \\
(\text { IRI }=151-200)\end{array}$ & Trigger $>151$ & 170 & 61 & $\begin{array}{l}\text { Resurfacing Partial } \\
\text { 3-R Standards }\end{array}$ \\
\hline $\begin{array}{c}\text { Poor } \\
(\text { IRI }=>200)\end{array}$ & Trigger $>200$ & 214 & 26 & Reconstruction \\
\hline All Conditions & $\mathrm{n} / \mathrm{a}$ & $\mathrm{n} / \mathrm{a}$ & 661 & $\begin{array}{l}\text { Maintenance } \\
\text { (AAMEX) }\end{array}$ \\
\hline
\end{tabular}

Table 5-12 Non-Interstate Non-NHS COMP Pavement Treatment Thresholds

\begin{tabular}{|c|c|c|c|c|}
\hline Condition (IRI) & $\begin{array}{c}\text { Deficiency } \\
\text { Level IRI }\end{array}$ & $\begin{array}{c}\text { Existing } \\
\text { Average IRI }\end{array}$ & $\begin{array}{c}\text { Lane- } \\
\text { miles }\end{array}$ & $\begin{array}{c}\text { "Initial" Treatment } \\
\text { (Year 2001) }\end{array}$ \\
\hline $\begin{array}{c}\text { Excellent-Good } \\
\text { (IRI= 60 - 100) }\end{array}$ & Trigger $>118$ & 79 & 128 & Do Nothing \\
\hline $\begin{array}{c}\text { Good } \\
\text { (IRI }=101-125)\end{array}$ & Trigger $>118$ & 103 & 2 & Do Nothing \\
\hline $\begin{array}{c}\text { Good - Fair } \\
(\text { IRI }=126-150)\end{array}$ & Trigger $>134$ & 131 & 21 & Preventive Maintenance \\
\hline $\begin{array}{c}\text { Fair } \\
\text { (IRI }=151-200)\end{array}$ & Trigger $>151$ & 152 & 1 & $\begin{array}{c}\text { Resurfacing Partial 3-R } \\
\text { Standards }\end{array}$ \\
\hline $\begin{array}{c}\text { Poor } \\
\text { (IRI }=>200)\end{array}$ & Trigger $>200$ & $\mathrm{n} / \mathrm{a}$ & 0 & Reconstruction \\
\hline All Conditions & $\mathrm{n} / \mathrm{a}$ & $\mathrm{n} / \mathrm{a}$ & 153 & Maintenance (AAMEX) \\
\hline
\end{tabular}

The methodology used for the treatment of pavements that were initially in poor condition is illustrated in Figure 5-5. Pavements in fair condition follow a similar process, but the analyst compares the initial IRI to 151 and the initial treatment for pavements with IRI >151 would be Resurfacing Partial 3-R Standards. 


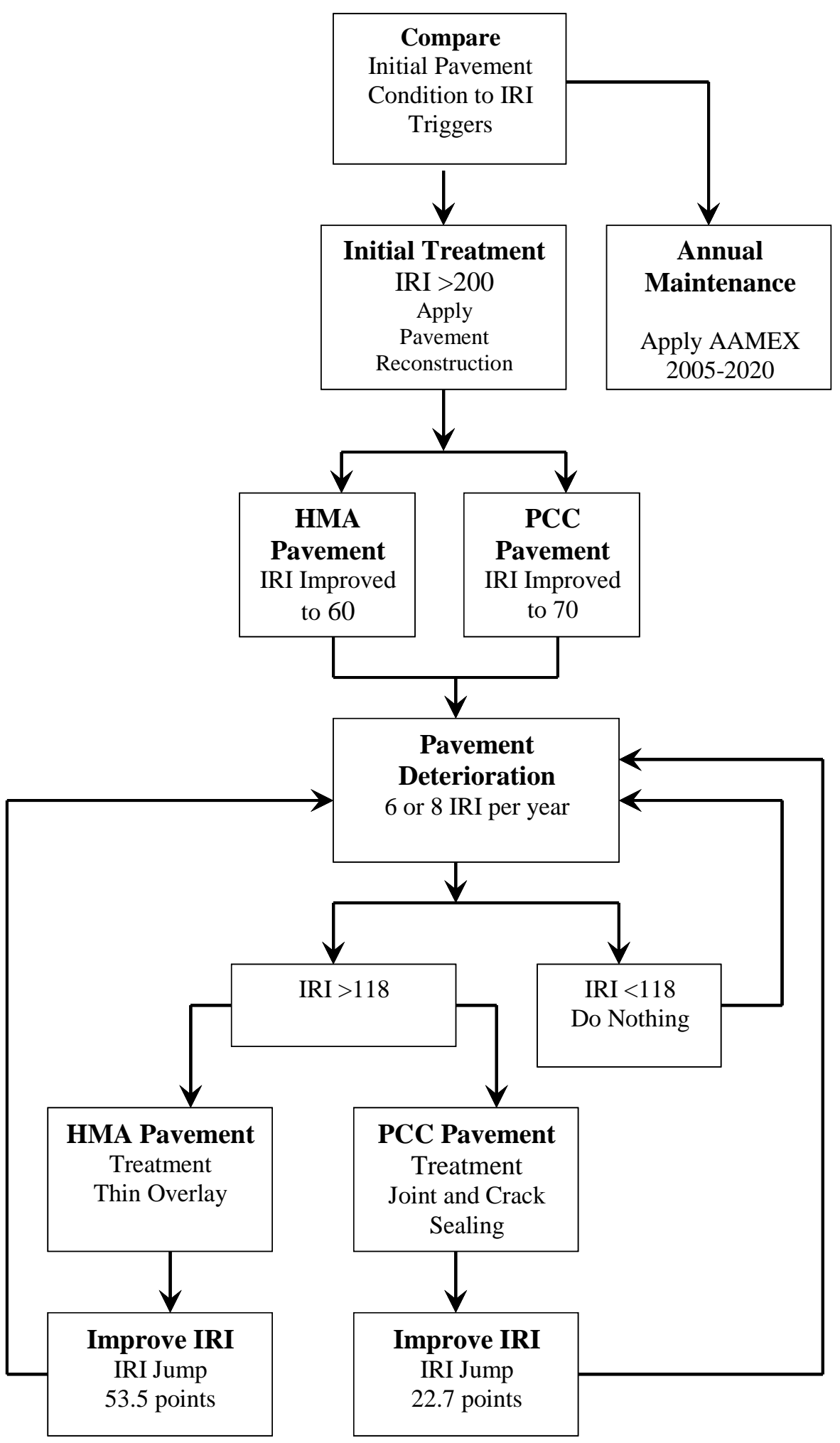

Figure 5-5 Methodology for Poor Pavements 


\subsection{Network Analysis Results}

As previously discussed, the manual condition analysis method utilizes information on average costs per lane-mile for treatments by pavement type as described by Lamptey et al. (2004) and average annual maintenance expenditure (AAMEX) models by Labi and Sinha (2003). The total pavement needs included the costs to maintain the existing pavement.

Scenario A uses a pavement deterioration rate of 8.0 IRI per year, and Scenario B uses a pavement deterioration rate of 6.0 IRI per year. The 15 -year pavement preservation need for existing roads under Scenario A for the period 2006-2020 is $\$ 5,544,222,285$; while under Scenario B it is $\$ 4,938,927,145$; as shown in Tables 5-13 and 5-14. The preservation needs discussed in this section do not include any shoulder work or added-capacity projects. The term "repairs only" applies to those costs associated with the "initial" treatments applied in the year 2001. The 15-year need between 2006 and 2020 was estimated by deducting the expected preservation expenditures during 2002-2005 from the 2002-2020 needs. Data from 2002 and 2003 was used to estimate preservation expenditures during 2002-2005.

Table 5-13 Fifteen-year Pavement Condition Preservation Needs Scenario A

\begin{tabular}{|c|c|c|c|c|}
\hline & Interstate & $\begin{array}{c}\text { Non-Interstate } \\
\text { NHS }\end{array}$ & $\begin{array}{c}\text { Non-Interstate } \\
\text { Non NHS }\end{array}$ & $\begin{array}{l}\text { Total all } \\
\text { Locations }\end{array}$ \\
\hline Lane-Miles of Analysis & 4,143 & 4,814 & 17,972 & 26,929 \\
\hline 2002 Initial Repair Costs & $\$ 30,152,561$ & $\$ 77,218,728$ & $\$ 729,036,542$ & $\$ 836,407,831$ \\
\hline 2002 AAMEX & $\$ 3,507,973$ & $\$ 6,742,570$ & $\$ 25,451,291$ & $\$ 35,701,834$ \\
\hline $\begin{array}{c}\text { Deterioration } \\
2003-2020\end{array}$ & $\$ 519,055,202$ & $\$ 672,580,430$ & $\$ 2,917,184,584$ & $\$ 4,108,820,216$ \\
\hline AAMEX 2003-2020 & $\$ 59,635,545$ & $\$ 114,623,682$ & $\$ 432,671,952$ & $\$ 606,931,179$ \\
\hline $\begin{array}{l}\text { Planning \& Design (9\%) } \\
\text { (Repairs Only) }\end{array}$ & $\$ 49,428,699$ & $\$ 67,481,924$ & $\$ 328,159,901$ & $\$ 445,070,524$ \\
\hline $\begin{array}{l}\text { Cost Overruns }(10 \%) \\
\text { (Repairs Only) }\end{array}$ & $\$ 56,062,154$ & $\$ 81,546,915$ & $\$ 397,305,002$ & $\$ 534,914,072$ \\
\hline Subtotal 2002-2020 & $\$ 717,842,134$ & $\$ 1,020,194,249$ & $\$ 4,829,809,273$ & $\$ 6,567,845,656$ \\
\hline Less 2002-2005 Spendinga & & & & $-\$ 1,023,623,371$ \\
\hline Adjusted Subtotal & & & & $\$ 5,544,222,285$ \\
\hline \multicolumn{5}{|c|}{$\begin{array}{l}\text { a. Based on FY } 2002 \text { and FY } 2003 \text { highway infrastructure spending on pavement preservation data received from the Budget and } \\
\text { Fiscal Management Division of INDOT. } \\
\text { Costs are expressed in Year } 2002 \text { constant dollars. } \\
\text { The term "repairs only" applies to those costs associated with the "initial" treatment applied in the year } 2001 . \\
\text { Added-capacity improvements are not included in the costs. }\end{array}$} \\
\hline
\end{tabular}


Table 5-14 Fifteen-year Pavement Condition Preservation Needs Scenario B

\begin{tabular}{|c|c|c|c|c|}
\hline & Interstate & $\begin{array}{c}\text { Non-Interstate } \\
\text { NHS }\end{array}$ & $\begin{array}{c}\text { Non-Interstate } \\
\text { Non NHS }\end{array}$ & $\begin{array}{l}\text { Total all } \\
\text { Locations }\end{array}$ \\
\hline Lane-Miles of Analysis & 4,419 & 5,135 & 19,170 & 28,725 \\
\hline 2002 Initial Repair Costs & $\$ 30,152,561$ & $\$ 77,218,728$ & $\$ 729,036,542$ & $\$ 836,407,831$ \\
\hline 2002 AAMEX & $\$ 3,507,973$ & $\$ 6,742,570$ & $\$ 25,451,291$ & $\$ 35,701,834$ \\
\hline Deterioration 2003-2020 & $\$ 512,200,685$ & $\$ 617,304,103$ & $\$ 2,478,419,895$ & $\$ 3,607,924,683$ \\
\hline AAMEX 2003-2020 & $\$ 57,037,087$ & $\$ 113,467,786$ & $\$ 431,719,453$ & $\$ 602,224,326$ \\
\hline $\begin{array}{l}\text { Planning \& Design }(9 \%) \\
\text { (Repairs Only) }\end{array}$ & $\$ 48,811,792$ & $\$ 62,507,055$ & $\$ 288,671,079$ & $\$ 399,989,926$ \\
\hline $\begin{array}{l}\text { Cost Overruns }(10 \%) \\
\text { (Repairs Only) }\end{array}$ & $\$ 55,364,129$ & $\$ 75,527,578$ & $\$ 349,410,208$ & $\$ 480,301,916$ \\
\hline Subtotal 2002-2020 & $\$ 707,074,228$ & $\$ 952,767,820$ & $\$ 4,302,708,468$ & $\$ 5,962,550,516$ \\
\hline Less 2002-2005 Spending $^{a}$ & & & & $-\$ 1,023,623,371$ \\
\hline Adjusted Subtotal & & & & $\$ 4,938,927,145$ \\
\hline \multicolumn{5}{|c|}{$\begin{array}{l}\text { a. Based on FY } 2002 \text { and FY } 2003 \text { highway infrastructure spending on pavement preservation data received from the INDOT's } \\
\text { Budget and Fiscal Management Division. } \\
\text { The term "repairs only" applies to those costs associated with the "initial" treatment applied in the year } 2001 . \\
\text { Added-capacity improvements are not included in the costs. } \\
\text { Costs are expressed in Year } 2002 \text { constant dollars. }\end{array}$} \\
\hline
\end{tabular}




\section{CHAPTER 6 : PROCEDURE FOR EVALUATING ANNUAL PAVEMENT PRESERVATION COST}

For fiscal planning and programming, it is necessary to know the expected costs of preservation projects. However, it is not certain that the current version of INDOT's Pavement and

Bridge Management systems incorporates a direct and comprehensive analysis of the costs and service lives in a manner that would be consistent with INDOT's financial planners. There is a need to develop simple and reliable procedures in order for INDOT's planners to be able to predict preservation costs without going through a complex modeling process. The following procedure was developed in order to help INDOT's Policy and Fiscal Management and Planning divisions predict properly the dollars needed each year for pavement preservation activities. These activities do not include new pavement construction. The developed procedure is based on the fact that there is a correlation between time and the percentage of lane miles of the state roads that receive preservation activities each year. Given that the rate at which the system size increases is very constant, it is possible to predict for any given year the number of lane miles that are going to be treated. Using the average unit costs of preservation for the preceding years ( 2 or 3 generally), the total preservation cost can be derived easily. This cost can then be broken down by rehabilitation and non rehabilitation activities, which comprise maintenance and reconstruction. Costs per functional system can also be determined. The following categories are considered: Interstate roads, Non Interstate roads that are on the National Highway System (NHS) and finally state roads that are not on the NHS.

The procedure can be summarized as follows:

1. System size prediction

2. Percentage of system to be treated

3. Estimation of total preservation cost using unit cost per lane mile

4. Rehabilitation and Non-rehabilitation cost (maintenance and reconstruction)

5. Preservation cost by functional system 


\subsection{Total System Size Prediction}

First, the number of lane miles in the system for each year was plotted against the years. A statistical relation was estimated that enables the determination of the total size of Indiana's state highway system for any given year, as follows:

$$
\text { Number of lanes miles }=83.275 * Y \mathrm{E} A \mathrm{R}-138144
$$

The observed data and the plot are shown as Figure 6-1. Using the developed equation, the system size of Indiana's state highway system for each future year can be determined through extrapolation.

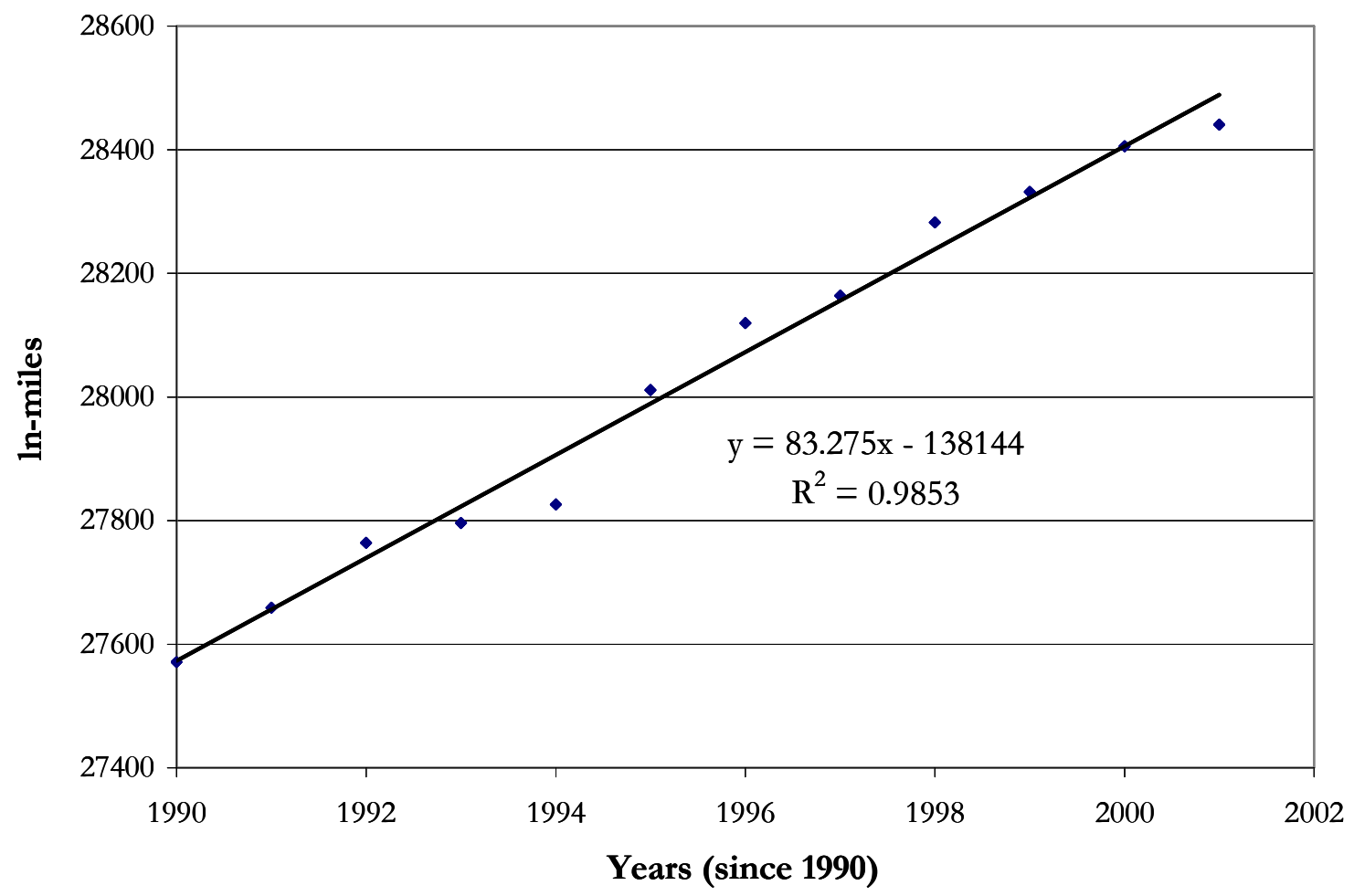

Figure 6-1 Indiana’s highway system size versus time 
Example: For the year 2008, the total number of lane-miles in the state can be estimated to be:

$$
\text { Number of lane miles }=83.275 * 2008-138,144=29,072 \text { lane miles }
$$

\subsection{Percentage of system to be treated}

The percentage of lane miles in the system receiving preservation treatment each year was plotted against the years. A time series model was then developed and the following statistical relationship (2) that predicts the percentage of the system that will receive preservation treatment for any given year was estimated. The data obtained is shown on Figure 6-2.

Percentage of system to be preserved $=0.0328^{*}(\# \text { of years from 1990 })^{\wedge}(0.3513)$

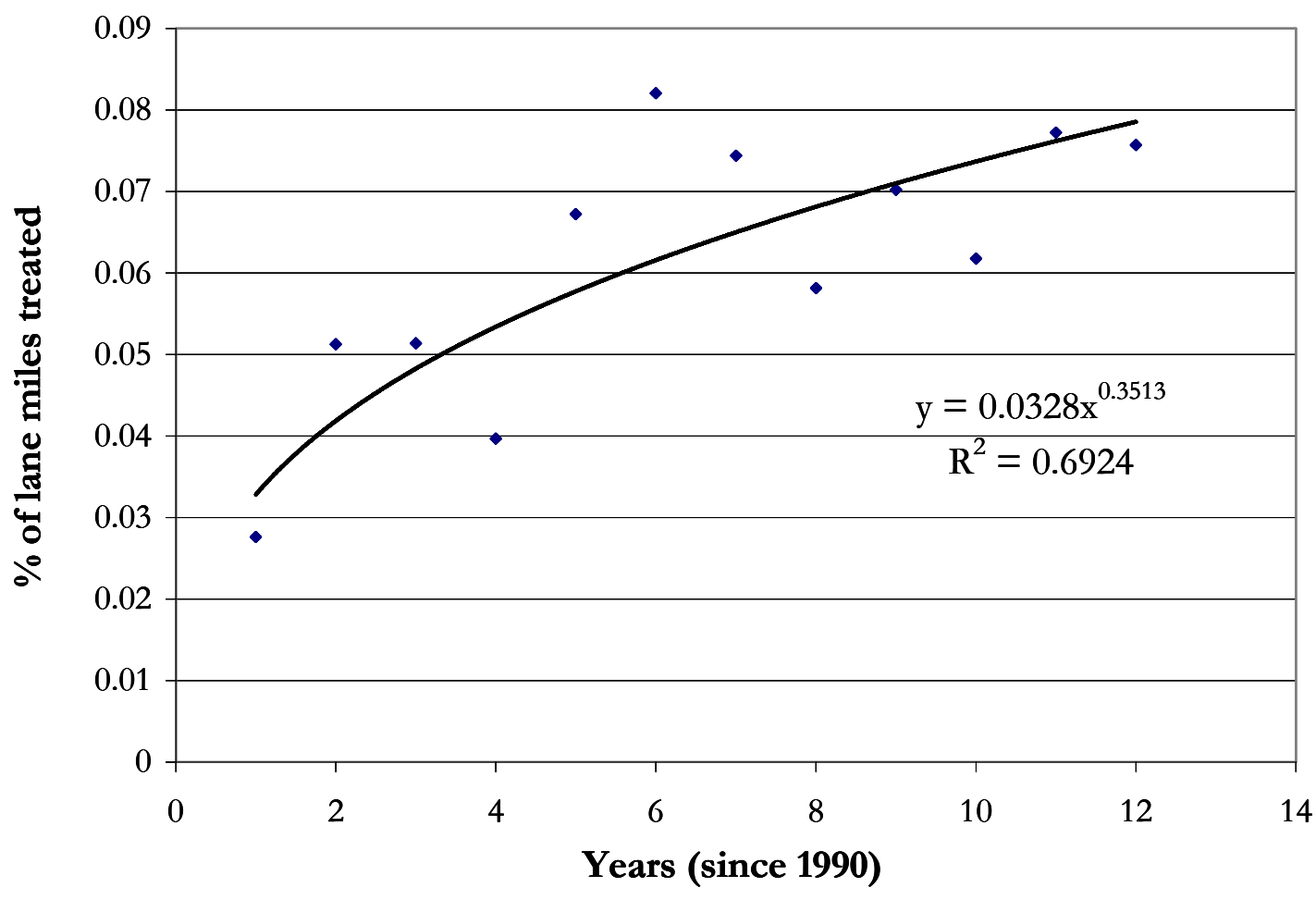

Figure 6-2 Percentage of system preserved versus time 
Example: The percentage of the system that is going to receive a treatment in 2008 can be determined as follows:

$$
\% \text { of system }=0.0328 * 19^{\wedge}(0.3513)=0.092278
$$

Therefore, the number of lane miles in the system on which preservation activities are going to be performed can be derived, using the following relationship:

Number of lane miles to be treated $=\%$ percentage of system to be treated $*$ system size

Found in

step 1

In 2008, the number of lane miles that are going to receive a treatment can be estimated at:

\# of lane miles to receive treatment $=0.092278 * 29072.2=2682.72$ lane miles

6.3 Estimation of total preservation cost using unit cost per lane mile

The total preservation cost for the entire system can be obtained by multiplying the number of lane miles to be treated by the average unit cost for preservation for the last 3 years.

Average unit cost from 1999 to $2001=\$ 151,375.69$

Thus, the total cost to preserve the system can be estimated by multiplying the unit cost to the total number of lane miles to be treated. The following relationship enables to estimate the total preservation cost for pavements:

Total cost of preservation $=$ Number of lane miles to be treated ${ }^{*}$ Average unit cost for the past 3 years.

Example: In 2008, the total cost to preserve the pavement in the system in 2008 will be: 


$$
\text { Total cost of preservation }=2682.72 * \$ 151,375.69=\$ 406,098,591
$$

Using the same procedure, the pavement preservation costs for 2002 and 2003 can be predicted and compared to the true values as shown on Table 6-1.

Table 6-1 Comparison of Actual and Predicted Pavement Preservation Costs for 2002 and 2003

\begin{tabular}{|c|c|c|c|}
\hline Years & Actual Expenditure & Predicted value & Percentage difference \\
\hline 2002 & $\$ 335,600,000$ & $\$ 349,306,993$ & $+4 \%$ \\
\hline 2003 & $\$ 318,408,552$ & $\$ 359,565,218$ & $+13 \%$ \\
\hline
\end{tabular}

The values found are consistent with the engineering needs determined in the previous chapter. The average annual pavement preservation cost for the 15-year period 2006-2020 is estimated at $\$ 331,784$ to $\$ 369,615$ in the previous chapter. 


\subsection{Rehabilitation and Non rehabilitation cost}

- Percentage of lane miles rehabilitated

The number of lane miles rehabilitated each year as a percentage of the system is plotted against the years and a correlation was found. The following statistical relationship estimates the percentage of the system to be rehabilitated for any given year.

$$
\% \text { of system }=0.0248^{*}(\# \text { of years from 1990 })^{\wedge}(0.3705)
$$

The plot and the observed data are shown on Figure 6-3. The percentage of the system to be rehabilitated can be determined through extrapolation using the developed equation.

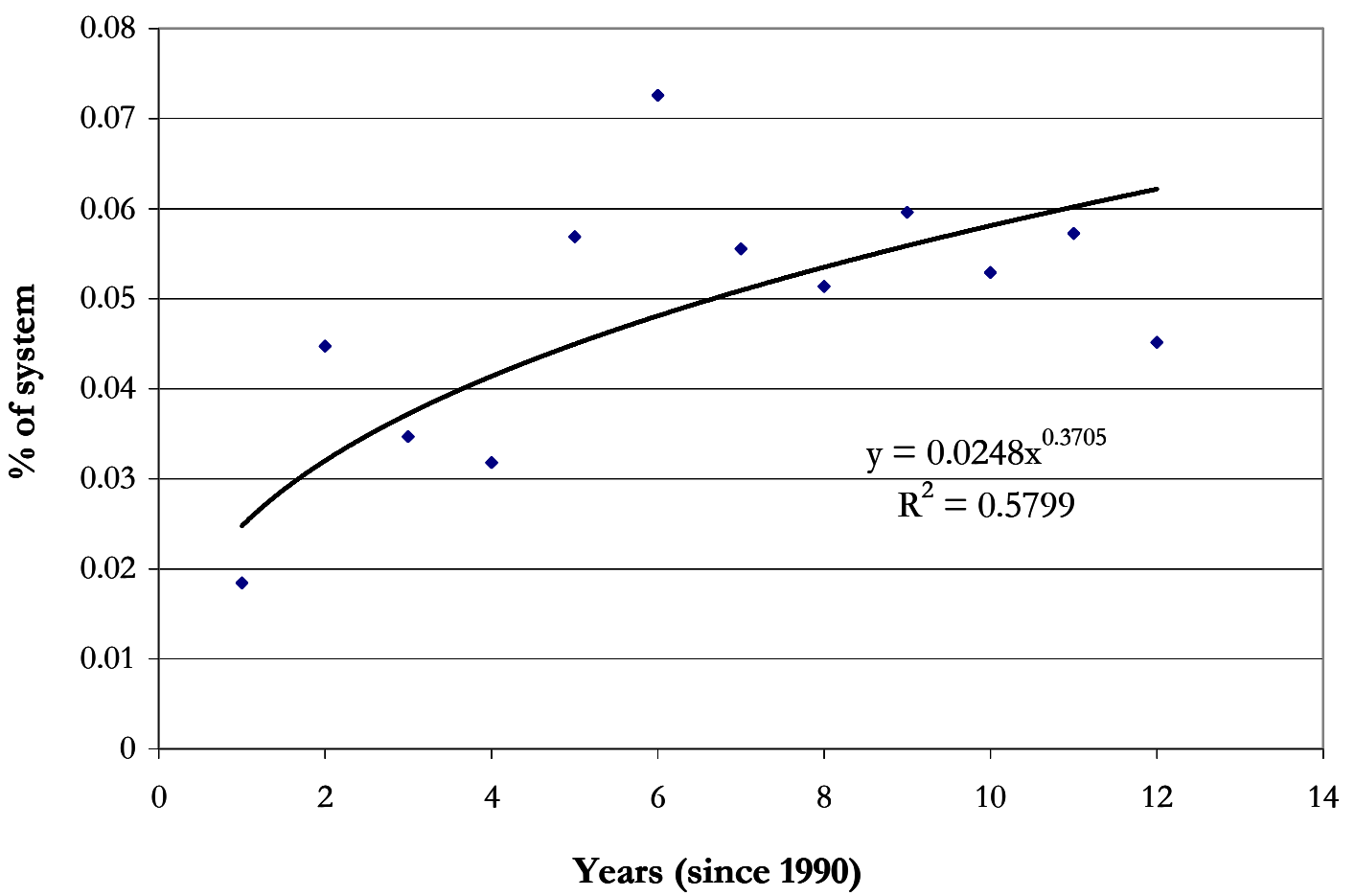

Figure 6-3 Percentage of system rehabilitated versus time 
Example: The percentage of the system that is going to be rehabilitated in 2008 is:

$$
\% \text { of system }=0.0248 * 19^{\wedge}(0.3705)=0.0738
$$

The number of lane miles to be rehabilitated each year can be easily derived using the following simple relationship:

Number of lane miles to be rehabilitated $=\%$ percentage of system to be rehabilitated $*$ system size

In 2008, number of lane miles on which rehabilitation activities are going to be performed is:

Number of lane miles to be rehabilitated $=0.0738 * 29072.2=2145.52$ lane miles

- Total cost of rehabilitation

The total cost of rehabilitation can be derived by using the average unit cost per lane mile calculated for the past three years.

Average unit cost of rehabilitation for past 3 years $(199-2001)=\$ 121,851.738$

Therefore, the total cost of rehabilitation activities can be estimated by the following simple and direct relationship:

Total cost of rehabilitation $=$ Number of lane miles to be rehabilitated $*$ Average unit cost for the past 3 years (7)

Example: Using the same example for the year 2008, the total cost needed to rehabilitate pavements is estimated at:

Total cost of rehabilitation $=2145.52 * \$ 121,851.738=\$ 261,436,359$ 
- Non-rehabilitation cost (Maintenance + Reconstruction)

Knowing the preservation cost and the rehabilitation cost, the amount to be spent on maintenance and reconstruction can be directly determined by taking the difference.

Non Rebabilitation cost $=$ Total preservation cost - Rehabilitation cost

Example: In 2008, non rehabilitation costs can be predicted to be:

Non Rebabilitation cost $=\$ 406,098,591-\$ 261,436,359=\$ 144,662,231.4$

\subsection{Preservation cost by Highway Class}

To estimate, the pavement preservation cost for each highway class, the percentage of money spent on each highway class found for the last two years can be used.

For example, Table 6-2 gives the percentage of money spent on the different highway classes in 2001 and 2000.

Table 6-2 Percentage of money spent on different highway classes (2000 and 2001)

\begin{tabular}{|c|c|c|c|}
\cline { 2 - 4 } \multicolumn{1}{c|}{} & INT & NIN & NNN \\
\hline 2001 & 0.2244 & 0.2768 & 0.4987 \\
\hline 2000 & 0.1632 & 0.3929 & 0.4438 \\
\hline
\end{tabular}

* INT: Interstate roads

NIN: Non Interstate roads in the NHS (National Highway System)

NNN: State roads that are not in the NHS.

Therefore, the average can be taken and the pavement preservation cost for each highway class can be found.

Example: If these averages are used to predict the preservation cost by highway class for 2008, the total pavement preservation cost found above will be multiplied by the averages calculated. Thus the pavement preservation costs in 2008 predicted for each highway class are shown on Table 6-3. 
Table 6-3 2008 Pavement Preservation Costs by Highway Class

\begin{tabular}{|c|c|c|}
\hline & $\begin{array}{c}\text { P.C. of Cost } \\
\text { Average of } 2000 / 2001\end{array}$ & $\begin{array}{c}\text { Estimated Pavement } \\
\text { Preservation Cost }\end{array}$ \\
\hline INT & 0.1938 & $\$ 78,701,906$ \\
\hline NIN & 0.3348 & $\$ 135,961,808$ \\
\hline NNN & 0.4712 & $\$ 191,353,656$ \\
\hline
\end{tabular}




\section{CHAPTER 7 : DEVELOPMENT OF BRIDGE PRESERVATION COST MODELS}

\subsection{Introduction}

The current version of the bridge management software used by INDOT incorporates up to 50 distinct project types. However, no direct and comprehensive analysis of construction costs of these project types has been conducted to date. In the absence of recent cost analysis efforts and models, INDOT bridge management engineers resort to the use of cost values developed several years ago (Saito et al., 1988), duly adjusted for inflation. Although the cost estimates from the earlier study may appear reasonable, their continued reliability has not been tested against current cost expenditures. Also, changes in construction materials and technological advances are likely to have a significant impact on unit costs of various bridge preservation treatments. According to NCHRP Synthesis 227 (Thompson and Markow, 1996) lack of reliable sources for accurate cost data is a problem faced by current bridge management systems. Uncertainties in cost analysis can lead to incorrect decisions, particularly in selecting feasible strategies.

After an investigation of recent contracts and identification of the work performed in each contract, it was found that the available data would allow the development of cost models for the following activities:

1) Bridge replacement

2) Deck rehabilitation

3) Deck rehabilitation and superstructure rehabilitation

4) Deck replacement

5) Deck replacement, superstructure, and substructure rehabilitation

6) Deck replacement and superstructure rehabilitation

7) Superstructure replacement

8) Superstructure replacement and substructure rehabilitation

9) Bridge widening 
In the present chapter, the results obtained for the different models developed are presented and the best models for prediction are also specified.

\subsection{Cost Estimation of Bridge Replacement}

Bridge replacement entails a complete replacement of the entire bridge structure. Some bridges that are replaced also may be widened. Bridge replacement costs depend on the length, width, and height of the bridge; the number and length of individual spans; the superstructure material and substructure material; structural type; bridge location; and feature being crossed such as a rail, or highway or river (Hawk, 2003).

The cost models were developed on the basis of 82 bridge replacement contracts during the time period 1996 to 2002. The bridge replacement cost items were divided into four categories:

1) Superstructure Replacement Cost (SUPC),

2) Substructure Replacement Cost (SUBC),

4) Approach Cost (APPC),

3) "Other Cost" (OTHC).

Separate models were developed for these four cost components. Each of these cost components was represented as a function of bridge characteristics and other indirect factors such as location or weather. The total bridge replacement cost is the summation of the four cost components. The best models were determined after validation on the basis of the Root Mean Square Error (RMSE). 


\subsubsection{Slab Bridge Replacement Cost Models}

The schematic illustration of a typical concrete slab bridge types is shown in Figure 7-1. Deck slab structures are the simplest type of bridge superstructures. Also, slab bridges are the easiest to construct and are frequently used for relatively short spans. The structural form of deck slabs is very efficient at distributing point loads because of its two-way spanning ability and high torsional strength (Gupta, 2003).
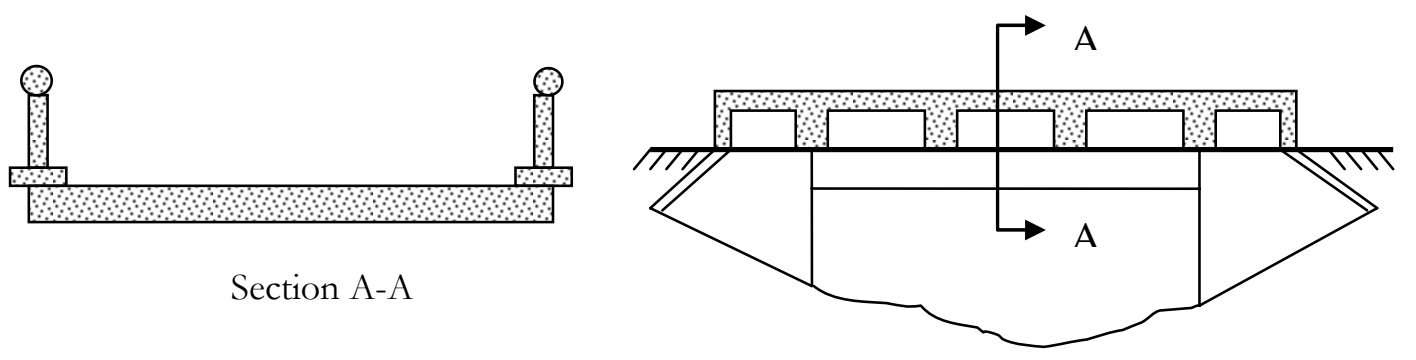

Figure 7-1 Schematic Illustration of Typical Concrete Slab Bridge Types

It was found that on average, the superstructure replacement cost component accounted for $24 \%$ of the total replacement cost, while the contribution of the substructure to replacement costs was the least at $9 \%$. Approach cost represented the largest part of the total replacement cost (almost $41 \%$ ), while the share of the "other cost" component was $26 \%$.

\subsubsection{Superstructure Replacement Cost Model for Slab Bridges}

Initial analysis showed that for slab bridges, the deck area has a strong influence on the total superstructure cost. As expected, the larger the deck area, the higher the superstructure cost. For modeling, several functional forms were explored, including the linear form. On Table 7-1 is shown a summary of the Superstructure Replacement Cost Models developed for Slab Bridges. 
Table 7-1 Summary of Superstructure Replacement Cost Models for Slab Bridges

\begin{tabular}{llc}
\hline MODEL FORM & MODEL & $\mathrm{R}^{2}$ \\
\hline Linear & SUPC $=-19.451+1.392 * B L+1.134 * T D W+39.585^{*}$ Pre-stressed & 0.417 \\
\hline Cobb-Douglas (1) & $S U P C=0.0806^{*} B L^{1.0053} T D W^{0.814}$ & 0.545 \\
\hline Constrained Cobb-Douglas & $S U P C=0.06045^{*} B L^{0.999} T D W^{0.841}$ & 0.535 \\
\hline Cobb-Douglas (2) & $S U P C=\left(0.2598+0.066^{*} \text { Pre-stressed }\right)^{* B L^{0.8122 *} T D W^{0.7223}}$ & 0.616 \\
\hline Transformed Cobb-Douglas & $S U P C=\mathrm{EXP}\left(0.477383^{*} B L^{0.3150 *} T D W^{0.250}\right)$ & 0.743 \\
\hline SUPC is the total superstructure cost in $\$ 1000$ 's year 2002 & \\
BL is the bridge length in feet \\
TDW is the total deck width in feet \\
Pre-stressed is 1 if superstructure is made of pre-stressed concrete, 0 otherwise
\end{tabular}

The models with highest $\mathrm{R}^{2}$ were chosen for validation: the Cobb-Douglas (2) and the Transformed Cobb-Douglas model. After validation, the Cobb-Douglas (2) model, with the pre-stressed variable included, showed the best performance. Table 7-2 shows the details of this model.

Table 7-2 Details of Best Superstructure Replacement Cost Model for Slab Bridges

\begin{tabular}{|c|c|c|c|c|}
\hline \multicolumn{5}{|c|}{$S U P C=(\mathrm{A}+\mathrm{B} *$ Pre-stressed $) * B L^{\mathrm{C} *} T D W^{\mathrm{D}}$} \\
\hline \multicolumn{5}{|c|}{ [Cobb-Douglas (2) Form] } \\
\hline Explanatory Variable & & ficient & Standard Error & t-Statistic \\
\hline Constant & $\bar{A}$ & 0.2598 & 0.0921 & 2.8212 \\
\hline Pre-stressed & B & 0.0660 & 0.0382 & 1.7290 \\
\hline$B L$ & $\mathrm{C}$ & 0.8122 & 0.1964 & 4.0839 \\
\hline$T D W$ & $\overline{\mathrm{D}}$ & 0.7223 & 0.1745 & 3.8926 \\
\hline & & 0.616, & $=26$ & \\
\hline
\end{tabular}




\subsubsection{Substructure Replacement Cost Models for Slab Bridges}

A similar analysis was performed for the substructure replacement cost for slab bridges. A positive trend in the relationship between the total substructure replacement cost and the deck area was also found for slab bridges. Several functional forms were investigated. A summary of the results are presented in Table 7-3 and the details of the best model after validation are given in Table 7-4. Although the $\mathrm{R}^{2}$ value was not high, the variables included were found to be highly significant.

Table 7-3 Summary of the Substructure Replacement Cost Models for Slab Bridges

\begin{tabular}{llc}
\hline MODEL FORM & MODEL & $\mathrm{R}^{2}$ \\
\hline Linear & $S U B C=15.919+3.634^{*} S U B H$ & 0.147 \\
\hline Average Cost & $S U B C=5.1292^{*} S U B H$ & 0.149 \\
\hline Cobb-Douglas & $S U B C=1.2603 * B L^{0.1124} \mathrm{TDW}^{0.3914} S U B H^{0.767}$ & 0.267 \\
\hline Transformed Cobb-Douglass & $S U B C=\exp \left(3.0449 * S U B H^{0.0869}\right)$ & 0.327 \\
\hline
\end{tabular}

SUBC is the total substructure replacement cost expressed in $\$ 1000$ 's year 2002 constant dollar $S U B H$ is the substructure height in feet

Table 7-4 Details of Best Substructure Replacement Cost Model for Slab Bridges

\begin{tabular}{lcccc}
\hline \multicolumn{5}{c}{$S U B C=\exp \left(\mathrm{A}^{*} S U B H^{\mathrm{B}}\right)$} \\
[Transformed Cobb-Douglas Form] \\
\hline Explanatory Variable & Coefficient & Standard Error & t-Statistic \\
\hline Constant & A & 3.0449 & 0.2831 & 10.7567 \\
\hline SUBH & B & 0.0869 & 0.0272 & 3.1988 \\
\hline \multicolumn{5}{c}{$\mathrm{R}^{2}=0.327, \mathrm{~N}=24$} \\
\hline
\end{tabular}

\subsubsection{Approach Replacement Cost for Slab Bridges}

Data on bridge approach lengths were not available. Therefore, approach cost was modeled in terms of other variables besides the approach length. However, due to the poor $\mathrm{R}^{2}$, even for the 
best model, it was decided to estimate the approach replacement cost for slab bridges using an average cost of $\$ 73.11$ per square foot of deck area.

\subsubsection{4 “Other Cost” for Slab Bridge Replacement}

"Other cost" includes all those items related to traffic control measures, excavation, mobilization and demobilization, and office expenses. As the $\mathrm{R}^{2}$ was poor for all models, it was decided to use an average cost of $\$ 49.12$ per square foot of deck area for estimation of the "other cost" for slab bridge replacement cost.

\subsubsection{Pre-stressed Beam Bridge Replacement Cost Models}

Beam or girder superstructure types consist of a deck slab supported by longitudinal beams or girders as illustrated in Figure 7-2. The longitudinal beam or girders may in turn be supported by abutments, piers, bents, or floor beams (Gupta, 2003). The longitudinal beams or girders may have any cross section, with I, T, or box sections being the most common in Indiana. These elements may be in either reinforced or pre-stressed concrete. However, in the present dataset, bridges of this type had only pre-stressed element sections. One characteristic of such superstructures is the use of transverse intermediate diaphragms.
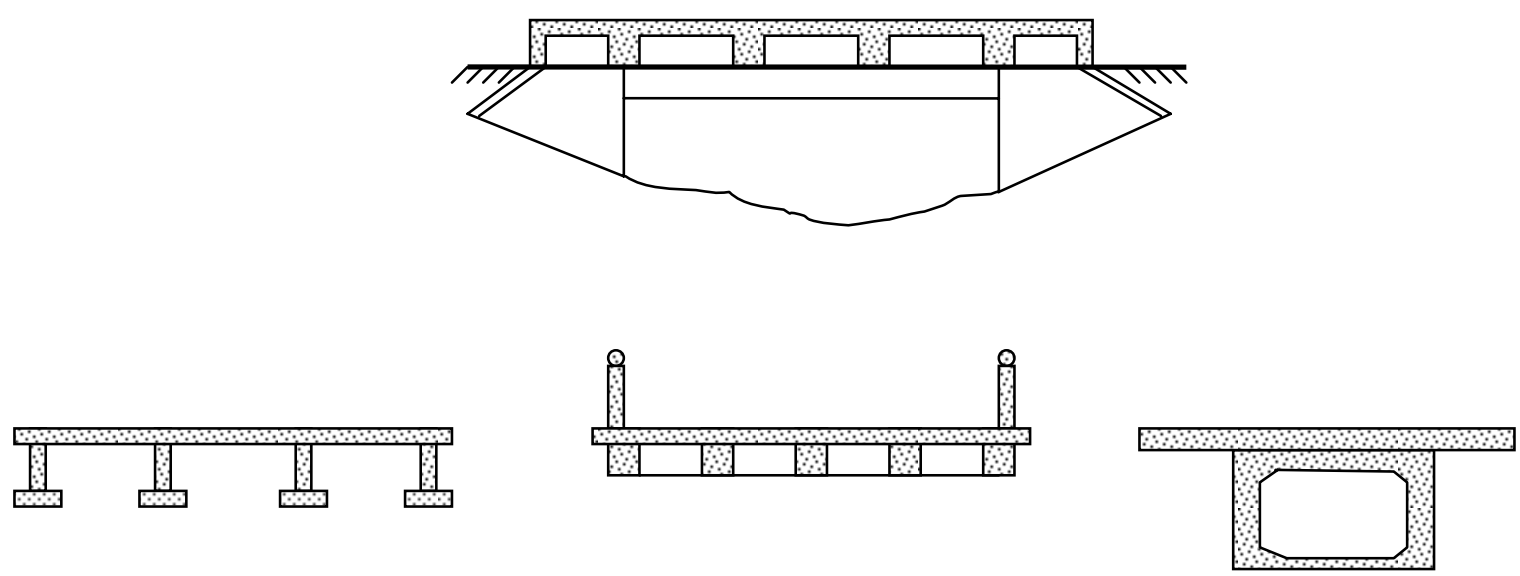

Figure 7-2 Schematic Illustration of Typical Pre-stressed Concrete Bridge Sections 


\subsubsection{Superstructure Replacement Cost Model for Pre-stressed Beam Bridges}

A summary of the models developed for the superstructure replacement of pre-stressed beam bridges is shown on Table 7-5. The superstructure replacement cost for pre-stressed beam bridges was found to be independent of substructure height. After validation, the Transformed Cobb-Douglas Form was the best model and its details are shown on Table 7-6.

Table 7-5 Summary of Superstructure Replacement Cost Models for Pre-stressed Beam Bridges

\begin{tabular}{ccc}
\hline MODEL FORM & MODEL & $\mathrm{R}^{2}$ \\
\hline Linear & $S U P C=-26.544+0.051 * D A$ & 0.968 \\
\hline Cobb-Douglas & $S U P C=0.0244^{*} B L^{1.0879} * T D W^{1.0424}$ & 0.972 \\
\hline Constrained Cobb-Douglas & $S U P C=0.05308^{*} B L^{1.000 *} T D W^{0.98236}$ & 0.967 \\
\hline Transformed Cobb-Douglas & $S U P C=\exp \left(0.632^{*} B L^{0.166 *} T D W^{0.1394}\right)$ & 0.977 \\
\hline$S U P C$ is the superstructure replacement cost for beam bridges in $\$ 1000$ (Year 2002) & \\
$D A$ is the deck area in square feet & \\
$B L$ is the bridge length in feet & \\
$T D W$ is the total deck width in feet &
\end{tabular}

Table 7-6 Details of Best Model for Superstructure Replacement Cost of Pre-stressed Beam Bridges

\begin{tabular}{|c|c|c|c|c|}
\hline \multicolumn{5}{|c|}{$\begin{array}{c}S U P C=\operatorname{EXP}\left(\mathrm{A}^{*} B L^{\mathrm{B} *} T D W^{\mathrm{C}}\right) \\
\text { [Transformed Cobb-Douglas Form] }\end{array}$} \\
\hline \multirow{2}{*}{$\begin{array}{c}\text { Explanatory Variable } \\
\text { Constant }\end{array}$} & \multicolumn{2}{|c|}{ Coefficient } & \multirow{2}{*}{$\begin{array}{c}\text { Standard Error } \\
0.0486\end{array}$} & \multirow{2}{*}{$\begin{array}{r}\text { t-Statistic } \\
2.0952\end{array}$} \\
\hline & $\mathrm{A}$ & 0.6328 & & \\
\hline$B L$ & $\mathrm{~B}$ & 0.1667 & 0.0050 & 27.3493 \\
\hline$T D W$ & $\mathrm{C}$ & 0.1395 & 0.0201 & 12.4800 \\
\hline \multicolumn{5}{|c|}{$\mathrm{R}^{2}=0.977, \mathrm{~N}=32$} \\
\hline
\end{tabular}




\subsubsection{7.2.2.2Substructure Replacement Cost Models for Pre-stressed Beam Bridges}

Substructure cost was found to have a strong relationship with deck area. Various functional forms were tested, and the best models are presented on Table 7-7. After validation, it was concluded that the linear form was the most appropriate model for estimating substructure replacement cost for pre-stressed beam bridges. Table 7-8 presents details of the linear model.

Table 7-7 Summary of Substructure Replacement Cost Models for Pre-stressed Beam Bridges

\begin{tabular}{ccc}
\hline MODEL FORM & MODEL & $\mathrm{R}^{2}$ \\
\hline Linear & SUBC $=-37.848+0.023 * D A$ & 0.850 \\
\hline Cobb-Douglas & $S U B C=0.4867 * B L^{1.1070}$ & 0.834 \\
\hline Constrained Cobb-Douglas & $S U B C=0.9564718^{*} B L^{1.000}$ & 0.826 \\
\hline
\end{tabular}

Table 7-8 Details of Best Substructure Replacement Cost Model for Pre-stressed Beam Bridges

\begin{tabular}{ccccc}
\hline \multicolumn{5}{c}{$\begin{array}{c}S U B C=\mathrm{A}+\mathrm{B}^{*} D A \\
\text { [Linear Form }]\end{array}$} \\
\hline Explanatory Variable & Coefficient & Standard Error & t-Statistic \\
\hline Constant & A & -37.848 & 21.811 & -1.735 \\
\hline$D A$ & $\mathrm{~B}$ & 0.023 & 0.002 & 13.097 \\
\hline \multicolumn{5}{c}{$\mathrm{R}^{2}=0.850, \mathrm{~N}=32$} \\
\hline
\end{tabular}

\subsubsection{7.2.2.3 Approach Cost for Replacement of Pre-stressed Beam Bridges}

Assuming that the approach length is directly proportional to the bridge length, it is expected that the approach cost would have a direct relationship with the bridge length. Three models are presented in Table 7-9, and the best model was found to be the Constrained CobbDouglas after validation. 
Table 7-9 Summary of the Approach Cost Models for Pre-stressed Beam Bridge Replacement

\begin{tabular}{ccc}
\hline MODEL FORM & MODEL & $\mathrm{R}^{2}$ \\
\hline Linear & $A P P C=-771.858+0.563 * B L+19.047 * T D W+18.708 * S U B H$ & 0.654 \\
\hline Cobb-Douglas & $A P P C=0.2884 * B L^{0.2990 * T D W^{1.1518} * S U B H^{0.5517}}$ & 0.742 \\
\hline Constrained Cobb-Douglas & $A P P C=0.7206^{*} B L^{0.2784 *} T D W^{0.9464} * S U B H^{0.5567}$ & 0.731 \\
\hline Transformed Cobb-Douglas & $A P P C=\exp \left(1.758^{*} B L^{0.084 * T D W^{0.166 * S U B H}}\right.$ & $0.069)$ \\
\hline
\end{tabular}

Table 7-10 Details of Best Approach Cost Model for Pre-stressed Beam Bridge Replacement

\begin{tabular}{|c|c|c|c|c|}
\hline \multicolumn{5}{|c|}{$\begin{array}{l}A P P C=\mathrm{A}^{*} B L^{\mathrm{B} *} T D W^{\mathrm{C}} * S U B H^{\mathrm{D}} \\
\text { [Constrained Cobb Douglas Form] }\end{array}$} \\
\hline Explanatory Variable & \multicolumn{2}{|c|}{ Coefficient } & \multirow{2}{*}{$\begin{array}{c}\text { Standard Error } \\
0.6802\end{array}$} & \multirow{2}{*}{$\frac{\text { t-Statistic }}{1.0593}$} \\
\hline Constant & A & 0.7206 & & \\
\hline$B L$ & $\mathrm{~B}$ & 0.2784 & 0.1165 & 2.3900 \\
\hline$T D W$ & $\mathrm{C}$ & 0.9464 & 0.2195 & 4.3111 \\
\hline SUBH & $\mathrm{D}$ & 0.5567 & 0.2085 & 2.6703 \\
\hline \multicolumn{5}{|c|}{$\mathrm{R}^{2}=0.731, \mathrm{~N}=32$} \\
\hline
\end{tabular}

\subsubsection{7.2.2.4 “Other Cost” for Pre-stressed Beam Bridge Replacement}

A summary of all models developed for this category is presented in Table 7-11. Upon validation, the Constrained Cobb Douglas Model was found to be the best model; Table 7-12 presents details of the Constrained Cobb-Douglas model. 
Table 7-11 Summary of the "Other Cost" Models for Pre-stressed Beam Bridge Replacement

\begin{tabular}{ccc}
\hline MODEL FORM & MODEL & $\mathrm{R}^{2}$ \\
\hline Linear & OTHC $=-784.420+0.682^{*} B L+17.425^{*} T D W+16.373 * S U B H$ & 0.751 \\
\hline Cobb-Douglas & OTHC $=0.0422^{*} B L^{0.4283 *} T D W^{1.3412} * S U B H^{0.6577}$ & 0.847 \\
\hline $\begin{array}{c}\text { Constrained Cobb- } \\
\text { Douglas }\end{array}$ & OTHC $=0.15008^{*} B L^{0.43493 *} \mathrm{TDW}^{1.000 * S U B H^{0.65372}}$ & 0.823 \\
\hline $\begin{array}{c}\text { Transformed } \\
\text { Cobb-Douglas }\end{array}$ & OTHC $=\exp \left(1.687109 * B L^{0.093161 *} \mathrm{TDW}^{\left.0.093161 * S U B H^{0.1319967}\right)}\right.$ & 0.810 \\
\hline
\end{tabular}

Table 7-12 Details of Best "Other Cost" Model for Beam Bridge Replacement

\begin{tabular}{|c|c|c|c|}
\hline \multicolumn{4}{|c|}{$O T H C=A^{*} B L^{\mathrm{B} *} S U B H^{\mathrm{C}} * T D W$} \\
\hline \multicolumn{4}{|c|}{ [Cobb-Douglas Form] } \\
\hline Explanatory Variable & Coefficient & Standard Error & t-Statistic \\
\hline Constant & $\begin{array}{ll}\text { A } & 0.1501\end{array}$ & 0.0902 & 1.6646 \\
\hline$B L$ & 0.4349 & 0.0943 & 4.6124 \\
\hline SUBH & $\begin{array}{ll}\mathrm{C} & 0.6537\end{array}$ & 0.1998 & 3.2714 \\
\hline \multicolumn{4}{|c|}{$\mathrm{R}^{2}=0.823, \mathrm{~N}=32$} \\
\hline
\end{tabular}

\subsubsection{Steel Bridge Replacement Cost}

Due to the insufficient number of observations, it was not possible to develop steel bridge replacement cost models. The construction types of steel bridges in the dataset were steel beam, plate girder, and box girder bridges (Appendix E). Steel beam bridge spans ranged from 10 to 17 feet, and are typically used for small road bridges. Plate girder bridge spans ranged from 20 to 200 feet. Average unit costs for the replacement of the various bridge elements are presented in Table 7-13. In comparison with those for concrete bridges, steel superstructure replacement unit costs were relatively low. However, the approach and "other cost" per square feet of deck area for steel bridges were higher than for concrete bridges. Finally, the total bridge replacement unit cost for steel bridges was lower than the total unit cost for concrete bridges, as shown in Figure 7-3. The results should be used with caution as the sample size for steel bridges was relatively small. 
Table 7-13 Descriptive Statistics of Replacement Unit Cost: for Steel Structure

\begin{tabular}{cccccc}
\hline \multirow{2}{*}{ STEEL BRIDGES } & Number of & \multicolumn{4}{c}{ Unit Cost per $\mathrm{ft}^{2}$ of Deck Area } \\
\cline { 3 - 6 } & Observations & Mean & Minimum & Maximum & Std. \\
Unit Super Replacement Cost & 6 & 56.66 & 52.02 & 67.54 & 7.06 \\
Unit Sub Replacement Cost & 6 & 17.12 & 10.54 & 31.26 & 9.28 \\
Unit Approach Cost & 6 & 56.35 & 33.35 & 102.59 & 32.18 \\
Unit “Other Cost" & 6 & 45.12 & 22.68 & 71.13 & 20.99 \\
\hline Total Unit Cost & 6 & 176.94 & 122.12 & 248.41 & 53.34 \\
\hline
\end{tabular}

Costs expressed in Year 2002 constant dollar.

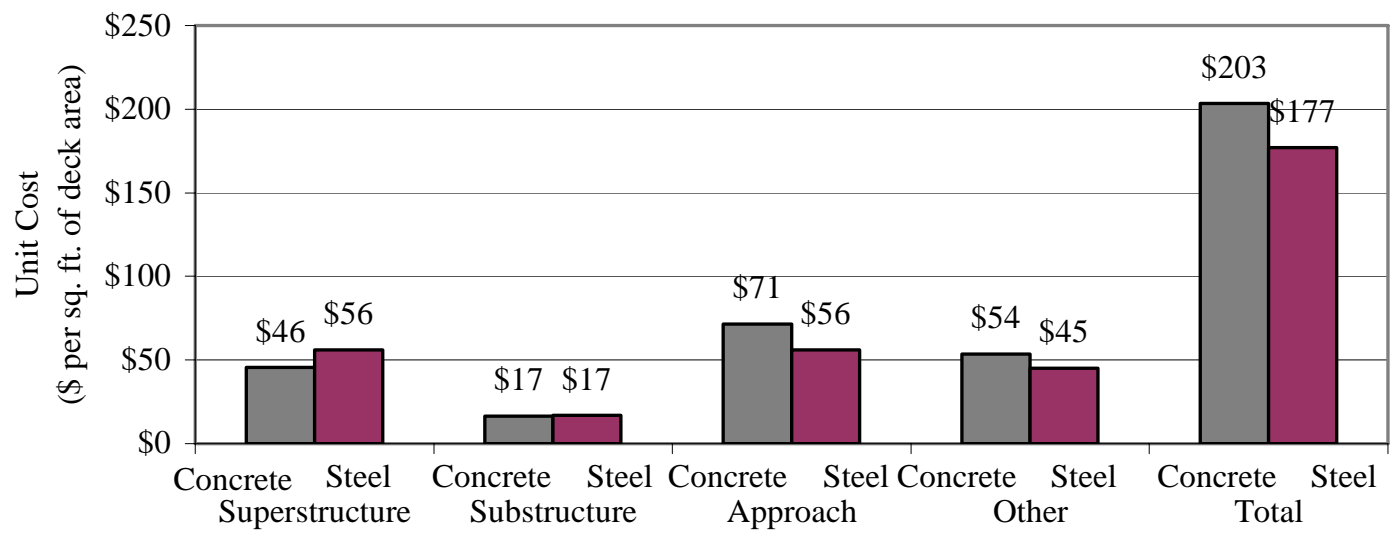

Figure 7-3 Comparison of Unit Cost of Bridge Replacement between Steel and Concrete Bridges

\subsubsection{Summary and Conclusions for Bridge Replacement Cost Modeling}

Bridge replacement costs were analyzed for concrete and steel bridges. For concrete bridges, sufficient data was available and models were developed. For steel bridges there was insufficient number of observations therefore only unit cost values were estimated. The recommended models with for prediction purposes are shown in Table 7-14.

It was found that the total bridge replacement unit cost for steel bridges was lower than for concrete bridges and this was largely attributed to the lower approach costs and "other" unit costs for steel bridges compared to such costs for concrete bridges. In general, it was found that approach and "other cost" represented over $50 \%$ of the total replacement cost. 
Table 7-14 Summary of Bridge Replacement Cost for Concrete Bridges

\begin{tabular}{|c|c|c|c|c|}
\hline $\begin{array}{l}\text { Super } \\
\text { Type }\end{array}$ & Cost & $\begin{array}{c}\text { Unit } \\
\text { Cost } \\
\left(\$ / \mathrm{ft}^{2}\right)\end{array}$ & Bridge Replacement Cost Models & $\mathrm{R}^{2}$ \\
\hline \multirow{4}{*}{ 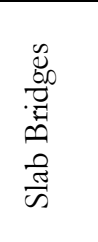 } & SUPC & 43.01 & $S U P C=\operatorname{EXP}\left(0.4774 * B L^{\left.0.3150 * T D W^{0.250}\right)}\right.$ & 0.74 \\
\hline & $S U B C$ & 16.26 & $S U B C=\exp \left(3.0449 * S U B H^{0.0869}\right)$ & 0.33 \\
\hline & $A P P C$ & 73.11 & $A P P C=53.6713+0.1970 * A D T$ & 0.29 \\
\hline & OTHC & 49.12 & $O T H C=B L^{1.1273}$ & 0.30 \\
\hline \multirow{4}{*}{ 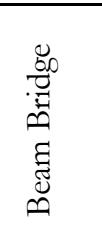 } & SUPC & 46.35 & $S U P C=\exp \left(0.6320 * B L^{0.1661 * T D W^{0.1394}}\right)$ & 0.98 \\
\hline & $S U B C$ & 16.58 & $S U B C=\exp \left(0.5811 * B L^{0.2245 *} T D W^{0.1530 *} S U B H^{0.1133}\right)$ & 0.84 \\
\hline & $A P P C$ & 70.88 & 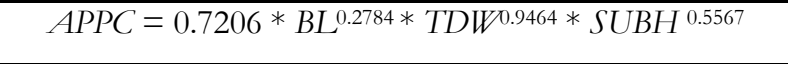 & 0.73 \\
\hline & OTHC & 55.08 & $O T H C=0.1501 * B L^{0.4349 *} T^{2} W^{1.000} * S U B H^{0.6537}$ & 0.82 \\
\hline \multirow{4}{*}{ 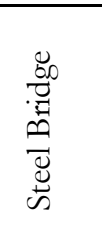 } & SUPC & 56.66 & $S U P C=56.66^{*} D A$ & NA \\
\hline & $S U B C$ & 17.12 & $S U B C=17.12^{*} D A$ & NA \\
\hline & $A P P C$ & 56.35 & $A P P C=56.35^{*} D A$ & NA \\
\hline & OTHC & 45.12 & $O T H C=45.12 * D A$ & NA \\
\hline
\end{tabular}

SUPC is the superstructure replacement cost in $\$ 1000$ (expressed in Year 2002 constant dollar) SUBC is the substructure replacement cost in $\$ 1000$ (expressed in Year 2002 constant dollar) $A P P C$ is the approach cost in $\$ 1000$ (expressed in Year 2002 constant dollar) OTHC is the "other cost" in $\$ 1000$ (expressed in Year 2002 constant dollar)

$B L$ is the bridge length in feet

$T D W$ is the total deck width in feet

SUBH is the substructure Height in feet

$A D T$ is the Average Daily Traffic 


\subsection{Cost Estimation for Bridge Rehabilitation Activities}

Rehabilitation and repair activities are major repairs that are usually performed by contractors. These activities include functional and structural improvements such as bridge widening, bridge raising, lowering pavement thickness and structure strengthening. Figure 7-4 shows the rehabilitation activities identified in the dataset after an exhaustive examination of recent INDOT bridge contracts. The number of observations found in each category type is shown in parenthesis.

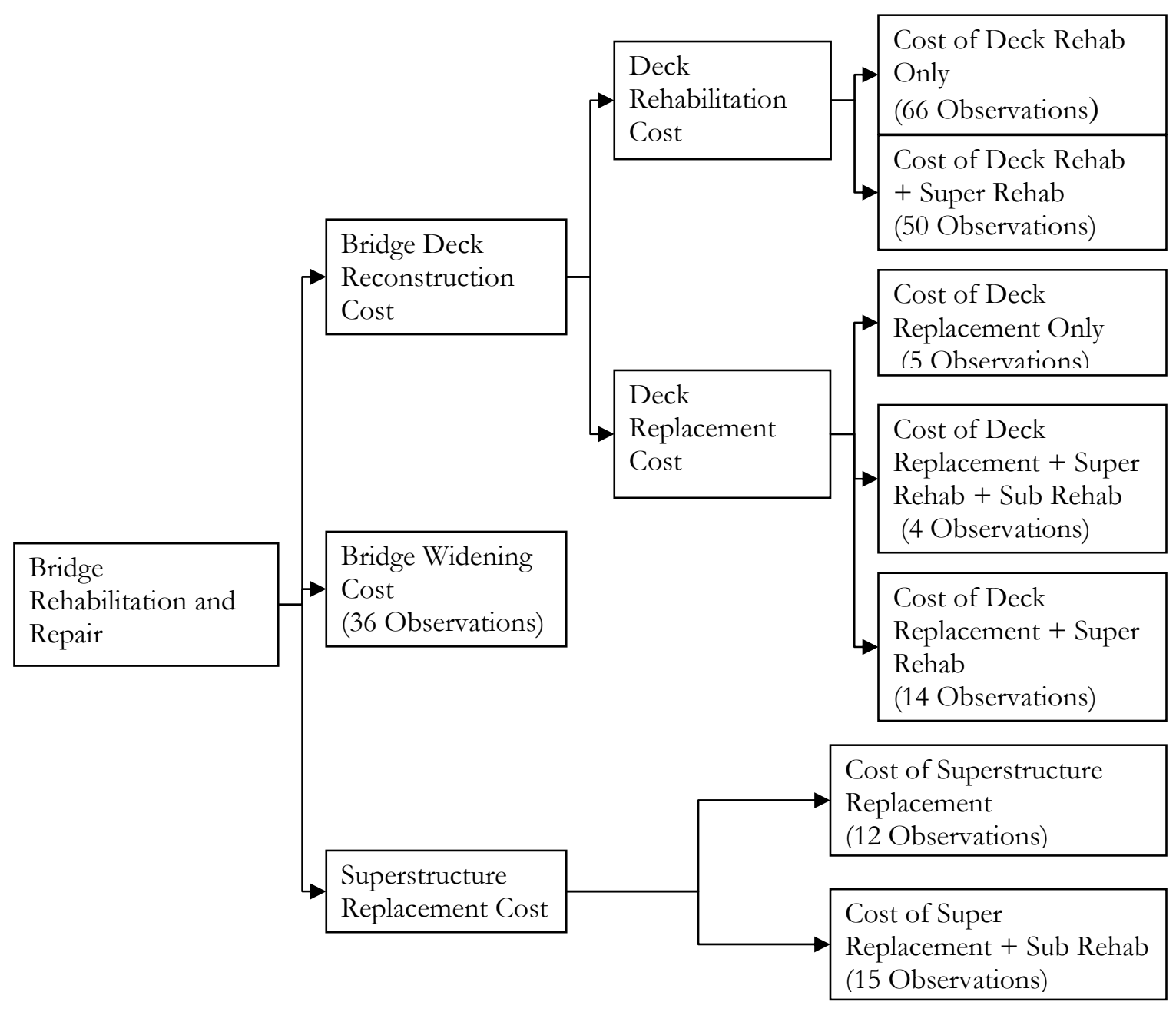

Figure 7-4 Classification of Rehabilitation Cost Models Developed in Present Study 


\subsubsection{Deck Rehabilitation Cost Model}

Deck rehabilitation contracts include such activities as the removal of structure railing and deck overlay, full depth or partial deck patching, and deck overlay. Deck rehabilitation is the most common bridge preservation activity and is typically applied to bridges approximately 20 years after initial construction. Deck rehabilitation may also include other activities such as hydro-demolition, deck transverse joint repair (sawing, cleaning, sealing), hole drilling, application of epoxy coating on bars, concrete patching, and bridge railing restoration. The total rehabilitation cost for each contract was divided into deck rehabilitation primary cost (DHC), which includes all items directly related to the deck rehabilitation work, and "other cost" (OTHC) which are items such as traffic maintenance, demolition, or clearing right-of-way. Summaries of the models developed to estimate primary costs and "Other Costs" for deck rehabilitation are shown on Table 7-15 and 7-16.

Table 7-15 Summary of Deck Rehabilitation Primary Cost Models for all Bridge Types

\begin{tabular}{llc}
\hline MODEL FORM & MODEL & $\mathrm{R}^{2}$ \\
\hline Linear (1) & $D H C=0.0161 * D A$ & 0.527 \\
\hline Linear (1) & $D H C=65.438+0.011 * D A$ & 0.833 \\
\hline Cobb-Douglas & $D H C=0.2110^{*} B L^{0.6360 *} \mathrm{TDW}^{0.8873}$ & 0.871 \\
\hline
\end{tabular}

$D H C$ is the deck rehabilitation cost in $\$ 1000$ 's year 2002

$D A$ is the deck area in square feet

$B L$ is the bridge length in feet

$T D W$ is the total deck width in feet

Table 7-16 Summary of “Other Cost” Models for Deck Rehabilitation Contracts

\begin{tabular}{lll}
\hline MODEL FORM & MODEL & $\mathrm{R}^{2}$ \\
\hline Linear (1) & OTHC $=142.636+0.009$ ADT & 0.287 \\
\hline Linear (2) & OTHUC $=52.8246-0.0023$ DA & 0.338 \\
\hline Inverse & OTHUC $=166,103 / D A$ & 0.739 \\
\hline OTHC is the total "Other cost" in \$1000's year 2002 & \\
OTHUC is the unit "Other cost" in \$ year 2002 & \\
ADT is the Average Daily Traffic & \\
$D A$ is the deck area in square feet &
\end{tabular}


Table 7-17 and Table 7-18 present the details for the models considered best explain deck rehabilitation primary and "other cost" respectively after validation.

Table 7-17 Details of Best Deck Rehabilitation Primary Cost Model for all Bridge Types

\begin{tabular}{|c|c|c|c|}
\hline \multicolumn{4}{|c|}{$\begin{array}{l}D H C=A^{*} B L^{\mathrm{B} *} T D W^{\mathrm{C}} \\
\text { [Cobb-Douglas Form] }\end{array}$} \\
\hline Explanatory Variable & Coefficient & Standard Error & t-statistic \\
\hline Constant & 0.2110 & 0.1181 & 1.786 \\
\hline$B L$ & 0.6360 & 0.0358 & 17.746 \\
\hline$T D W$ & C 0.8873 & 0.1197 & 7.413 \\
\hline & $\mathrm{R}^{2}=0.871, \mathrm{I}$ & $=46$ & \\
\hline
\end{tabular}

Table 7-18 Details of Best Unit “Other Cost” Model for Deck Rehabilitation, all Bridge Types

\begin{tabular}{|c|c|c|c|}
\hline \multicolumn{4}{|c|}{$\begin{array}{c}\text { OTHUC }=A / D A \\
\text { [Inverse Form] }\end{array}$} \\
\hline Explanatory Variable & Coefficient & Standard Error & t-statistic \\
\hline$\overline{D A}$ & $\begin{array}{ll}\text { A } & 166103\end{array}$ & 7762.3841 & 21.3981 \\
\hline
\end{tabular}




\subsubsection{Deck and Superstructure Rehabilitation Cost Model}

The combined cost of deck and superstructure rehabilitation was modeled using deck rehabilitation contracts where the superstructure rehabilitation cost accounted for over $5 \%$ of the total contract cost. Those contracts had substantial superstructure rehabilitation and included such simple items as jacking and supporting trusses or beams and cleaning and painting diaphragms as well as more complex activities involving retrofit work, bearing assembly, beam repair, or straightening steel beam. In deck and superstructure rehabilitation contracts, superstructure rehabilitation items could account for $5-25 \%$ of the total cost.

Table 7-19 presents the linear models found for deck + superstructure rehabilitation primary cost. However, no model was found appropriate to explain the "other cost." Large variations in "other cost" were caused by site characteristics and traffic control measures associated with the project. Therefore, it was necessary to perform a one-way analysis of variance (ANOVA) on the deck and superstructure rehabilitation "other cost" data with respect to the deck area. A unit "other cost" of $\$ 31$ per square foot for bridges with a deck area lower than 8,000 square feet, and $\$ 16$ per square foot above 8,000 square foot was found.

Table 7-19 Summary of Primary Cost Models for Deck + Superstructure Rehabilitation for all Bridge Types

\begin{tabular}{llc}
\hline MODEL FORM & MODEL & $\mathrm{R}^{2}$ \\
\hline Linear (1) & $D S H=119.571-0.016 * D A-40.844 *$ Steel & 0.671 \\
\hline Linear (2) & $D S H=87.684-0.017 * D A$ & 0.673 \\
\hline Linear (3) & $D S H=75.606+93.986 * N H S+0.016 * D A$ & 0.767 \\
\hline Linear (4) & $D S H=103.911+0.015 * D A+91.130 * N H S-35.787 *$ Steel & 0.784 \\
\hline
\end{tabular}

Validation showed that the linear model 4 was the best of the models developed. Its details are presented in Table 7-20. 
Table 7-20 Details of the Best Primary Cost Model for Deck + Superstructure Rehabilitation for all Bridge Types

\begin{tabular}{lllll}
\hline $\begin{array}{l}\text { DSH }=\mathrm{A}+\mathrm{B}^{*} \mathrm{DA}+\mathrm{C}^{*} \mathrm{NHS}+\mathrm{D} * \text { Steel } \\
\text { [Linear Form (4)] }\end{array}$ & & & \\
\hline Explanatory Variable & Coefficient & Standard Error & t-statistic \\
\hline Constant & $\mathrm{A}$ & 103.911 & 23.531 & 4.416 \\
\hline $\mathrm{D} A$ & $\mathrm{~B}$ & 0.015 & 0.002 & 8.882 \\
\hline NHS & $\mathrm{C}$ & 91.130 & 23.815 & 3.827 \\
\hline Steel & $\mathrm{D}$ & -35.787 & 19.860 & -1.802 \\
\hline $\mathrm{R}^{2}=0.784, \mathrm{~N}=38$ & & & & \\
\hline
\end{tabular}

$D A$ is the deck area in square feet

NHS is 1-for bridges on National Highway System, and 0- Otherwise Steel is 1 - for steel bridges, 0 - Otherwise

\subsubsection{Deck Replacement Cost Model}

Deck replacement consists of restoring bridge deck structural integrity by removal and replacement of the existing deteriorated deck bridge. Deck replacement contracts involve not only deck replacement but may include superstructure rehabilitation and/or substructure rehabilitation. In the data used in the present study, only five contracts were identified to have deck replacement and no other extra work, four contracts were identified to have substantial substructure and superstructure rehabilitation work, and 15 contracts comprised not only deck replacement but also superstructure rehabilitation. Due to data limitations, cost models could not be developed for deck replacement only, and as such only average values were estimated for this category of preservation.

\section{Deck Replacement Only}

Table 7-21 presents average of the primary and "other cost" for deck replacement contracts. Also, Table 7-22 presents the average unit cost of the primary cost and "other cost" for deck replacement contracts. An average total unit cost of $\$ 54$ per sq. $\mathrm{ft}$. was found in the present study. 
Table 7-21 Descriptive Statistics for Deck Replacement Total Cost

\begin{tabular}{|c|c|c|c|c|c|}
\hline \multirow{2}{*}{ Deck Replacement } & \multirow{2}{*}{$\begin{array}{l}\text { Number of } \\
\text { Observations }\end{array}$} & \multicolumn{4}{|c|}{ Total Cost $(\$ 1000)$} \\
\hline & & Mean & Minimum & Maximum & $\begin{array}{l}\text { Std. } \\
\text { Deviation }\end{array}$ \\
\hline Primary Cost & 5 & 146.23 & 105.01 & 212.12 & 39.40 \\
\hline "Other Cost" & 5 & 169.24 & 114.06 & 205.43 & 39.84 \\
\hline Total Cost & 5 & 319.53 & 251.06 & 410.09 & 37.01 \\
\hline
\end{tabular}

Costs are expressed in Year 2002 constant dollar

Table 7-22 Descriptive Statistics for Deck Replacement Unit Cost

\begin{tabular}{|c|c|c|c|c|c|}
\hline \multirow{2}{*}{ Deck Replacement } & \multirow{2}{*}{$\begin{array}{l}\text { Number of } \\
\text { Observations }\end{array}$} & \multicolumn{4}{|c|}{ Unit Cost (\$ per $\mathrm{ft}^{2}$ of deck area) } \\
\hline & & Mean & Minimum & Maximum & $\begin{array}{l}\text { Std. } \\
\text { Deviation }\end{array}$ \\
\hline Unit Primary Cost & 5 & 24.44 & 18.81 & 32.59 & 5.40 \\
\hline Unit "Other Cost" & 5 & 29.59 & 16.84 & 43.78 & 11.31 \\
\hline Unit Total Cost & 5 & 54.81 & 36.42 & 79.03 & 16.59 \\
\hline
\end{tabular}

Costs are expressed in Year 2002 constant dollar

\section{Deck Replacement + Superstructure + Substructure Rehabilitation}

Deck replacement contracts where superstructure rehabilitation and substructure rehabilitation each contributed over $5 \%$ to overall contract costs were considered for this category. Only four contracts fitted this description. Tables 7-23 and 7-24 present the average total and unit cost of the sub-components for deck replacement, superstructure and substructure rehabilitation contracts. The average unit cost computed was $\$ 97.55$ per square foot and the standard deviation was fairly small. Among the sub-components, the superstructure cost and "other cost" were those that varied the most. Substructure total cost and unit cost were relatively consistent among the various contracts in this category. 
Table 7-23 Descriptive Statistics for Deck Replacement + Superstructure + Substructure Rehabilitation Cost

\begin{tabular}{lllllll}
\hline \multirow{2}{*}{$\begin{array}{l}\text { Deck Replacement, Super } \\
\text { Substructure Rehabilitation }\end{array}$} & and & $\begin{array}{l}\text { Number } \\
\text { Observations }\end{array}$ & of & \multicolumn{3}{l}{ Total Cost $(\$ 1000)$} \\
\cline { 4 - 6 } & & & Mean & Minimum & Maximum & $\begin{array}{l}\text { Std. } \\
\text { Deviation }\end{array}$ \\
\hline Deck Replacement Cost & 4 & 211.70 & 127.36 & 381.82 & 115.45 \\
Superstructure Rehab Cost & 4 & 217.78 & 97.65 & 380.36 & 119.73 \\
Substructure Rehab Cost & 4 & 66.33 & 33.08 & 95.98 & 33.09 \\
\hline "Other Cost" & 4 & 214.28 & 129.54 & 289.51 & 78.13 \\
\hline
\end{tabular}

Costs are expressed in Year 2002 constant dollar

Table 7-24 Descriptive Statistics for Deck Replacement + Superstructure + Substructure Rehabilitation Cost

\begin{tabular}{|c|c|c|c|c|c|}
\hline \multirow{2}{*}{$\begin{array}{l}\text { Deck Replacement, Super } \\
\text { Substructure Rehabilitation }\end{array}$} & \multirow{2}{*}{$\begin{array}{l}\text { Number } \\
\text { Observations }\end{array}$} & \multicolumn{4}{|c|}{ Unit Cost ( $\$ / \mathrm{ft}^{2}$ of deck area) } \\
\hline & & Mean & Minimum & Maximum & $\begin{array}{l}\text { Std. } \\
\text { Deviation }\end{array}$ \\
\hline Unit Deck Replacement Cost & 4 & 27.50 & 20.07 & 35.09 & 6.19 \\
\hline Unit Super Rehab Cost & 4 & 30.97 & 16.34 & 60.15 & 19.94 \\
\hline Sub Rehab Unit Cost & 4 & 9.03 & 5.22 & 15.18 & 4.32 \\
\hline Unit "Other Cost" & 4 & 30.04 & 20.48 & 48.45 & 12.52 \\
\hline
\end{tabular}

Costs are expressed in Year 2002 constant dollar

\subsubsection{Deck Replacement + Superstructure Rehabilitation Cost Model}

Deck replacement + superstructure rehabilitation cost was the most common combination among the deck replacement contracts. Replacing bridge deck typically involves complex engineering procedures, including superstructure rehabilitation activities such as replacement of bearings and addition or strengthening of beams.

A summary of the models developed for primary cost is shown on Table 7-25. Similarly, Table 7-27 shows the models developed for "Other Costs" for Deck Replacement and Superstructure Rehabilitation contracts. The best models for primary and "other cost" for are presented in Table 7-26 and Table 7-28, respectively. 
Table 7-25 Summary of Deck Replacement + Superstructure Rehabilitation Primary Cost Models for all Bridge Types

\begin{tabular}{llr}
\hline MODEL FORM & MODEL & $\mathrm{R}^{2}$ \\
\hline Linear & $D R S H=-491.708+1.990 * B L+10.590 * T D W+263.352^{*} N H S$ & 0.777 \\
\hline Cobb-Douglas & $D R S H=B L^{0.7566 * T D W^{0.5759}}$ & 0.694 \\
\hline Improved Cobb-Douglas & $D R S H=\left(-162.954+264.835^{*} N H S\right)+B L^{0.6314 * T D W^{0.7927}}$ & 0.812 \\
\hline
\end{tabular}

Table 7-26 Best Deck Replacement + Superstructure Rehabilitation Primary Cost Model for all Bridge Types

\begin{tabular}{|c|c|c|c|}
\hline \multicolumn{4}{|c|}{$\begin{array}{l}D R S H=(\mathrm{A}+\mathrm{B} * N H S)+B L^{\mathrm{C} * T D W^{\mathrm{D}}} \\
\text { [Improved Cobb-Douglas Form] }\end{array}$} \\
\hline Explanatory Variable & Coefficient & Standard Error & t-statistic \\
\hline Constant & A $\quad-162.953$ & 91.848 & -1.774 \\
\hline NHS & B 264.836 & 112.461 & 2.355 \\
\hline$B L$ & $\begin{array}{ll}\text { C } & 0.631\end{array}$ & 0.114 & 5.518 \\
\hline$T D W$ & D 0.793 & 0.165 & 4.806 \\
\hline $\mathrm{R}^{2}=0.812, \mathrm{~N}=15$ & & & \\
\hline
\end{tabular}

Table 7-27 Summary of Deck Replacement + Super Rehabilitation "Other Cost" Models for all Bridge Types

\begin{tabular}{llc}
\hline MODEL FORM & MODEL & $\mathrm{R}^{2}$ \\
\hline Linear (1) & OTH $=-269.990+10.040 * B L+10.040 * T D W$ & 0.707 \\
\hline Linear (2) & $O T H=105421+0.028^{*} D A$ & 0.592 \\
\hline Cobb-Douglas & $O T H=B L^{0.3522 * T D W^{1.0611}}$ & 0.760 \\
\hline Constrained Cobb-Douglas & $O T H=B L^{0.4301 * T D W^{1.000}}$ & 0.766 \\
\hline
\end{tabular}


Table 7-28 Details of Best Deck Replacement + Super Rehabilitation “Other Cost” Model for all Bridge Types

\begin{tabular}{|c|c|c|c|c|}
\hline \multicolumn{5}{|c|}{$D S H=\mathrm{A}^{*} B L^{\mathrm{C}} * T D W^{\mathrm{D}}$} \\
\hline \multicolumn{5}{|c|}{ [ Constrained Cobb-Douglas Form] } \\
\hline Explanatory Variable & & fficient & Standard Error & t-statistic \\
\hline$B L$ & B & 0.386 & 0.101 & 3.820 \\
\hline$T D W$ & & 1.000 & 0.135 & 7.418 \\
\hline \multicolumn{5}{|c|}{$\mathrm{R}^{2}=0.766, \mathrm{~N}=15$} \\
\hline
\end{tabular}

\subsubsection{Superstructure Replacement Cost Model}

Superstructure replacement contracts include replacement of the bearing on an old bridge, and replacement of steel or concrete beams and structures. In the dataset, it was found that some superstructure replacement contracts had deck rehabilitation work but represented only up to $2 \%$ of the total contract cost. Those contracts were categorized as superstructure-replacement-only contracts.

Table 7-29 summarizes the various forms attempted to estimate the cost. Deck Area was found as the most significant variable. Also, Substructure Height was found significant. The linear form was found to be the best model for predictions.

The number of observations was not enough to carry out validation of the models. Therefore, it is suggested that the developed models could be validated in future studies as additional data becomes available.

Table 7-29 Summary of Superstructure Replacement Primary Cost Models for all Bridge Types

\begin{tabular}{llc}
\hline MODEL FORM & MODEL & $\mathrm{R}^{2}$ \\
\hline Linear & $S R=-125.121+0.080^{*} D A+14.650^{*} S U B H$ & 0.954 \\
\hline Cobb-Douglas & $S R=0.02653 * B L^{1.4235 * T D W^{0.7545}}$ & 0.976 \\
\hline Constrained Cobb-Douglas & $S R=0.2052 * B L^{1.000 * T D W^{0.8033}}$ & 0.956 \\
\hline
\end{tabular}


Table 7-30 Details of Best Superstructure Replacement Primary Cost Model for all Bridge Types

\begin{tabular}{lllcc}
\hline \multicolumn{5}{c}{$S \mathrm{R}=\mathrm{A}+\mathrm{B} * \mathrm{DA}+\mathrm{C}^{*} \mathrm{SUBH}$} \\
& [Linear Form] & \\
\hline Explanatory Variable & Coefficient & Standard Error & t-statistic \\
\hline Constant & $\mathrm{A}$ & -125.121 & 78.088 & -1.602 \\
\hline $\mathrm{DA}$ & $\mathrm{B}$ & 0.080 & 0.007 & 11.974 \\
\hline SUBH & $\mathrm{C}$ & 14.650 & 7.555 & 1.939 \\
\hline \multicolumn{5}{c}{$\mathrm{R}^{2}=0.954, \mathrm{~N}=12$} \\
\hline
\end{tabular}

Table 7-31 Summary of Superstructure Replacement "Other Cost" Models for all Bridge Types

\begin{tabular}{llc}
\hline MODEL FORM & MODEL & $\mathrm{R}^{2}$ \\
\hline Linear & OTHC $=67.042+0.049 * D A+824.556 *$ CONCRETE & 0.915 \\
\hline Linear & OTHC $=38.905+0.023 * A D T+1.928 * B L$ & 0.904 \\
\hline Cobb-Douglas & OTHC $=0.29293 * B L^{0.71388 * T D W^{1.000 .}}$ & 0.857 \\
\hline
\end{tabular}

Table 7-32 Details of Best Superstructure Replacement "Other Cost" Model for all Bridge Types

\begin{tabular}{lllll}
\hline \multicolumn{5}{c}{ OTHC $=\mathrm{A}+\mathrm{B} * \mathrm{D} A+\mathrm{C} *$ CONCRETE } \\
\multicolumn{5}{c}{ [Linear Form $]$} \\
\hline Explanatory Variable & Coefficient & Standard Error & t-statistic \\
\hline Constant & $\mathrm{A}$ & 67.042 & 30.245 & 2.217 \\
\hline $\mathrm{DA}$ & $\mathrm{B}$ & 0.049 & 0.007 & 7.262 \\
\hline CONCRETE & $\mathrm{C}$ & 824.556 & 131.060 & 6.291 \\
\hline \multicolumn{5}{c}{$\mathrm{R}^{2}=0.915, \mathrm{~N}=12$} \\
\end{tabular}

$D A$ is the deck area in square feet

$S U B H$ is the substructure height in feet

$B L$ is the bridge length in feet

$T D W$ is the total deck width in feet

CONCRETE is 1- for concrete superstructure bridges, 0 - otherwise $A D T$ is the Average Daily Traffic 


\subsubsection{Superstructure Replacement + Substructure Rehabilitation Cost Models}

In superstructure replacement contracts, there are other associated activities in addition to the main superstructure replacement activities. For instance, the substructure may be modified or upgraded to accomplish the stability of the new superstructure system. Superstructure replacement contracts that involve substantial substructure rehabilitation above $5 \%$ of the total contract cost were analyzed in this section. Substructure rehabilitation can account for $6-15 \%$ of the total contract cost. As in the previous sections, Table 7-33 and Table 7-35 present the developed models of primary and "other cost" for superstructure replacement and substructure rehabilitation contracts. Table 7-34 and Table 7-36 present the best models.

Table 7-33 Summary of Superstructure Replacement + Substructure Rehabilitation Primary Cost Models for all Bridge Types

\begin{tabular}{llc}
\hline MODEL FORM & MODEL & $\mathrm{R}^{2}$ \\
\hline Linear $(1)$ & $S R B H=0.088627 * D A$ & 0.840 \\
\hline Linear $(2)$ & $S R B H=95.876+408.421 * D A+0.059 * N H S$ & 0.848 \\
\hline Cobb-Douglas & $S P B H=B L^{1.000 *} T D W^{0.3847}$ & 0.854 \\
\hline
\end{tabular}

Table 7-34 Details of Best Superstructure Replacement + Substructure Rehabilitation Primary Cost Model for all Bridge Types

\begin{tabular}{lllll}
\hline$S R B H=B L^{\mathrm{C}} * T D W^{\mathrm{D}}$ & & & & \\
{$[$ Cobb-Douglas Form $]$} & & & & \\
\hline Explanatory Variable & Coefficient & Standard Error & t-statistic \\
\hline$B L$ & $\mathrm{~B}$ & 1.000 & 0.0992 & 10.0767 \\
\hline$T D W$ & $\mathrm{C}$ & 0.3685 & 0.1576 & 2.3387 \\
\hline $\mathrm{R}^{2}=0.854, \mathrm{~N}=15$ & & & & \\
\hline
\end{tabular}


Table 7-35 Summary of Superstructure Replacement + Substructure Rehabilitation "Other Cost" Models

\begin{tabular}{llr}
\hline MODEL FORM & MODEL & $\mathrm{R}^{2}$ \\
\hline Cobb-Douglas & OTHC $=(0.0431+0.0359 * N H S-0.027 \text { Prestressed })^{*} D A$ & 0.887 \\
\hline Linear $(1)$ & OTHC $=7.428+0.044 * D A$ & 0.597 \\
\hline Linear $(2)$ & OTHC $=68.081+0.038 * D A-254.692 *$ Prestressed $+467.957 * N H S$ & 0.749 \\
\hline
\end{tabular}

Table 7-36 Details of Best Superstructure Replacement + Substructure Rehabilitation “Other Cost" Model OTHC $=\left(\mathrm{A}+\mathrm{B}^{*}\right.$ NHS $+\mathrm{C} *$ Prestressed $) * D A$

[Cobb-Douglas Form]

\begin{tabular}{lcclc}
\hline Explanatory Variable & Coefficient & Standard Error & t-statistic \\
\hline Constant & A & 0.0431 & 0.006 & 6.9815 \\
\hline NHS & B & 0.0359 & 0.008 & 4.7358 \\
\hline Prestressed & C & -0.0271 & 0.008 & -3.3961 \\
\hline $\mathrm{R}^{2}=0.887, \mathrm{~N}=15$ & & & \\
\hline DA is the deck area in sq.ft. \\
Pre-stressed is 1- for pre-stressed bridges, 0- Otherwise \\
NHS is 1- for bridges on National Highway System, 0- Otherwise
\end{tabular}


The predicted and actual contract costs were plotted to identify the accuracy of the models obtained. As can be seen in Figure 7-5, the models performed satisfactorily for contracts up to $\$ 2,000,000$. For contracts higher than $\$ 2,000,000$, the models tended to underestimate the actual cost.

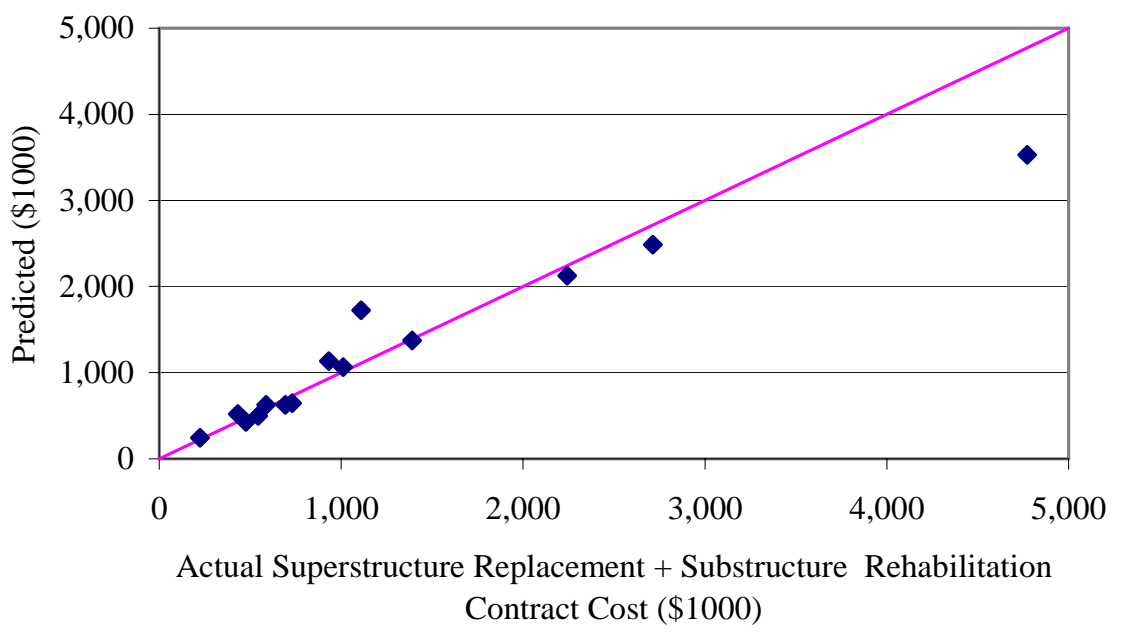

Figure 7-5 Predicted and Actual Cost for Superstructure Replacement + Substructure Rehabilitation

\subsubsection{Bridge Widening Cost Model}

A bridge needs to be widened if it has a width deficiency or if it needs to accommodate future increased traffic. In the dataset, such contracts involved widening up to 53 feet. Some contracts involved construction of new piers or reinforced concrete piles, addition of beams, or rehabilitation of the existing superstructure elements. All bridge widening contracts involved deck rehabilitation work that ranged from one to $10 \%$ of the total cost.

Several variables were found significant. The DELTATDW variable, the difference between the total deck width before and after the widening, was found significant. This was expected since this variable best reflects the physical amount of work done on a bridge. Bridge widening primary 
cost models are shown in Table 7-37. For the best model, the adjusted $\mathrm{R}^{2}$ was computed as 0.934 and the details are presented in Table 7-38.

Linear models were developed and also the Cobb-Douglas model for estimating "other cost" (Table 7-39). The Cobb-Douglas model was found to best predict bridge widening "other cost" and is presented in Table $7-40$.

Table 7-37 Summary of Bridge Widening Primary Cost Models

\begin{tabular}{llc}
\hline MODEL FORM & MODEL & $\mathrm{R}^{2}$ \\
\hline Linear 1 & $B W C=-618.395+10.155^{*} T D W+1.565^{*} B L+14.606^{*} S U B H$ & 0.934 \\
& $+183.834 * H W Y+9.922^{*}$ DeltaTDW $+0.009 * A D T$ & \\
\hline Linear 2 & $B W C=-172.48+0.034 * D A+15.506^{*} S U B H^{*}+227.151 * H W A Y$ & 0.925 \\
& $+10.186^{*}$ DeltaTDW $+0.008^{*} A D T$ & \\
\hline Cobb-Douglas & $B W C=\left(0.31045+0.00992 * S U B H * B L^{0.636121 * T D W^{1.000}}\right.$ & 0.904 \\
\hline
\end{tabular}

Table 7-38 Details of Best Bridge Widening Primary Cost Model for all Bridge Types

\begin{tabular}{|c|c|c|c|}
\hline \multicolumn{4}{|c|}{$\begin{array}{l}B W C=\mathrm{A}+\mathrm{B} * T D W+\mathrm{C} * B L+\mathrm{D} * S U B H+\mathrm{E}^{*} H W Y+\mathrm{F}^{*} D \text { eltaTDW } W+\mathrm{G}^{*} A D T \\
{[\text { Linear 1] }}\end{array}$} \\
\hline Explanatory Variable & Coefficient & Standard Error & t-statistic \\
\hline (Constant) & -618.398 & 97.687 & -6.330 \\
\hline DELTATDW & 9.922 & 2.863 & 3.466 \\
\hline$T D W$ & 10.155 & 1.785 & 5.690 \\
\hline SUBHF & 14.606 & 3.356 & 4.353 \\
\hline$B L$ & 1.565 & 0.231 & 6.784 \\
\hline$A D T$ & 0.009 & 0.003 & 2.600 \\
\hline$H W Y$ & 183.834 & 56.678 & 3.243 \\
\hline $\mathrm{R}^{2}=0.934, \mathrm{~N}=28$ & & & \\
\hline
\end{tabular}


Table 7-39 Summary of Bridge Widening "Other Cost" Models for all Bridge Types

\begin{tabular}{llc}
\hline MODEL FORM & MODEL & $\mathrm{R}^{2}$ \\
\hline Linear & OTHC $=-94.975+39.856 .725 *$ DeltaTDW+0.017*DA & 0.923 \\
\hline Linear & OTHC $=-353.603+37.644^{*}$ DeltaTDW+6.644*TDW+0.569*BL & 0.935 \\
\hline Cobb-Douglas & OTHC $=B L^{0.330217 * T D W^{0.743507 * D e l t a} T D W^{0.64523}}$ & 0.945 \\
\hline
\end{tabular}

$B W C$ is the bridge widening primary cost in $\$$ Year 2002

OTHC is the "other cost" in \$ Year 2002

$D A$ is the deck area in square feet

$B L$ is the bridge length in feet

$T D W$ is the total deck width in feet

DeltaTDW is the difference between the total deck width before and after widening in $\mathrm{ft}$ NHS is 1- for bridges on National Highway System, 0- Otherwise

$H W Y$ is 1 - for bridges crossing highways, 0 - Otherwise (rail or waterways)

$S U B H$ is substructure height in feet

Table 7-40 Details of Best Bridge Widening "Other Cost" Model for all Bridge Types

\begin{tabular}{lllll}
\hline OTHC $=\mathrm{BL}^{\mathrm{A} *} \mathrm{TDW}^{\mathrm{B} *}$ DeltaTDWC & & \\
\hline Explanatory Variable & Coefficient & Standard Error & t-statistic \\
\hline $\mathrm{BL}$ & A & 0.330 & 0.0865 & 3.816 \\
\hline TDW & B & 0.744 & 0.123 & 6.039 \\
\hline Delta TDW & C & 0.645 & 0.049 & 13.104 \\
\hline $\mathrm{R}^{2}=0.945, \mathrm{~N}=28$ & & & & \\
\hline
\end{tabular}




\subsubsection{Summary and Conclusions for Bridge Rehabilitation Cost Models}

In this section, cost models for rehabilitation activities were developed. The total contract cost of the rehabilitation activity was divided into two cost components: one cost component includes all items directly related to the specific rehabilitation activity, e.g., deck rehabilitation primary cost; and the second cost component, "other cost," included all indirect cost items. In order to determine the best model for each cost component, several statistical parameters were considered: $\mathrm{t}$ statistic, R-square value, and standard errors of the regression coefficients. Also, whenever possible, the models were validated to test their predictive accuracy.

Also, the model results show that the cost of bridge rehabilitation activities generally depend on the bridge dimensions (length, deck width, or deck area). It was determined that deck and superstructure rehabilitation costs depend not only on the deck area, but also on the bridge material and the highway road class of the bridge. Bridge widening involves many activities and its cost was found to depend on several factors, such as bridge size, substructure height, additional deck width, and traffic level. In general, it was found that the "other cost" of rehabilitation costs also depends on the bridge size. The models that best estimate the costs of various rehabilitation treatments are presented Table 7-41. 
Table 7-41 Summary of Rehabilitation Cost Models

\begin{tabular}{|c|c|c|}
\hline ACTIVITY & DIRECT-RELATED COST & OTHER COST \\
\hline $\begin{array}{l}\text { Deck } \\
\text { Rehabilitation } \\
(D H)\end{array}$ & $\underset{0.8873369}{D H C}=0.210970 * B L 0.635993 * T D W$ & $O T H U C=\$ 166,101 / D A$ \\
\hline Deck $\quad+$ & & \\
\hline $\begin{array}{l}\text { Superstructure } \\
\text { Rehabilitation } \\
(D S H)\end{array}$ & $\begin{array}{c}D S H=103.911+0.015 * D A+91.130 \\
* N H S-35.787 * \text { Steel }\end{array}$ & $\begin{array}{l}\text { For } D A<8000 \text { sq. ft. } \$ 31.83 * D A \text {. } \\
\text { For } D A>8000 \text { sq. ft. } \$ 16.01 * D A \text {. }\end{array}$ \\
\hline $\begin{array}{l}\text { Deck } \\
\text { Replacement } \\
(D R)\end{array}$ & $D R U C=\$ 24.44 * D A$ & $O T H U C=\$ 29.59 * D A$. \\
\hline $\begin{array}{l}\text { Deck } \\
\text { Replacement }+ \\
\text { Super } \\
\text { Rehabilitation } \\
(D R S H)\end{array}$ & $\begin{aligned} D R S H C & =(-162.9536+264.835 * N H S) \\
& +B L^{0.63144 * T D W^{0.79272}}\end{aligned}$ & $O T H C=B L^{0.430053 *} T D W^{1}$ \\
\hline $\begin{array}{l}\text { Deck } \\
\text { Replacement }+ \\
\text { Super }+ \text { Sub } \\
\text { Rehabilitation } \\
(D R S B H)\end{array}$ & $D R S B H U C=\$ 67.50 * D A$. & $O T H U C=\$ 30.04 * D A$. \\
\hline $\begin{array}{l}\text { Superstructure } \\
\text { Replacement } \\
\text { (SR) }\end{array}$ & $S R C=0.2052 * B L^{1 *} T D W^{0.80330}$ & $\begin{aligned} O T H C & =-89.045+0.066 * D A \\
& +254.205 * \text { Concrete }\end{aligned}$ \\
\hline $\begin{array}{l}\text { Super } \\
\text { Replacement }+ \\
\text { Sub } \\
\text { Rehabilitation } \\
(\text { SRBH) }\end{array}$ & $S R B H C=B L^{1.000 *} T D W^{0.3847}$ & 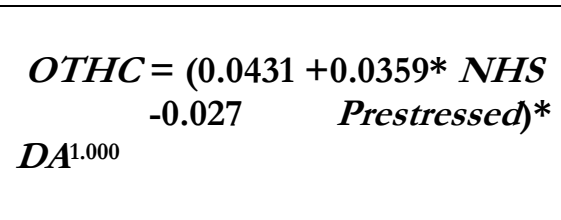 \\
\hline $\begin{array}{l}\text { Bridge } \\
\text { Widening } \\
(B W)\end{array}$ & $\begin{array}{rl}B W C= & -618.395+10.155 * T D W \\
+1.565 * & B L \\
& +14.606 * S U B H+183.834 * H W Y \\
& +9.922 * D e l t a T D W+0.009 * A D T\end{array}$ & $\begin{aligned} \underset{0.743507}{O T H C} & =B L \quad 0.330217 * T D W \\
& * \text { Delta } T D W^{0.64523}\end{aligned}$ \\
\hline
\end{tabular}

$B L$ is the bridge length in feet

$T D W$ is the total deck width in feet

NHS is 1- for a bridge on NHS, 0- Otherwise

$D A$ is the deck area in square feet

$S U B H$ is the substructure height in feet

$H W Y$ is 1 - for bridges crossing highways, 0- Otherwise

DeltaTDW is the difference in total deck width before and after bridge widening

ADT is the Average Daily Traffic

Concrete is 1- for concrete bridges, 0- Otherwise

Steel is 1 - for steel bridges, 0 - Otherwise

Prestressed is 1-for pre-stressed bridges, 0- Otherwise 


\subsection{4 Overall Summary and Conclusions for Bridge Preservation Cost Models}

The present chapter discussed a literature review carried out to acquire an insight into past efforts at bridge cost modeling. The chapter also discusses the development of cost models for bridge preservation costs, which include bridge replacement and bridge rehabilitation activities. Various functional forms were investigated.

Bridge replacement cost was expressed as the sum of four components: superstructure replacement cost, substructure replacement cost, approach cost, and "other cost." After validation, the models developed were found to predict more accurately bridge replacement costs than previous studies. Bridge rehabilitation cost models were also developed. Bridge rehabilitation activity cost was expressed as the sum of the primary cost and the "other cost". Due to lack of data, it was possible to model only eight rehabilitation activities. Also, for some activities whose costs were modeled, validation was not possible due to the lack of additional data needed for the purpose. In general, based on the results summarized in Table 7-14 and Table 7-41, it was found that the cost models developed in the present study are fairly good for estimating bridge preservation costs.

For planning and budgeting, a requirement that is complementary to bridge preservation costs is a set of models that enable bridge managers to track bridge deterioration and establish their service lives so that the time when preservation is needed and the associated costs can be estimated. The next chapter discusses the estimation of bridge service lives. 


\section{CHAPTER 8 : ESTIMATION OF BRIDGE SERVICE LIVES}

Bridge age has often been considered as a representation of the combined effects of load and weather effects and it is often used as a surrogate for these variables, especially in situations where data is lacking. The age of a bridge deck can be expressed as a primary age (since the bridge was constructed) or a secondary age (since the bridge was last rehabilitated). Some previous studies have found age to be the most significant variable to explain the bridge deck deterioration (Bulusu and Sinha, 1997; Chase et al., 2000). In Figure 8-1 is presented the delineation of bridge age. It should be noted that the primary age of a bridge is same as the secondary age during the period of the construction and the first rehabilitation.

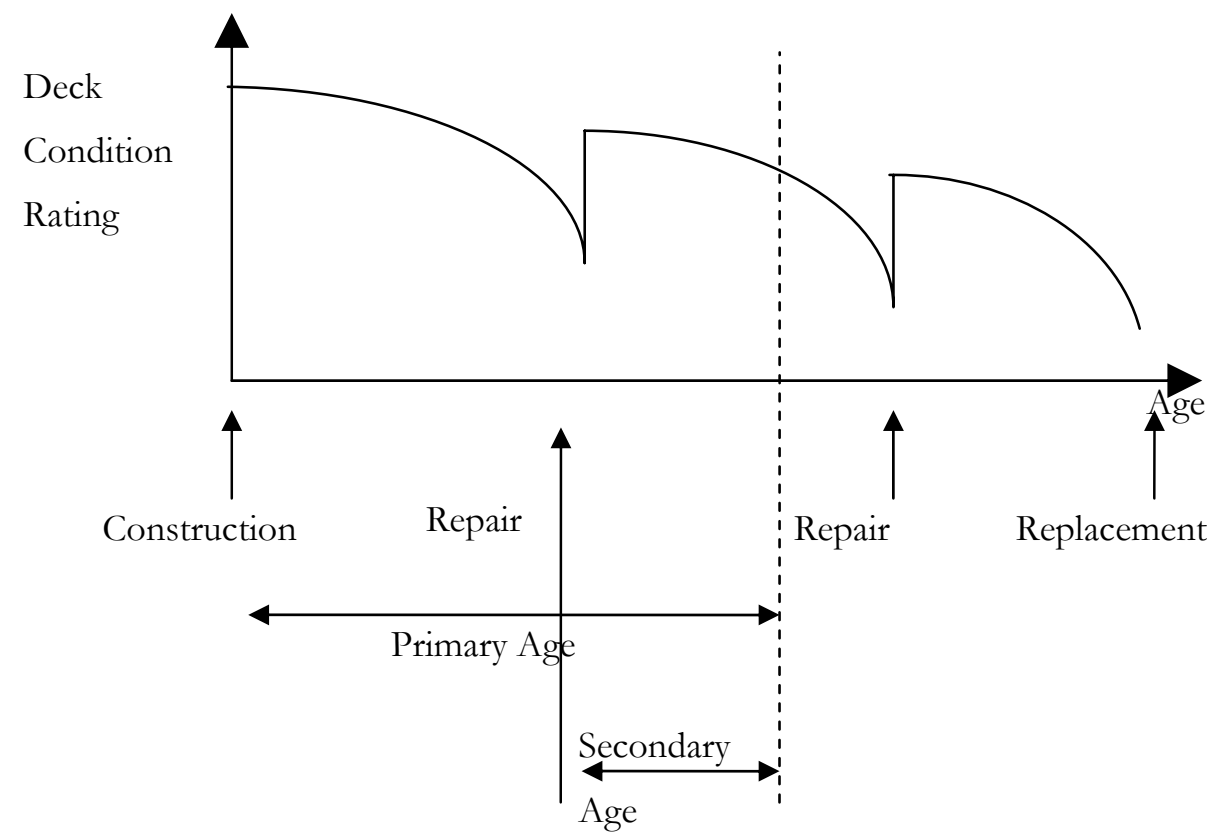

Figure 8-1 Delineation of Bridge Age 
Estimates of bridge service lives are helpful for budgeting, scheduling, and programming of rehabilitation, repair, and maintenance of bridge elements. A simple approach to determining network level funding for bridges is to refer to service life as a measure of effectiveness and to determine the number of bridges that are approaching the end of their service lives. The IBMS (Indiana Bridge Management System) approximates a design life and an activity profile with reasonable accuracy (Sinha et al. 1989). Life-cycle profiles for different types of bridges, including concrete, steel, pre-stressed concrete, timber, and masonry, were developed. At the network level, IBMS established that the mean age at which replacement occurs is approximately 70 years (primary age) for most steel and concrete bridge types. Table 8-1 and Table 8-2 were developed on the assumption that bridge replacement needs occur when bridges reach the age of 70 . According to profiles defined by INDOT, it is desirable that bridges received a major repair (deck rehabilitation, superstructure repair, or bridge rehabilitation) every 20 or 25 years in order to extend the design life to a service life of 70 to 80 years. For instance, for a typical concrete bridge it is suggested to have deck rehabilitation after 20 years (secondary age) of construction and a superstructure replacement after 15 years of the previous rehabilitation. Table 8-1 and Table 8-2 also show the number of bridges that would need a major rehabilitation due to the fact that 20 years have passed since their last major repair or since their construction. Current bridge replacement and rehabilitation needs are described as "backlog." In order to avoid double counting, it was assumed that for those bridges that are close to the end of their life (older than 50 years), and have not had any repair in the previous 20 years in the subsequent 20 years, replacement, rather than rehabilitation, was a better option.

For the estimation of future bridge preservation needs, the software package IBMS was not used for the following reasons:

- The data needed for the age-based analysis is not extensive and is easy to obtain. IBMS, on the other hand, requires extensive data including age, condition, geometry, structural deficiency, etc.

- The age of a bridge is closely related to its condition justifying the use of bridge age as a measure of its performance

- The age based approach proved to be consistent with the historical expenditure record on bridge preservation. 
Table 8-1 Results of Age-Based Physical Needs Assessment of Concrete Bridges, 2004-2015

\begin{tabular}{lcccc}
\hline Year & $\begin{array}{c}\text { Number of bridges } \\
\text { approaching the end } \\
\text { of service life }\end{array}$ & $\begin{array}{c}\text { Cumulative number of } \\
\text { bridges approaching } \\
\text { the end of service life }\end{array}$ & $\begin{array}{c}\text { Number of bridges } \\
\text { with more than 20 } \\
\text { years since the last } \\
\text { repair }\end{array}$ & $\begin{array}{c}\text { Cumulative number of } \\
\text { bridges with more than } \\
\text { 20 years since the last } \\
\text { repair }\end{array}$ \\
\hline 2005 & 339 & 339 & 588 & 588 \\
\hline 2006 & 32 & 371 & 115 & 703 \\
\hline 2007 & 34 & 405 & 102 & 805 \\
\hline 2008 & 32 & 437 & 101 & 906 \\
\hline 2009 & 17 & 454 & 76 & 1035 \\
\hline 2010 & 15 & 469 & 53 & 1214 \\
\hline 2011 & 23 & 492 & 94 & 1352 \\
\hline 2012 & 35 & 527 & 138 & 1479 \\
\hline 2013 & 7 & 534 & 127 & 1573 \\
\hline 2014 & 3 & 537 & 94 & \\
\hline 2015 & 4 & 541 & & 952 \\
\hline
\end{tabular}


Table 8-2 Results of Age-Based Physical Needs Assessment of Steel Bridges, 2004-2015

\begin{tabular}{ccccc}
\hline & $\begin{array}{c}\text { Number of } \\
\text { bridges } \\
\text { Year } \\
\text { approaching the } \\
\text { end of service life }\end{array}$ & $\begin{array}{c}\text { Cumulative } \\
\text { approaching the end } \\
\text { of service life }\end{array}$ & $\begin{array}{c}\text { Number of } \\
\text { than 20 years since } \\
\text { the last repair }\end{array}$ & $\begin{array}{c}\text { Cumulative } \\
\text { number of bridges } \\
\text { with more than 20 } \\
\text { years since the last } \\
\text { repair }\end{array}$ \\
\hline 2005 & 74 & 74 & 544 & 544 \\
\hline 2006 & 10 & 84 & 87 & 631 \\
\hline 2007 & 22 & 106 & 106 & 737 \\
\hline 2008 & 13 & 119 & 102 & 1062 \\
\hline 2009 & 12 & 131 & 102 & 1139 \\
\hline 2011 & 18 & 149 & 77 & 1228 \\
\hline 2012 & 16 & 173 & 89 & 1427 \\
\hline 2013 & 0 & 189 & 88 & 1513 \\
\hline 2014 & 0 & 189 & 111 & 960 \\
\hline
\end{tabular}

There are currently many bridges that need to be replaced and for the next 10 years the number will increase. From the age distribution of concrete bridges, a maximum need will occur in 2007 and 2012, four and nine years from now, and the need will decline thereafter. The age distribution of steel bridges presents a similar trend, and peak years will occur in 2007 and 2011, in four and eight years respectively. A total of 730 bridges would need replacement because they would be near the end of their lives in the next 10 years. In the case of bridge rehabilitation needs, it is expected that in 2006 and 2013 there will be a need for intensive rehabilitation activity for concrete bridges and in 2009 and 2014 for steel bridges. 


\title{
CHAPTER 9 : BRIDGE PRESERVATION EXPENDITURES
}

\author{
$9.1 \quad 9.1 \quad$ Age-Based Needs
}

After identifying the bridges needing replacement and rehabilitation based on their age, the capital cost of those needs were determined on the basis of average unit costs obtained from the recent contracts in the previous chapter. To determine the overall current replacement cost of each structure, average unit costs for concrete and steel bridges estimated in Chapter 7 were used $(\$ 196$ per square foot of deck area for concrete structures and $\$ 177$ for steel structures). Similarly, average unit cost of $\$ 54$ per square foot of deck area for deck rehabilitation was used to compute the bridge rehabilitation monetary needs. The results are summarized in Tables 9-1 and 9-2. 
Table 9-1 Age-Based Monetary Needs for Bridge Replacement, by Year and Structure Material

\begin{tabular}{|c|c|c|c|c|c|c|}
\hline \multirow[b]{2}{*}{ Year } & \multicolumn{2}{|r|}{ Concrete } & & \multirow[b]{2}{*}{$\begin{array}{l}\text { Steel } \\
\text { Deck Area } \\
\text { (sq. ft.) }\end{array}$} & \multirow[b]{2}{*}{$\begin{array}{c}\text { Steel } \\
\text { Bridge } \\
\text { Replacement } \\
\text { Unit Cost } \\
\text { (\$ per sq. ft. } \\
\text { of deck area) }\end{array}$} & \\
\hline & $\begin{array}{l}\text { Concrete } \\
\text { Bridge Deck } \\
\text { Area (sq.ft.) }\end{array}$ & $\begin{array}{c}\text { Bridge } \\
\text { Replacement } \\
\text { Unit Cost } \\
\text { (\$ per sq. ft. } \\
\text { of deck area) }\end{array}$ & $\begin{array}{c}\text { Concrete } \\
\text { Bridge } \\
\text { Replacement } \\
\text { Value } \\
\text { (\$millions) }\end{array}$ & & & $\begin{array}{c}\text { Steel } \\
\text { Bridge } \\
\text { Replacement } \\
\text { Value } \\
\text { (\$millions) }\end{array}$ \\
\hline 2005 & $1,214,187$ & 196 & 238 & 422,512 & 177 & 75 \\
\hline 2006 & 128,097 & 196 & 25 & 129,018 & 177 & 23 \\
\hline 2007 & 123,990 & 196 & 24 & 187,400 & 177 & 33 \\
\hline 2008 & 103,836 & 196 & 20 & 93,472 & 177 & 17 \\
\hline 2009 & 53,303 & 196 & 10 & 124,851 & 177 & 22 \\
\hline 2010 & 40,410 & 196 & 8 & 79,931 & 177 & 14 \\
\hline 2011 & 139,052 & 196 & 27 & 210,715 & 177 & 37 \\
\hline 2012 & 130,507 & 196 & 26 & 130,380 & 177 & 23 \\
\hline 2013 & 27,337 & 196 & 5 & - & 177 & - \\
\hline 2014 & 23,706 & 196 & 5 & - & 177 & - \\
\hline 2015 & 17,088 & 196 & 3 & - & 177 & - \\
\hline SUBTOTAL & $2,001,512$ & & $\$ 393$ & $1,378,278$ & & $\$ 244$ \\
\hline
\end{tabular}




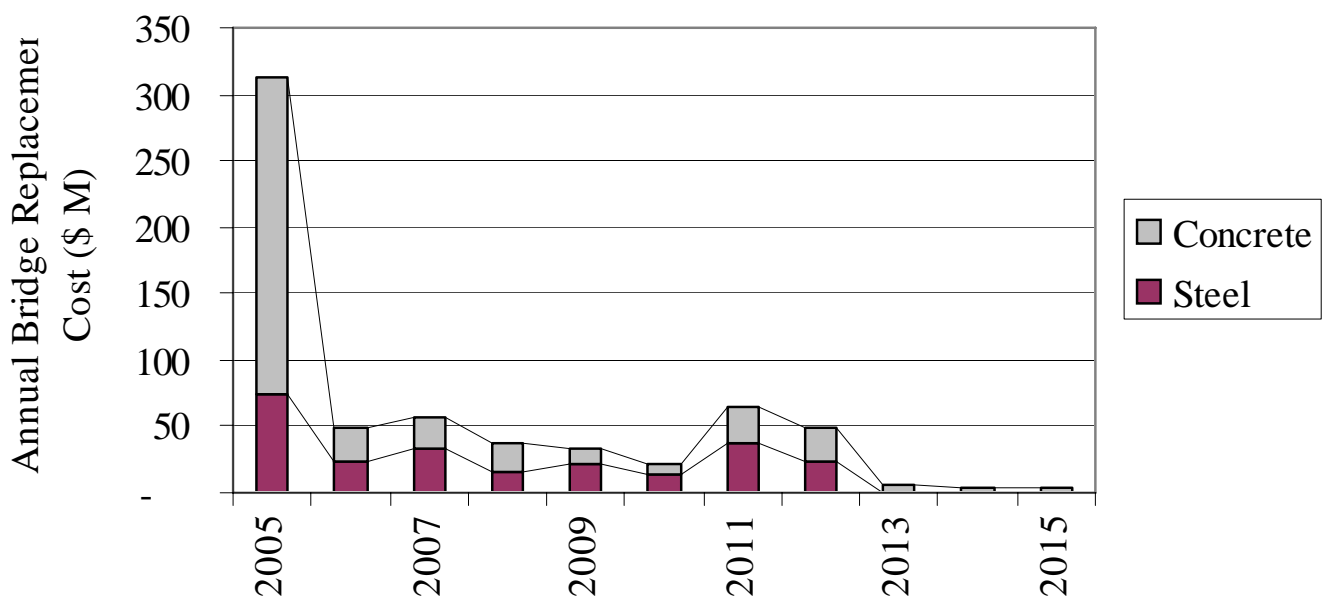

Figure 9-1: Bridge Replacement Monetary Needs

Table 9-2 Annual Deck Rehabilitation Needs by Structure Material

\begin{tabular}{|c|c|c|c|c|c|}
\hline \multirow{5}{*}{ Year } & Deck & \multicolumn{3}{|c|}{ Concrete } & \multirow{5}{*}{$\begin{array}{c}\text { Steel } \\
\text { Bridge Deck } \\
\text { Rehabilitation } \\
\text { Value } \\
\text { (\$millions) }\end{array}$} \\
\hline & Rehabilitation & Concrete & Bridge & Steel Deck & \\
\hline & Unit Cost & Bridge Deck & Rehabilitation & Area (sq. & \\
\hline & (\$ per sq. ft. & Area (sq.ft.) & Value & ft.) & \\
\hline & of deck area) & & (\$millions) & & \\
\hline 2005 & 54 & $3,972,739$ & 214 & $7,156,160$ & 385 \\
\hline 2006 & 54 & 644,893 & 35 & 922,400 & 50 \\
\hline 2007 & 54 & 565,471 & 30 & $1,255,181$ & 68 \\
\hline 2008 & 54 & 554,263 & 30 & $1,244,361$ & 67 \\
\hline 2009 & 54 & 478,903 & 26 & $1,682,189$ & 91 \\
\hline 2010 & 54 & 310,300 & 17 & $1,448,352$ & 8 \\
\hline 2011 & 54 & 578,427 & 31 & $1,073,833$ & 58 \\
\hline 2012 & 54 & 540,135 & 29 & $1,140,505$ & 61 \\
\hline 2013 & 54 & $1,003,561$ & 54 & $1,350,656$ & 73 \\
\hline 2014 & 54 & 815,272 & 44 & $1,376,697$ & 74 \\
\hline 2015 & 54 & 631,831 & 34 & $1,298,510$ & 70 \\
\hline SUBTOTAL & & $10,095,796$ & $\$ 544$ & $19,948,840$ & $\$ 1,075$ \\
\hline
\end{tabular}




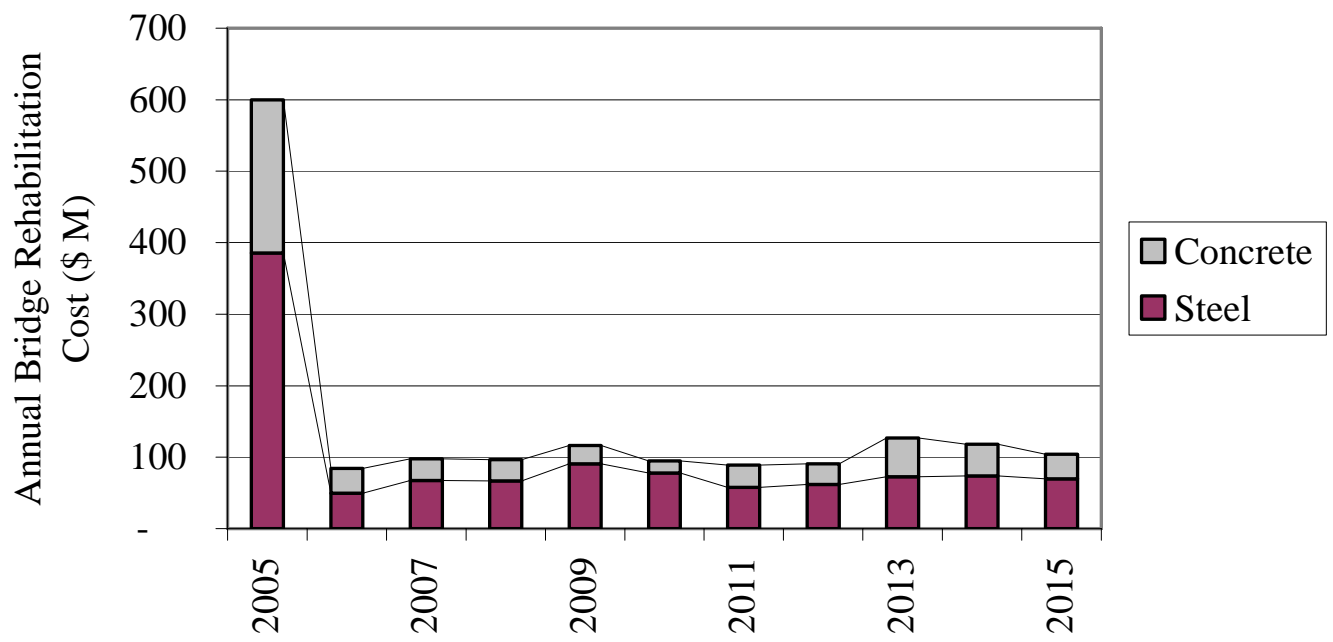

Figure 9-2 Bridge Rehabilitation Monetary Needs

Table 9-1 and Table 9-2 present the bridge preservation needs in terms of monetary cost. Again it is seen that the number of bridges that currently need replacement or rehabilitation is large and translates into a substantial funding outlay. The age-based approach to needs assessment indicated a total need of $\$ 2,256$ million, corresponding to an average cost per year of $\$ 205$ million over the period 2005-2015. In Figure 9-1, yearly needs for bridge replacement are presented, while Figure 9-2 shows the yearly needs for bridge rehabilitation. An average of $\$ 58$ million per year would be required for bridge replacement while the annual average bridge rehabilitation need would be $\$ 147$ per year during 2002-2015. The total bridge preservation need can thus be expected to be $\$ 205$ million per year. These engineering need estimates were compared with the historical record of bridge preservation expenditure as discussed in the following sections. 


\section{$9.2 \quad 9.2 \quad$ Estimated Needs Based on Historical Bridge Expenditures}

\subsubsection{Historical Expenditures}

The dollars spent on bridge replacement and rehabilitation activities can be compiled from 1996 to 2003. The data is provided from the INDOT Contracts Management Division. Table 9-3 presents the bridge expenditure from 1996 to 2003.

Table 9-3 Historical Bridge Expenditure (1996-2003)

\begin{tabular}{|c|c|c|}
\hline Year & $\begin{array}{c}\text { Bridge Expenditure } \\
\text { (current } \$)\end{array}$ & $\begin{array}{c}\text { Bridge } \\
\text { Expenditure } \\
(2002 \$)\end{array}$ \\
\hline 1996 & $\$ 45.1$ & $\$ 55.4$ \\
\hline 1997 & $\$ 75.4$ & $\$ 85.4$ \\
\hline 1998 & $\$ 11.9$ & $\$ 72.1$ \\
\hline 1999 & $\$ 113.1$ & $\$ 122.6$ \\
\hline 2000 & $\$ 110.9$ & $\$ 112.6$ \\
\hline 2001 & $\$ 103.6$ & $\$ 105.8$ \\
\hline 2002 & $\$ 124.8$ & $\$ 124.8$ \\
\hline 2003 & $\$ 149.5$ & $\$ 145.9$ \\
\hline
\end{tabular}




\subsubsection{Projected Expenditure on the Basis of Historical Trends}

The past bridge expenditure can be plotted against the years and a model can be developed to predict the expenditure for any the future years. The relationship determined allows calculating the total bridge expenditure for any given year. Figure 9-3 illustrates the data used and the results obtained. The equation developed is as follows:

Total Bridge Expenditure $=6 E+07 *(\# \text { of years from 1996 })^{\wedge} 0.4185$

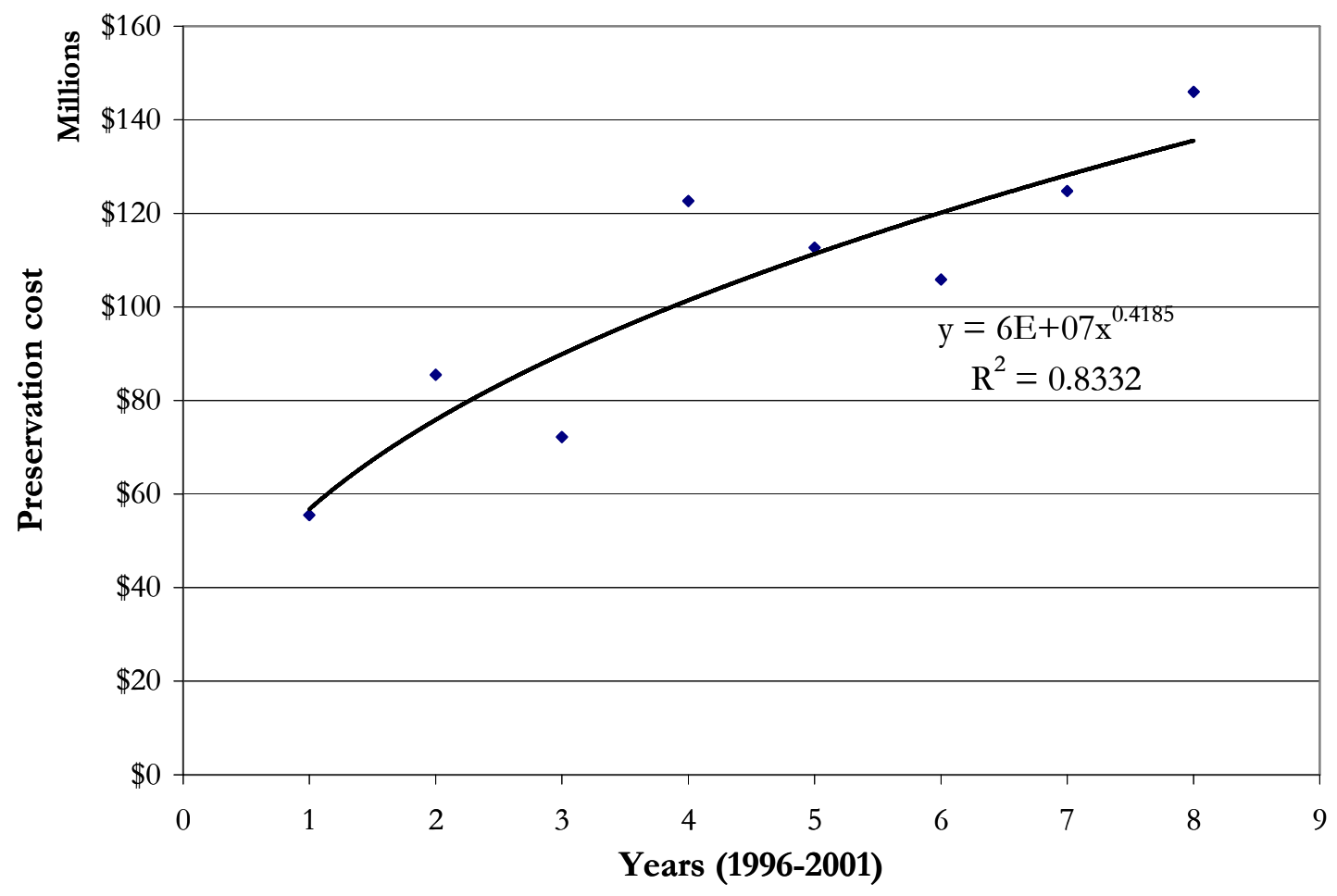

Figure 9-3 Modeling Bridge Preservation Expenditure

Using the above relationship, the bridge expenditure can be calculated for the next 10 years. Table 94 shows the expected expenditure from 2005 to 2015. 
Table 9-4 Projected Bridge Expenditure from 2005 to 2015

\begin{tabular}{|c|c|}
\hline Year & Predicted Value \\
\hline 2005 & $\$ 157$ \\
\hline 2006 & $\$ 163$ \\
\hline 2007 & $\$ 169$ \\
\hline 2008 & $\$ 175$ \\
\hline 2009 & $\$ 181$ \\
\hline 2010 & $\$ 186$ \\
\hline 2011 & $\$ 191$ \\
\hline 2012 & $\$ 196$ \\
\hline 2013 & $\$ 201$ \\
\hline 2014 & $\$ 205$ \\
\hline 2015 & $\$ 210$ \\
\hline Total & $\$ 2,038$ \\
\hline
\end{tabular}

An average of $\$ 185$ million per year can be found as bridge replacement and rehabilitation needs for the period considered.

\subsection{Comparison of Age-Based Needs and Needs Based on Past Expenditure}

The age-based needs can be compared to the needs determined using historical expenditure. The results obtained are shown on Table 9-5. The two analyses give similar results for the total needs expected in an 11-year period. Approximately $\$ 2$ billion will be spent on bridge replacement and rehabilitation activities from 2005 to 2015 . However, the value of the age-based needs determined for 2005 is very high because it represents the backlog or the current needs where the predicted needs based on historical expenditure are spread over the years. As expected, the total predicted expenditure based on past data which represents the state spending is less than the total predicted age-based needs which represent what is needed. On average $\$ 199$ million are expected to be spent annually using the age-based analysis and $\$ 185$ million per year are projected using the historical trends. The results obtained are illustrated in Figure 9-4. The two sets of estimates match well. As the amount being spent annually is less than what can be expected on the basis of age, there has been an 
accumulation of unmet needs each year which is represented by the backlog estimated in the agebased approach. Consequently, the simple regression model presented in Figure 9-3 can provide a good estimate of realistic future bridge preservation needs, assuming not all needs will be met each year.

Table 9-5 Comparison of Needs Based on Past Expenditures and Needs Based on Age

\begin{tabular}{ccc}
\hline Year & $\begin{array}{c}\text { Predicted Value Based } \\
\text { Historical Trends (\$Millions) }\end{array}$ & $\begin{array}{c}\text { Predicted Value } \\
\text { Based } \\
\text { On Age (\$Millions) }\end{array}$ \\
\hline 2005 & $\$ 157$ & $\$ 912$ \\
\hline 2006 & $\$ 163$ & $\$ 133$ \\
\hline 2007 & $\$ 169$ & $\$ 155$ \\
\hline 2008 & $\$ 175$ & $\$ 134$ \\
\hline 2009 & $\$ 181$ & $\$ 149$ \\
\hline 2010 & $\$ 186$ & $\$ 47$ \\
\hline 2011 & $\$ 191$ & $\$ 153$ \\
\hline 2012 & $\$ 196$ & $\$ 139$ \\
\hline 2013 & $\$ 201$ & $\$ 132$ \\
\hline 2014 & $\$ 205$ & $\$ 123$ \\
\hline 2015 & $\$ 210$ & $\$ 2,253$ \\
\hline Total & $\$ 2,038$ &
\end{tabular}




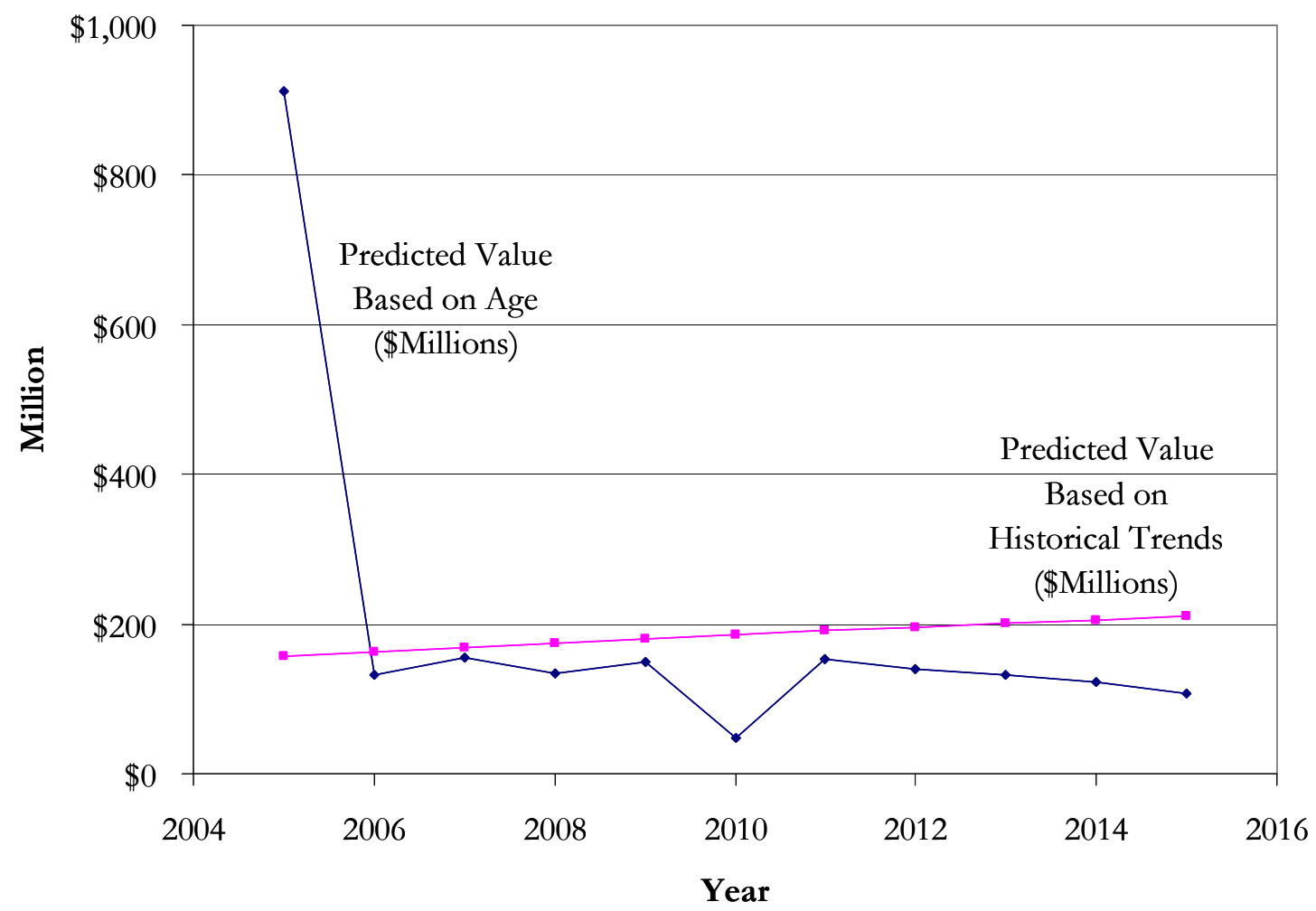

Figure 9-4 Needs Based on Age and Historical Trends 


\section{CHAPTER 10 : SUMMARY AND CONCLUSIONS}

The purpose of the present study was to develop a simple procedure for estimating pavement and bridge preservation needs for fiscal planning and budgeting. This was accomplished by comparing existing technical needs based on physical condition and detailed work estimates with the historical expenditure trends. In this chapter a summary of the estimation procedures to be used ins presented, followed by a discussion on the highlights of the study results.

For long term fiscal planning and budgeting, it is useful to establish simple procedures in order to estimate annual pavement and bridge preservation needs as it is time and effort consuming to perform detailed engineering analyses each year. Therefore in the present study, simple methods to estimate annual pavement and bridge preservation needs based on historical expenditure trends were developed. They were then compared to technical estimates of needs established with engineering o and were validated by engineering consuming. The procedures developed for pavements and bridges can be summarized as follows:

\subsection{Summary of Estimation Procedures}

The procedure for the estimation of pavement preservation needs can be summarized as follows:

1. Predict system size

Number of lanes miles $=83.275 * Y E A R-138144$

2. Estimate percentage of system to be treated

Percentage of system to be preserved $=0.0328^{*}(\# \text { ofyears from 1990 })^{\wedge}(0.3513)$

3. Estimate total pavement preservation needs using unit cost per lane mile

Total cost of pavement preservation $=$ Number of lane miles to be treated ${ }^{*}$ Average unit cost for the past 3 years.

4. Estimate rehabilitation and non-rehabilitation needs (maintenance and reconstruction)

$\%$ of system to be rehabilitated $=0.0248^{*}(\# \text { of years from 1990 })^{\wedge}(0.3705)$

Number of lane miles to be rehabilitated $=\%$ percentage of system to be rehabilitated $*$ system size 
Total cost of rehabilitation $=$ Number of lane miles to be rehabilitated $*$ Average unit cost for the past 3 years

Non Rehabilitation cost $=$ Total preservation cost - Rehabilitation cost

5. Estimate preservation needs by functional system

Use percentages of total pavement preservation cost for on each highway class found in recent years and multiply by the total preservation cost predicted in step 3 .

Total Bridge Preservation Cost $=6 \mathrm{E}+07^{*}(\#$ of years from 1996)^0.4185

Total Preservation Needs $=$ Total Pavement Preservation Need + Total Bridge Preservation Need

\subsection{Conclusions}

Pavement service lives and preservation treatment costs were estimated using statistical models developed. Models were developed for pavement deterioration rates in order to estimate remaining service lives. Pavement preservation cost models were also implemented. Pavement preservation needs for the period 2006-2020 were thus established using the appropriate models for preservation costs and deterioration rates. The annual pavement preservation needs were estimated at \$354-\$394 million. These needs were established based on engineering considerations. A procedure that allows the prediction of future preservation needs on the basis of historical trends was also developed. The procedure allows determining rehabilitation and non-rehabilitation costs for pavements as well as preservation costs for different highway classes. Estimates based on the procedure were compared to the amount spent on pavement preservation for 2002 and 2003 and the results were accurate by $4 \%$ and $13 \%$ respectively.

Cost models were developed for bridge replacement and rehabilitation activities. For replacement cost models, the cost of each component was modeled separately, and the overall cost structure was expressed as the sum of the costs of such components. Different replacement cost models were developed for slab bridges and beam section bridges because slab bridges are commonly used for short bridges and preliminary data analysis showed that these two bridges exhibit different relationships between cost and bridge characteristics. The models developed showed a significant improvement over the models currently used in IBMS. For steel bridges, replacement cost models 
were not developed due to an insufficient number of observations, but the average unit costs were reported.

Cost models were developed for seven bridge rehabilitation activities. The analysis also showed that the cost of rehabilitating bridge decks and superstructures depends not only on the deck area but also on the bridge material and the highway functional class.

Bridge preservation costs were assessed for the period 2006-2015 using an age-based approach. The annual average cost of preservation was estimated at $\$ 199$ million. A model based on past bridge expenditure was also developed and the results obtained for this model were consistent with the age-based projection. The annual average cost of preservation on the basis of historical records was estimated at $\$ 185$ million. The difference is the result of the accumulation of unmet needs each year which can be represented by the backlog determined with the age-based approach.

The study results are useful for long-term planning and budgeting as INDOT's Division of Policy and Fiscal Management and Planning will be able to schedule and monitor its pavement and bridge preservation cash flows in a more effective manner than what is possible at present. 


\section{REFERENCES}

Ben-Akiva, M. and Ramaswamy, R.., (1990) . "Estimation of highway pavement deterioration from in-service pavement data." Transportation Research Record 1272, Transportation Research Board, National Research Council, Washington, D.C.

Bulusu, S., and Sinha, K. C. (1997). "A Comparison of Methodologies to Predict Bridge Deterioration," Transportation Research Record 1597.

V. Carnahan, M.ASCE, W.J. Davis, M.Y. Shahin, P.L. Keane, and M.I. Wu. (1987). "Optimal Maintenance Decisions for Pavement Management," Journal of Transportation Engineering, vol113 n5, New York: ASCE, September 1987.

Chase, S. B., Small, E. P., and Nutakor, C., (2000). "An In-Depth Analysis of the National Bridge Inventory Database Utilizing Data Mining, GIS and Advanced Statistical Methods." Transportation Research Circular No 498. Transportation Research Board, Washington D.C.

Collura, J., Spring, G., and Black, K.B., (1993). "Service Lives and Costs of Local Highway Maintenance and Rehabilitation Treatments". Transportation Research Record 1397, Transportation Research Board, National Research Council, Washington, D.C.

Corvi, IE; Bullard, BG (1970). "A System of Estimating the Present Surface Condition and Remaining Service Life of Existing Pavement Sections”. Public Roads, Volume: 36, Issue: 5.

Feighan, K. J., Shahin, M. Y., and Sinha, K. C. (1987). "A dynamic programming approach to optimization for pavement management systems." Proc., 2nd North American Conf. on Managing Pavements, Toronto.

Geoffroy, D.N. (1996). "Synthesis of Highway Practice 223: Cost-effective Preventive Pavement Maintenance”. Transportation Research Board, National Research Council, Washington, D.C.

Griffith, A., Wyttenberg, K., Williams, J., Lynde, M., (2002). “Aggregate Resource Inventory and Needs Forecast Study". Final Report, SPR 314, Oregon Department of Transportation and FHWA, Washington, D.C.

Gulen, S., Woods, R., Weaver, J., and Anderson, V.L.,. (1994). "Correlation of Pavement Serviceability Rating with International Roughness Index”. Transportation Research Record 1435.

Hartgen, D.T., (1986). " How Good is the Highway Performance Monitoring System? A Comparison with the State Results". Transportation Research Record 1060, Transportation Research Board, National Research Council, Washington, D.C. 
Hartgen, D. T. (2000). "North Carolina Highways: Performance, Needs and Funding Options". John Locke Foundation.

Hawk, H. (2003). "Bridge Life-Cycle Cost Analysis" NCHRP Report 483 Transportation Research Board, Washington D.C.

Hodge, S. (2004). "An Assessment of Highway Financing Needs in Indiana”. M.S. Thesis, Purdue University, West Lafayette, IN.

Indiana Design Manual, Chapter 52, 1998.

INDOT (2000). 2000 Pavement Surface Report, December, 2000. INDOT Pavement Management Section, Program Development Division.: INDOT.

INDOT (2003). I-69: Evansville to Indianapolis Tier 1 Draft Environmental Impact Statement, Summary Chapter: INDOT.

Labi, S., and Sinha, K. C. (2003). "The Effectiveness of Maintenance and Its Impact on Capital Expenditures” (No. FHWA/IN/JTRP-2002/27). Joint Transportation Research Program, Purdue University. West Lafayette, IN.

Lamptey, G. et al. (2004). "Life Cycle Cost Analysis for Pavement Design Procedures". (No. FHWA/IN/JTRP-2004/28). Draft final report. Joint Transportation Research Program, Purdue University, West Lafayette, IN.

Rodriguez, M. M. (2004). “An Assessment of Preservation Needs of State Highway Bridges in Indiana”. M.S. Thesis. Purdue University, West Lafayette, IN.

Saito M., V.L. Anderson and Sinha K.C. (1988), "Bridge Replacement Cost Analysis". Transportation Research Record 1180, Transportation Research Board, Washington, D.C.

Sinha, K. C., Saito, M., Jiang, Y., Murthy, S., Tee, A., and Bowman, M. D.(1989), “The Development of Optimal Strategies for Maintenance, Rehabilitation and Replacement of Highway Bridges, Final Report Vol. 1: The Elements of Indiana Bridge Management System", Joint Highway Research Project, West Lafayette, IN.

Thompson P.D and Markow J, (1996). "Collecting and Managing Cost Data for Bridge Managements System”, NCHRP Synthesis 227, Transportation Research Board, National Academic Press, Washington, D.C.

Tonias, D.E. (1995). "Design, Rehabilitation and Maintenance of Modern Highways Bridges." MacGraw-Hill, Inc. New York. . 
APPENDICES 
Appendix A. Performance Curves

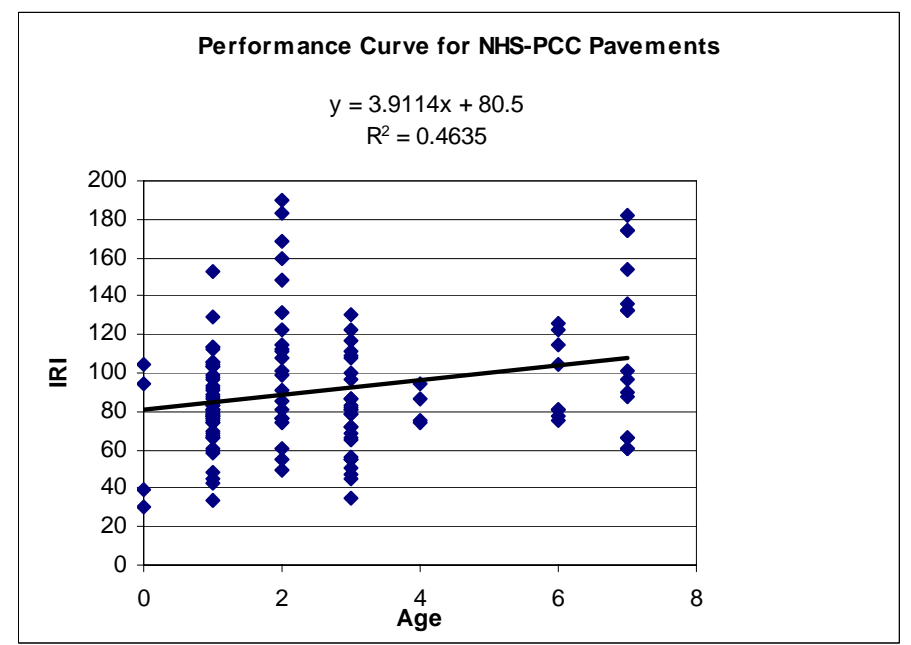

Performance Curves for NHS Composite Pavements
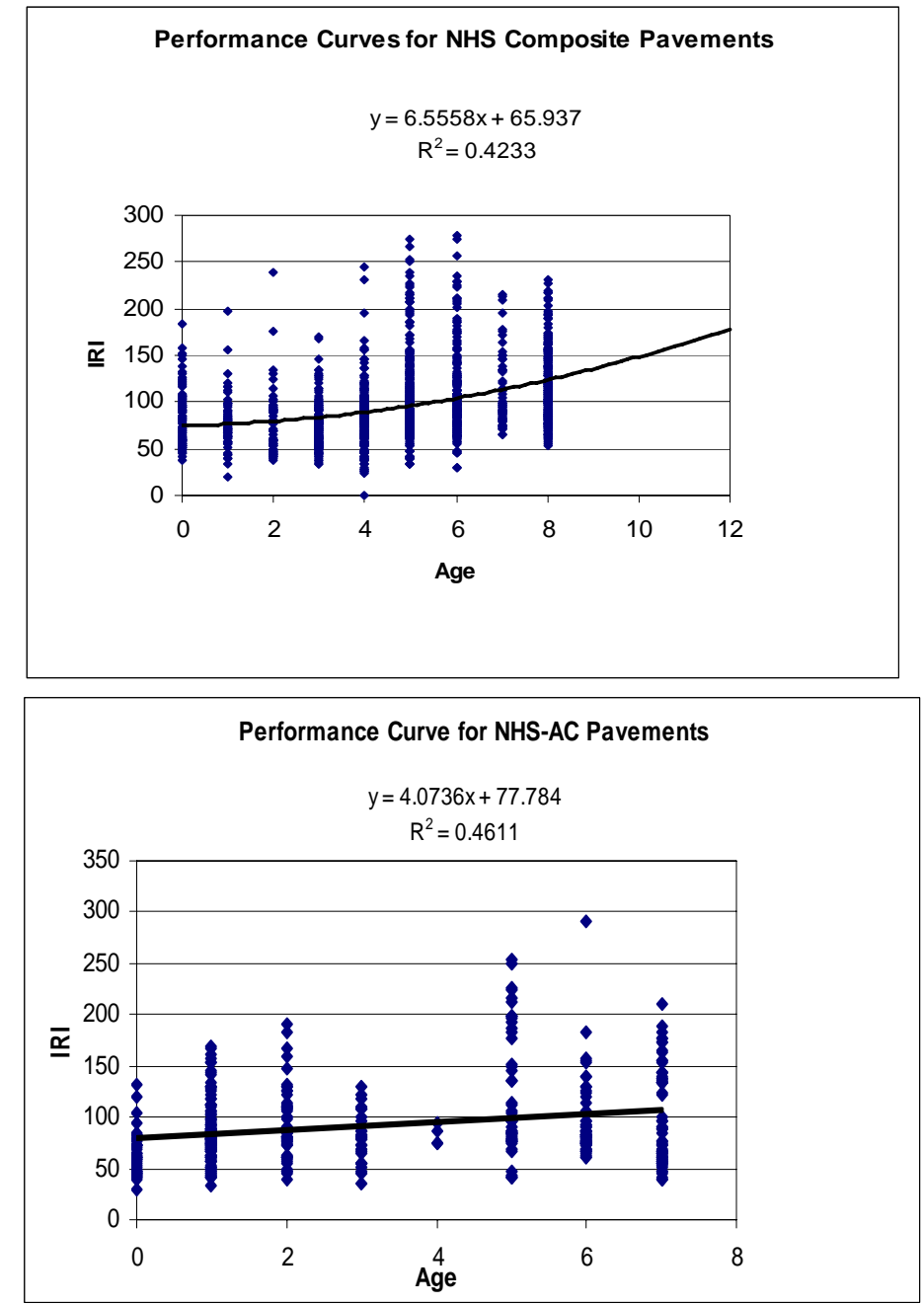

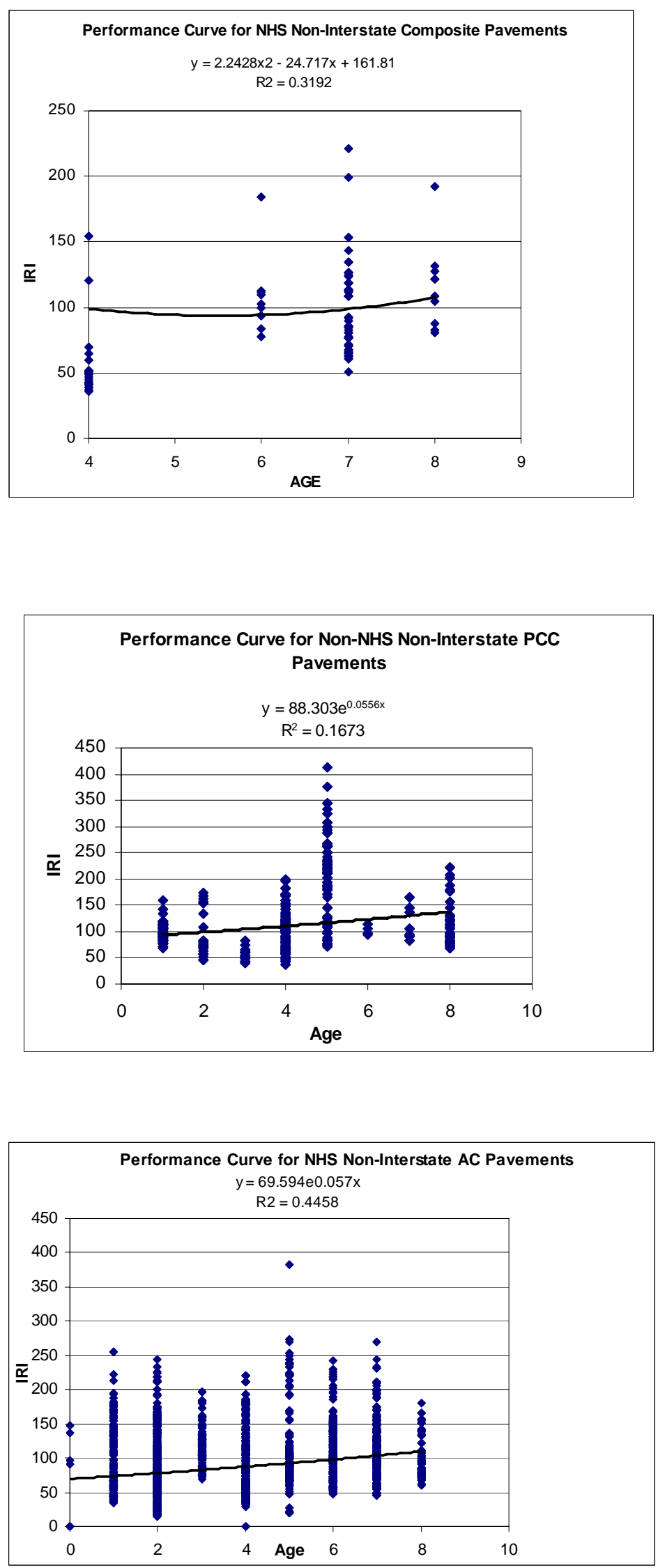

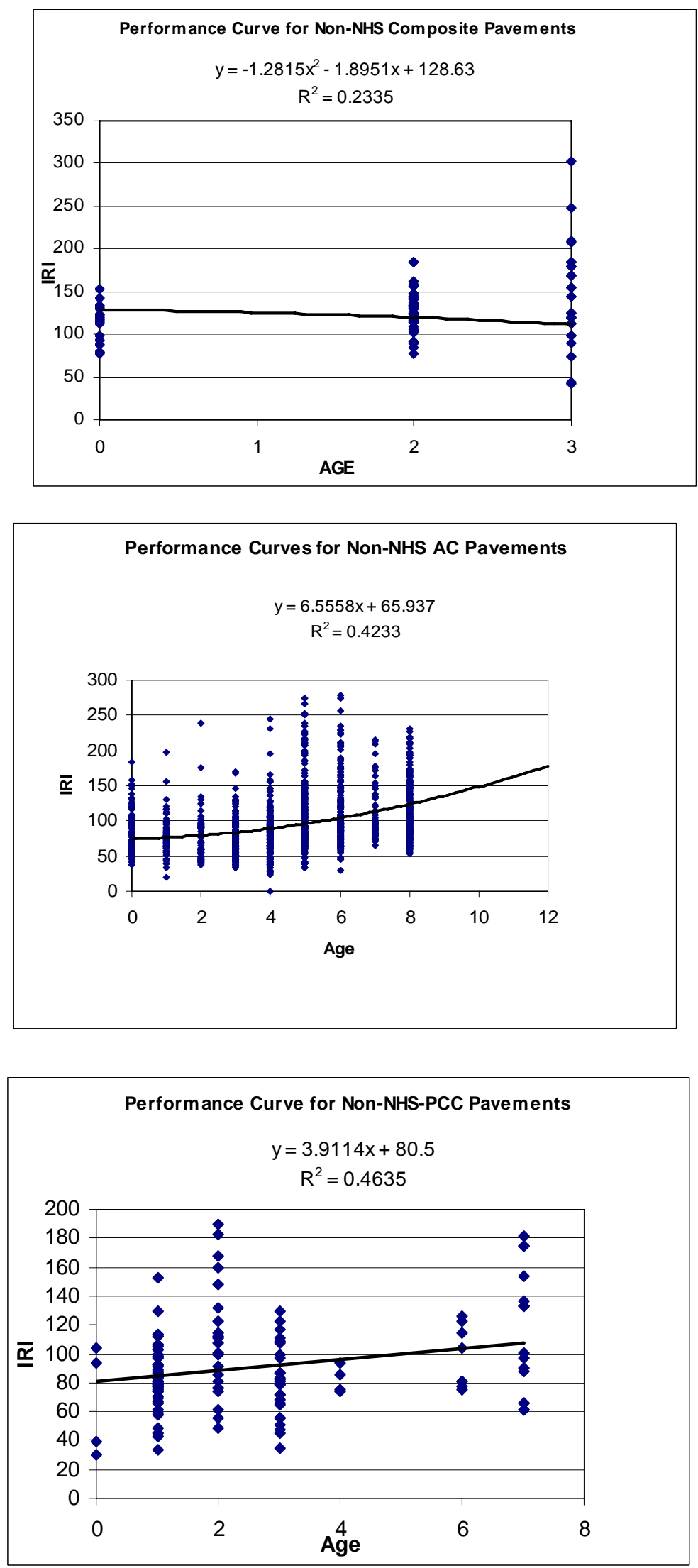
Appendix B. Cost Models for Asphaltic Concrete Pavements

\begin{tabular}{|c|c|c|}
\hline $\begin{array}{l}\text { Model } \\
\text { Type }\end{array}$ & Models & $\mathbf{R}^{2}$ \\
\hline Linear & $\begin{array}{l}\text { Cost }=8.748-0.356 \times \text { Lngth }+0.234 \times \text { Nr_Lns }+2.454 \times \text { Thk }-0.245- \\
\text { N_F }+0.148 \times \text { S_F }\end{array}$ & 0.365 \\
\hline Polynomial & $\begin{array}{l}\text { Cost }=2.345-1.254 \times \text { Lngth }^{5}+0.854 \times \mathrm{Nr} \_ \text {Lanes }^{4}+0.454 \times \mathrm{Thk}^{3}-0.545- \\
\text { N_F }\end{array}$ & 0.293 \\
\hline Polynomial & $\begin{aligned} \text { Cost }=1.726-1.254 \times \operatorname{Lngth}^{0.25}+ & 0.854 \times \mathrm{Nr} \_L a n e^{0.24}+0.454 \times \mathrm{Thk}^{0.68}-0.545 \times \mathrm{N} \_\mathrm{F}^{2.1} \\
& +1.148 \times \mathrm{S} \_\mathrm{F}^{0.56}\end{aligned}$ & 0.322 \\
\hline Polynomial & $\begin{array}{l}\text { Cost }=3.26+0.954 \times \text { Lngth }^{0.55}+0.854 \times N r \_ \text {Lanes }^{0.74}+0.146 \times \text { Thk }^{0.78}-0.721 \times \text { N_F } \\
+0.041 \times \text { S_F }\end{array}$ & 0.254 \\
\hline Logistic & $\begin{array}{l}(\text { Cost })^{0.5}=0.795+0.0156 \times \text { Lngth }+0.125 \times \text { Nr_Lanes }+0.454 \times \text { Thk } 1.245- \\
\text { N_F }+0.5448 \times \text { S_F }\end{array}$ & 0.211 \\
\hline
\end{tabular}

Cost Models for Portland Cement Concrete Pavements

\begin{tabular}{|c|c|c|}
\hline $\begin{array}{l}\text { Model } \\
\text { Type }\end{array}$ & Models & $\mathbf{R}^{2}$ \\
\hline Linear & Cost $=-1.356 \times$ Lngth $+0.334 \times$ Nr_Lns $+3.454 \times$ Thk $-0.215-\mathrm{N} \_F+1.240 \times S \_F$ & 0.315 \\
\hline Polynomial & $\begin{array}{l}\text { Cost }=3.125-0.254 \times \text { Lngth }^{5}+1.854 \times \text { Nr_Lanes }^{4}+2.454 \times \text { Thk }^{3}-1.545- \\
\text { N_F } F^{2}+0.148 \times S \_F^{1}\end{array}$ & 0.219 \\
\hline Polynomial & $\begin{aligned} \text { Cost }=1.726-1.254 \times \text { Lngth }^{0.62}+ & 0.854 \times \mathrm{Nr} \_ \text {Lanes }{ }^{0.77}+0.454 \times \text { Thk }^{0.91}-0.545 \times \mathrm{N} \_\mathrm{F}^{2.7} \\
& +1.148 \times \mathrm{S} \_\mathrm{F}^{2.56}\end{aligned}$ & 0.302 \\
\hline Polynomial & $\begin{array}{l}\text { Cost }=3.26+0.954 \times \text { Lngth }^{0.55}+0.854 \times N r \_L a n e s^{0.74}+0.146 \times \text { Thk }^{0.78}-0.721 \times \text { N_F } \\
+0.041 \times S \_F\end{array}$ & 0.287 \\
\hline Logistic & $\begin{array}{l}(\text { Cost })^{0.5}=2.355+0.0156 \times \text { Lngth }+0.125 \times \text { Nr_Lanes }+0.454 \times \text { Thk } 1.245- \\
\text { N_F }+0.5448 \times \text { S_F }\end{array}$ & 0.249 \\
\hline
\end{tabular}


Cost Models for Composite Pavements

\begin{tabular}{|c|c|c|}
\hline $\begin{array}{l}\text { Model } \\
\text { Type }\end{array}$ & Models & $\mathbf{R}^{2}$ \\
\hline Linear & $\begin{array}{l}\text { Cost }=8.748-0.356 \times \text { Lngth }+0.234 \times \text { Nr_Lns }+2.454 \times \text { Thk }-0.245- \\
\text { N_F }+0.148 \times \text { S_F }\end{array}$ & 0.365 \\
\hline Polynomial & $\begin{array}{l}\text { Cost }=2.345-1.254 \times \text { Lngth }^{5}+0.854 \times \text { Nr_Lanes } \\
\end{array}$ & 0.293 \\
\hline Polynomial & 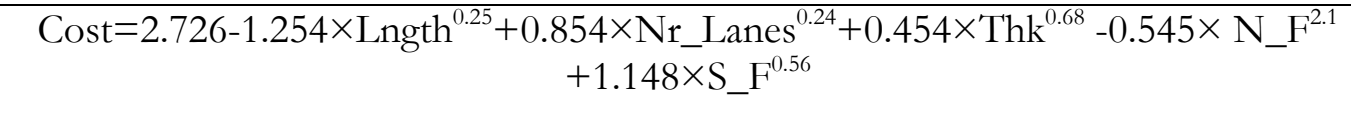 & 0.322 \\
\hline Polynomial & $\begin{array}{l}\text { Cost }=11.26+0.954 \times \text { Lngth }^{0.55}+0.854 \times \mathrm{Nr}_{\text {LLanes }}{ }^{0.74}+0.146 \times \mathrm{Thk}^{0.78}-0.721 \times \mathrm{N} \_\mathrm{F} \\
+0.041 \times \text { S_F }\end{array}$ & 0.254 \\
\hline Logistic & $\begin{array}{l}(\text { Cost })^{0.5}=0.895+0.0156 \times \text { Lngth }+0.125 \times \text { Nr_Lanes }+0.454 \times \text { Thk } 1.245- \\
\text { N_F }+0.5448 \times \text { S_F }\end{array}$ & 0.211 \\
\hline
\end{tabular}


Appendix C. INDOT

Pavement Treatment
Contracts Unit

Costs

Table C.0-1 Unit Pavement Treatment Costs

\begin{tabular}{|c|c|c|c|c|c|c|}
\hline \multirow{2}{*}{ Treatment } & \multirow{2}{*}{$\begin{array}{c}\text { Pavement } \\
\text { Type }\end{array}$} & \multirow{2}{*}{$\begin{array}{c}\text { No.of } \\
\text { Obs. }\end{array}$} & \multicolumn{4}{|c|}{$\begin{array}{l}\text { Cost per Lane Mile } \\
\text { (1000s) } 2002 \$\end{array}$} \\
\hline & & & Mean & Min. & Max. & $\begin{array}{l}\text { Std. } \\
\text { Dev. }\end{array}$ \\
\hline Added Travel Lanes & COMP & 1 & 21798 & 21798 & 21798 & 0 \\
\hline Added Travel Lanes & HMA & 46 & 2111 & 150 & 15170 & 2541 \\
\hline Added Travel Lanes & PCC & 14 & 2445 & 236 & 7103 & 2273 \\
\hline Added Travel Lanes, Bituminous & HMA & 1 & 263 & 263 & 263 & 0 \\
\hline Added Travel Lanes, Concrete & PCC & 6 & 4628 & 486 & 16027 & 5689 \\
\hline Asphalt Patching & HMA & 1 & 38 & 38 & 38 & 0 \\
\hline Auxillary Lane Construction & HMA & 3 & 149 & 9 & 414 & 229 \\
\hline Auxillary Lanes, Acel \& Dcel & HMA & 1 & 726 & 726 & 726 & 0 \\
\hline Bridge Deck Overlay & HMA & 1 & 295 & 295 & 295 & 0 \\
\hline Bridge Rehabilitation Or Repair & PCC & 0 & 0 & 0 & 0 & 0 \\
\hline Bridge Removal & HMA & 1 & 1067 & 1067 & 1067 & 0 \\
\hline Crack \& Seat Composite Pavement \& HMA Overlay & COMP & 20 & 673 & 230 & 3210 & 735 \\
\hline Crack \& Seat PCCP \& HMA Overlay & PCC & 5 & 209 & 2 & 379 & 188 \\
\hline Crack \& Seat PCCP \& HMA Overlay (P3R) & PCC & 6 & 644 & 2 & 3356 & 1332 \\
\hline Diamond Grinding & PCC & 0 & 0 & 0 & 0 & 0 \\
\hline Ditch Relocation & HMA & 1 & 807 & 807 & 807 & 0 \\
\hline Drainage Ditch Correction & HMA & 2 & 534 & 234 & 834 & 424 \\
\hline Dual Lane Existing Route & PCC & 2 & 2065 & 1430 & 2699 & 897 \\
\hline Full And Shallow Depth Patching & HMA & 1 & 31 & 31 & 31 & 0 \\
\hline Full And Shallow Depth Patching & PCC & 1 & 298 & 298 & 298 & 0 \\
\hline HMA Overlay, Functional & COMP & 17 & 314 & 7 & 1652 & 454 \\
\hline HMA Overlay, Functional & HMA & 88 & 210 & 3 & 3086 & 469 \\
\hline HMA Overlay, Functional & PCC & 4 & 129 & 9 & 406 & 187 \\
\hline HMA Overlay, Preventive Maintenance & COMP & 1 & 37 & 37 & 37 & 0 \\
\hline HMA Overlay, Preventive Maintenance & HMA & 26 & 73 & 18 & 296 & 71 \\
\hline HMA Overlay, Structural & HMA & 18 & 236 & 60 & 1022 & 249 \\
\hline Install New Guard Rail & HMA & 1 & 199 & 199 & 199 & 0 \\
\hline Install New Small Structure & HMA & 1 & 80 & 80 & 80 & 0 \\
\hline Interchange Modification & COMP & 1 & 1156 & 1156 & 1156 & 0 \\
\hline Interchange Modification & PCC & 0 & 0 & 0 & 0 & 0 \\
\hline Intersection Improvement & HMA & 5 & 234 & 190 & 301 & 45 \\
\hline Intersection Improvement & PCC & 1 & 123 & 123 & 123 & 0 \\
\hline Mill Full Depth And Bit Overlay & COMP & 3 & 356 & 17 & 753 & 372 \\
\hline Mill Full Depth And Bit Overlay & HMA & 2 & 366 & 226 & 507 & 199 \\
\hline New Br, Cont.Pres.Conc.Box Beam & HMA & 1 & 138 & 138 & 138 & 0 \\
\hline New Road Construction - CRC & PCC & 5 & 2991 & 1244 & 5875 & 1934 \\
\hline
\end{tabular}


Table C.0-2 Unit Costs of Pavement Treatments (Continued)

\begin{tabular}{|c|c|c|c|c|c|c|}
\hline \multirow{2}{*}{ Treatment } & \multirow{2}{*}{$\begin{array}{c}\text { Pavement } \\
\text { Type }\end{array}$} & \multirow{2}{*}{$\begin{array}{l}\text { No.of } \\
\text { Obs. }\end{array}$} & \multicolumn{4}{|c|}{$\begin{array}{c}\text { Cost per Lane Mile } \\
(1000 \mathrm{~s}) 2002 \$\end{array}$} \\
\hline & & & Mean & Min. & Max. & $\begin{array}{l}\text { Std. } \\
\text { Dev. }\end{array}$ \\
\hline New Road Construction, Composite & COMP & 1 & 2966 & 2966 & 2966 & 0 \\
\hline New Road Construction, HMA & HMA & 32 & 2545 & 14 & 22561 & 4472 \\
\hline New Road Construction, PCC & PCC & 31 & 3620 & 368 & 11010 & 2988 \\
\hline New Road, HMA Paving Only & HMA & 2 & 1424 & 720 & 2127 & 995 \\
\hline New Road, PCC Paving Only & PCC & 3 & 1224 & 484 & 2238 & 909 \\
\hline New Sign Installation & PCC & 1 & 2760 & 2760 & 2760 & 0 \\
\hline Other Methods Of Rehabing Pavement & COMP & 1 & 275 & 275 & 275 & 0 \\
\hline Other Methods Of Rehabing Pavement & HMA & 1 & 272 & 272 & 272 & 0 \\
\hline Other Type Project (Miscellaneous) & HMA & 1 & 994 & 994 & 994 & 0 \\
\hline Patch and Rehab HMA Pavement & COMP & 1 & 8226 & 8226 & 8226 & 0 \\
\hline Patch and Rehab HMA Pavement & HMA & 3 & 57 & 42 & 65 & 13 \\
\hline Patch and Rehab PCC Pavement & PCC & 2 & 97 & 27 & 167 & 100 \\
\hline Pavement Repair or Rehabilitation & COMP & 2 & 723 & 181 & 1265 & 766 \\
\hline Pavement Repair or Rehabilitation & HMA & 43 & 311 & 14 & 2718 & 505 \\
\hline Pavement Repair or Rehabilitation & PCC & 1 & 7 & 7 & 7 & 0 \\
\hline Pavement Replacement, HMA & HMA & 3 & 956 & 23 & 2268 & 1170 \\
\hline Pavement Replacement, New PCC & COMP & 1 & 3918 & 3918 & 3918 & 0 \\
\hline Pavement Replacement, New PCC & HMA & 5 & 1394 & 311 & 2376 & 917 \\
\hline Pavement Replacement, New PCC & PCC & 7 & 1454 & 441 & 2597 & 754 \\
\hline PCCP Cleaning and Sealing Joints & PCC & 10 & 269 & 16 & 1828 & 553 \\
\hline PCCP on Asphalt Pavement & HMA & 12 & 89 & 15 & 372 & 98 \\
\hline PCCP on PCC Pavement & PCC & 2 & 1247 & 509 & 1985 & 1044 \\
\hline PCCP Patching & PCC & 15 & 1145 & 20 & 10662 & 2717 \\
\hline Repair PCCP \& HMA Overlay & PCC & 7 & 156 & 10 & 561 & 217 \\
\hline Resurface (Partial 3-R Standards) & COMP & 18 & 383 & 47 & 1960 & 489 \\
\hline Resurface (Partial 3-R Standards) & HMA & 1405 & 297 & 8 & 7282 & 585 \\
\hline Resurface (Partial 3-R Standards) & PCC & 11 & 826 & 52 & 3503 & 1110 \\
\hline Resurface over Asphalt Pavement (Partial 3-R Standards) & HMA & 18 & 361 & 34 & 2619 & 719 \\
\hline Resurface PCC Pavement (Partial 3-R Standards) & PCC & 2 & 136 & 134 & 139 & 3 \\
\hline Road Reconstruction (3R/4R Standards) & COMP & 56 & 673 & 39 & 3394 & 749 \\
\hline Road Reconstruction (3R/4R Standards) & HMA & 104 & 784 & 39 & 4378 & 956 \\
\hline Road Reconstruction (3R/4R Standards) & PCC & 18 & 2118 & 128 & 9686 & 2749 \\
\hline Rubblize PCCP \& HMA Overlay & PCC & 18 & 2322 & 131 & 10789 & 2728 \\
\hline Sight Distance Improvement & HMA & 1 & 505 & 505 & 505 & 0 \\
\hline Small Structure, Replacement & HMA & 2 & 447 & 171 & 723 & 391 \\
\hline Surface Treatment, PM & HMA & 10 & 62 & 8 & 382 & 114 \\
\hline Vertical Sight Distance Correction & HMA & 1 & 906 & 906 & 906 & 0 \\
\hline Wedge And Level Only & HMA & 65 & 53 & 2 & 424 & 83 \\
\hline Widen Pavement and HMA Overlay & HMA & 6 & 262 & 25 & 648 & 230 \\
\hline
\end{tabular}

Source: Oware, 2004. JTRP Status Report - SPR 2810 Estimates of Costs and Service Lives of Pavement and Bridge Projects for Fiscal Planning and Programming. 
Appendix D. AAMEX Model Curves

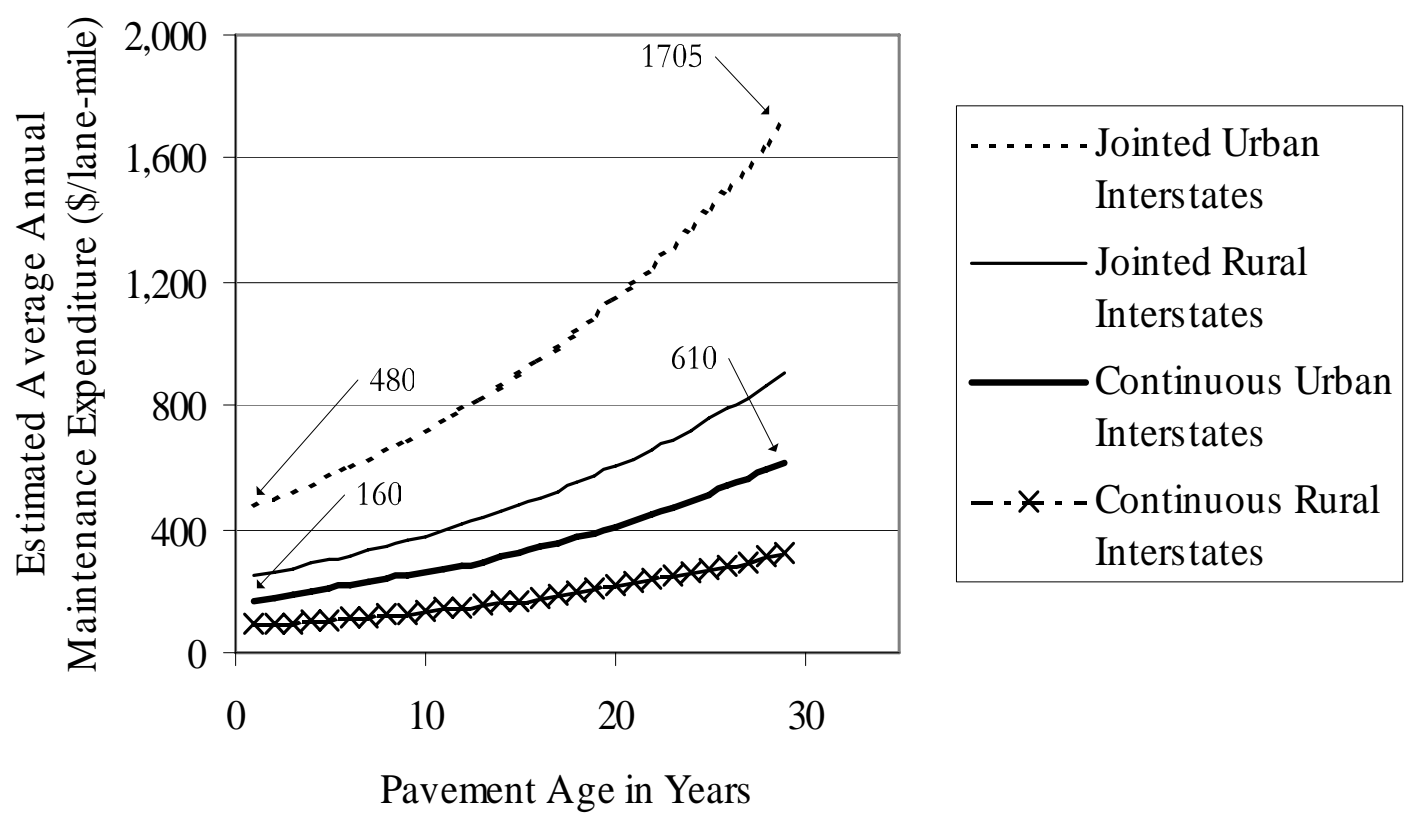

Figure D.0-1 Fitted Values for AAMEX Model, Rigid Interstate Pavements 1995\$

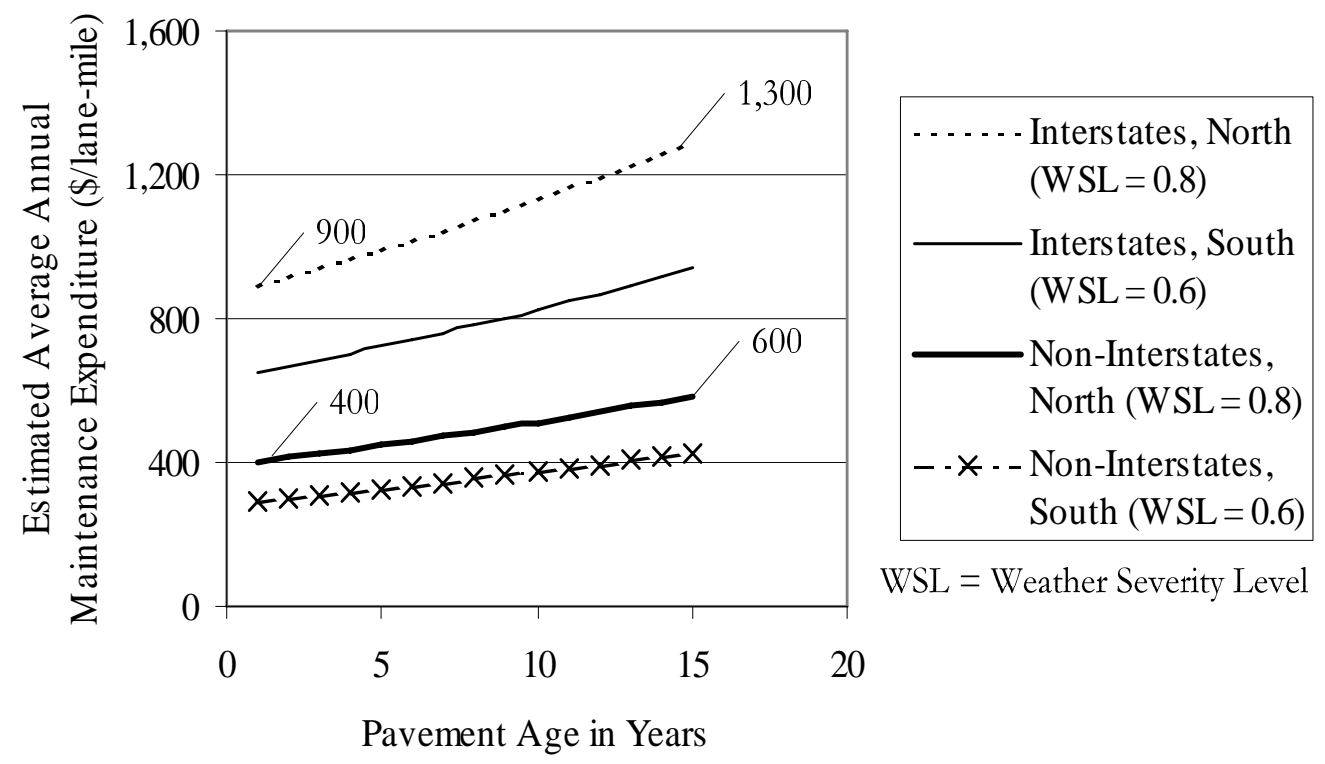

Figure D.0-2 Fitted Values for AAMEX Model, Rigid Interstate Pavements 1995\$ 

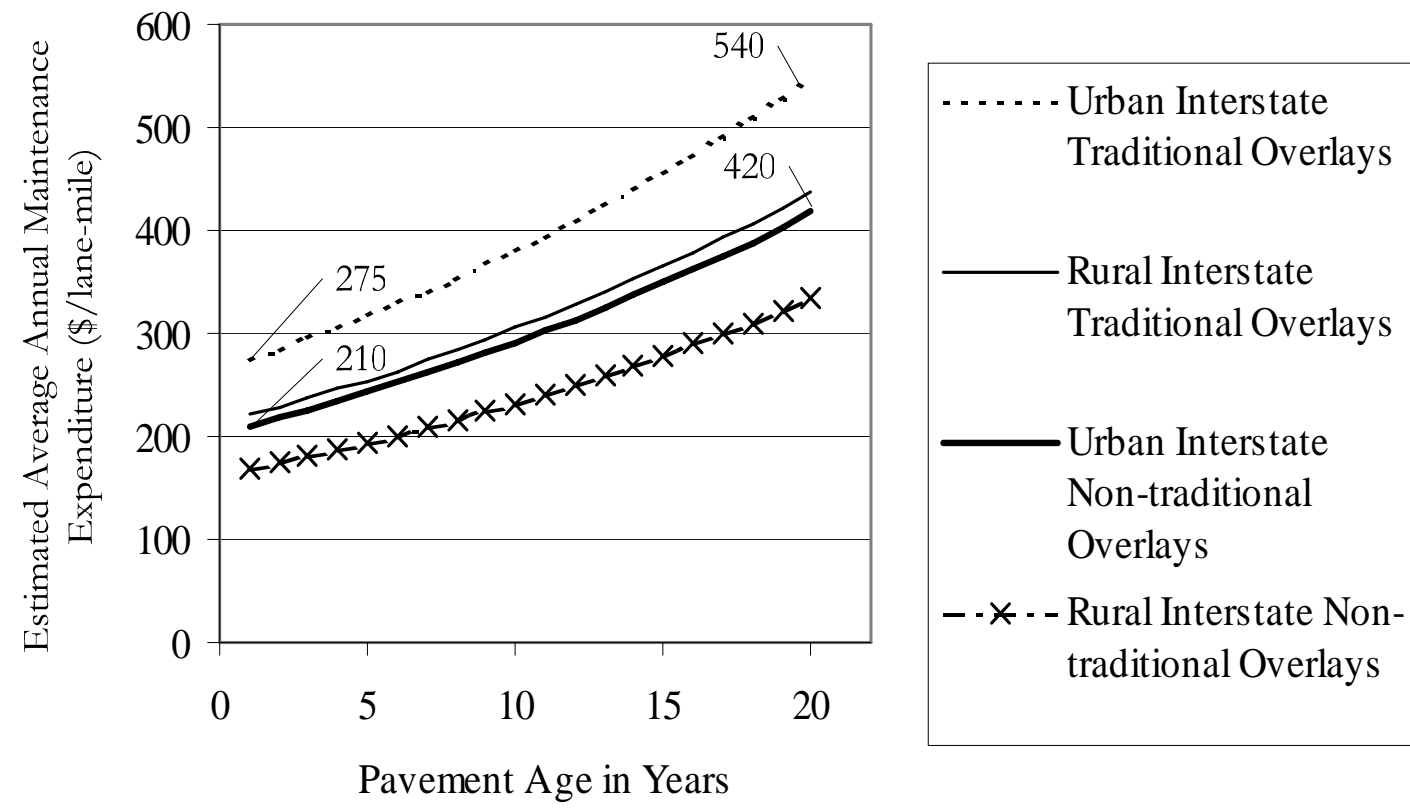

Figure D.0-3 Fitted Values for AAMEX Model, Interstate COMP Pavements 1995\$ 

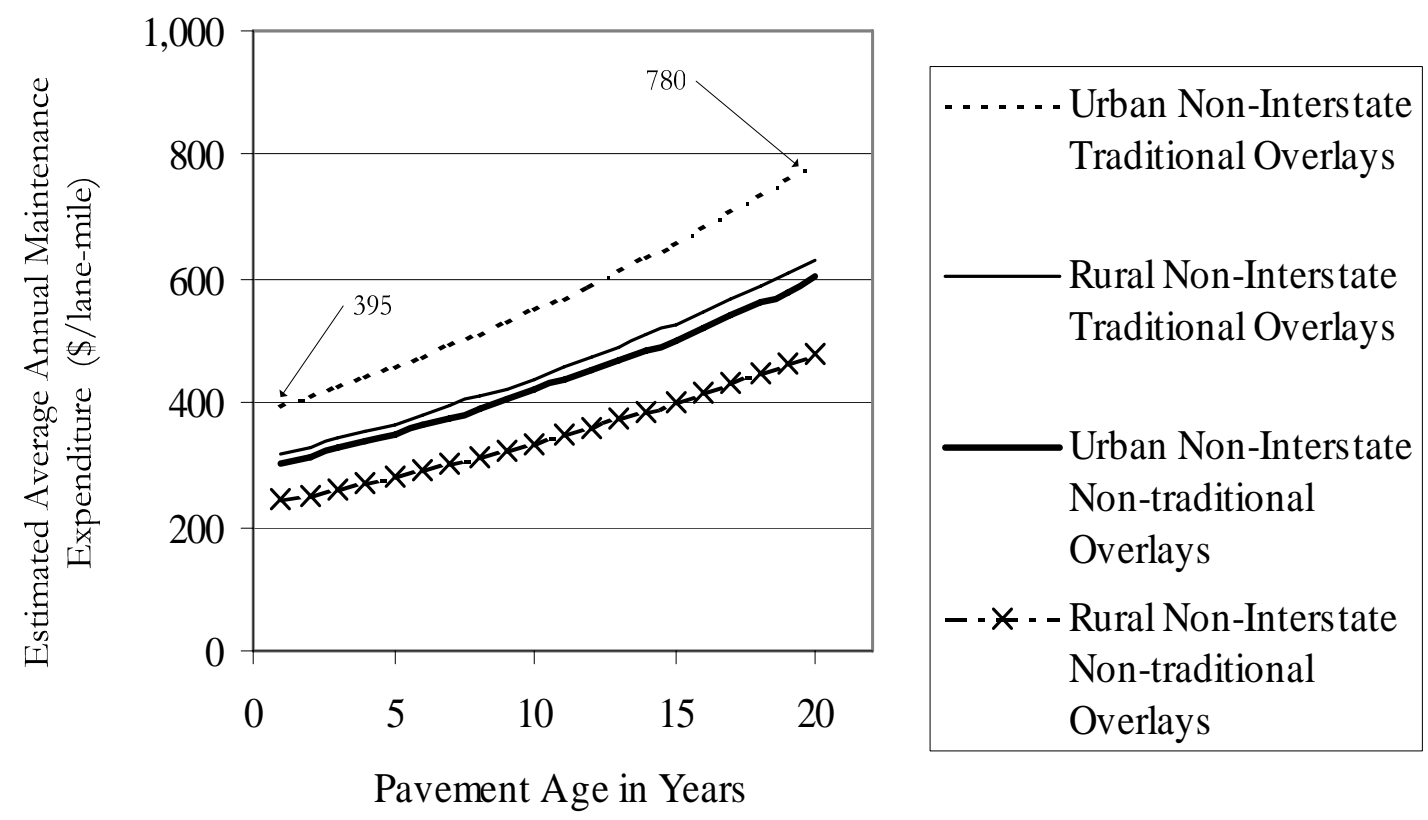

Figure D.0-4 Fitted Values for AAMEX Model, Non-Interstate COMP Pavements 1995\$ 
Appendix E. Bridge System Types

Bridge Type and Configurations

Depending on the superstructure material, bridges are classified as steel or concrete. The superstructure system is defined by its material and its superstructure construction features. Steel superstructures have typical configurations of beams, girders, trusses, and arches (Petros, 1996). Concrete superstructures have common forms of slab, box beam, T-beam, stringer, prestressed girder, or segmental construction. Multi-beams and Slab on stringer structures are for short span lengths and average clearance requirements. When a span becomes excessive other forms of structures must be evaluated. Steel and concrete box girder structures are utilized when bending and torsion are major concerns, however it can represent an expensive solution (Tonias, 1995).

Trusses: a truss is essentially a triangulated assembly or straight members. Trusses have two major characteristics and structural advantage: The primary member forces are axial loads, and the open-web system, accommodates a greater depth than an equivalent solid-web girder. In the past, the conventional truss bridge has been found to be economical for medium spans. However, recent advances in design and construction for both steel and concrete girders have tended to increase the economical span. Thus, truss bridges are now less favored in modern designs.
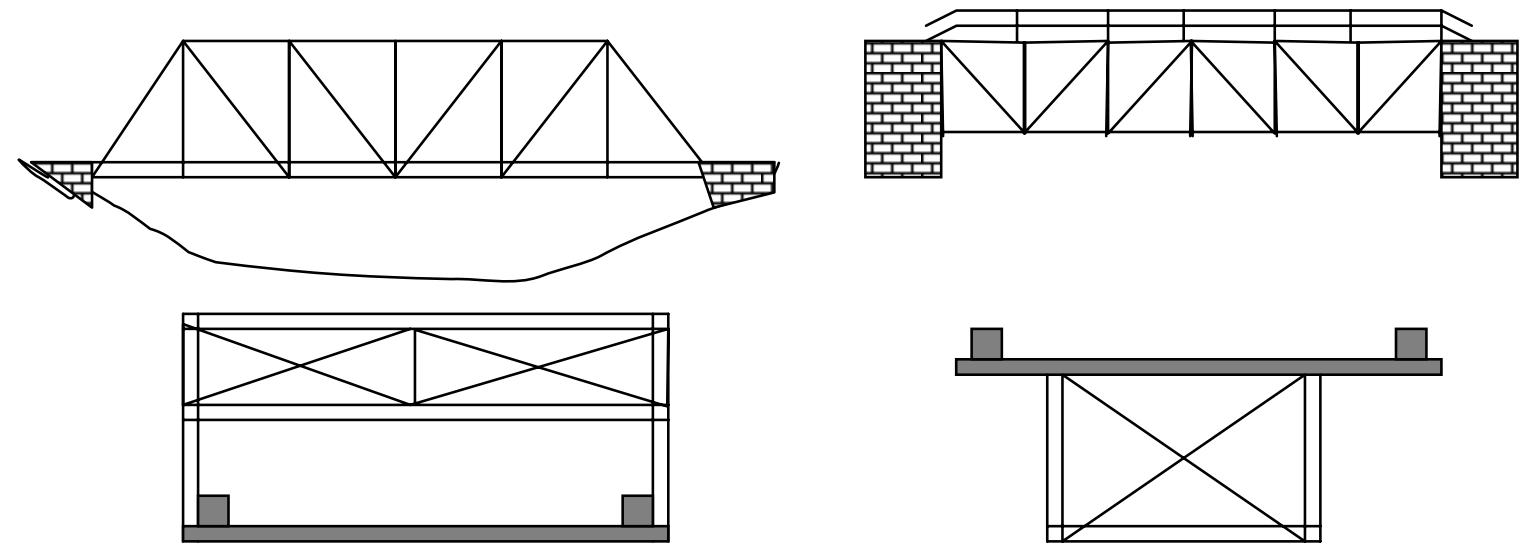

Figure A-1: Truss Systems

Steel Systems: 
Steel I-Beam: floor systems consist of the roadway slab and the supporting rolled beams. The concrete slab is usually $7 \frac{1 / 2}{2}$ to 9 inches thick, with reinforcement perpendicular to traffic. The majority of steel I-beam bridges have some kind of continuity.

Plate Girder and Box Girder Bridges: are designed with the intent to provide a more efficient arrangement and utilization of material than is possible with rolled beams. Typical floor systems consists of 1) steel grid floor resting on longitudinal stringers and main girders, 2) a concrete slab on transverse beams supported on two main girders, 3) multiple girders with or without haunches supporting a concrete slab, and 5) multiple box girders supporting a concrete slab.

Through girder bridges, are structures where the main longitudinal girders extend above the roadway (Figure 2).

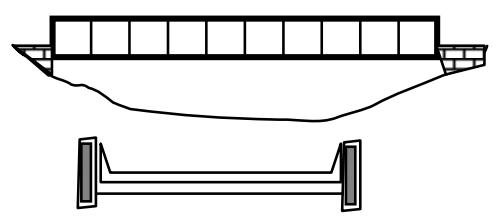

a) Through Girder

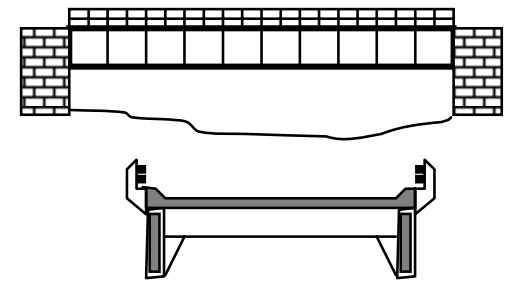

b) Deck Girder

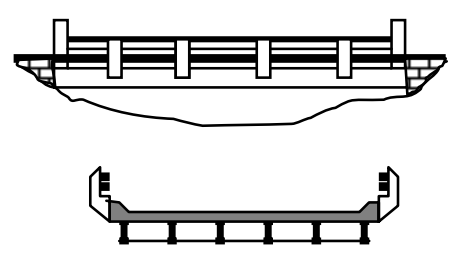

c) I Beam

Figure 2: Steel General Bridge Type

\section{Concrete Bridges:}

A reinforced concrete bridge consists of deck slabs, T-beams, through and box girders, and rigid frames. Pre-stressed or pre-cast concrete structures also add other structural types and enhance bridge adaptability. Typical example of concrete bridge types are shown in Figure A and Figure A-4
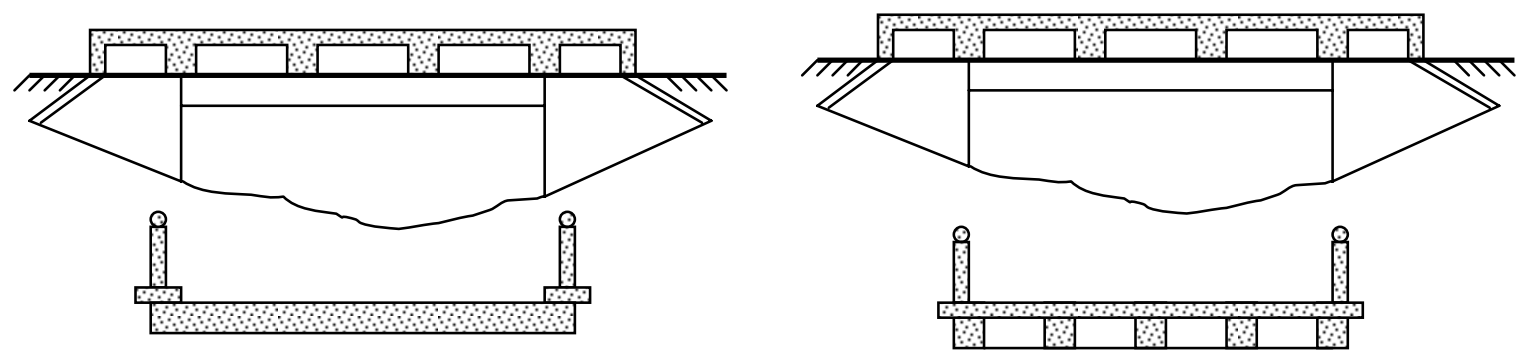

a) Concrete Slab
b) Concrete T-Beam

Figure 3: General Concrete Bridge Type (AASHTO)
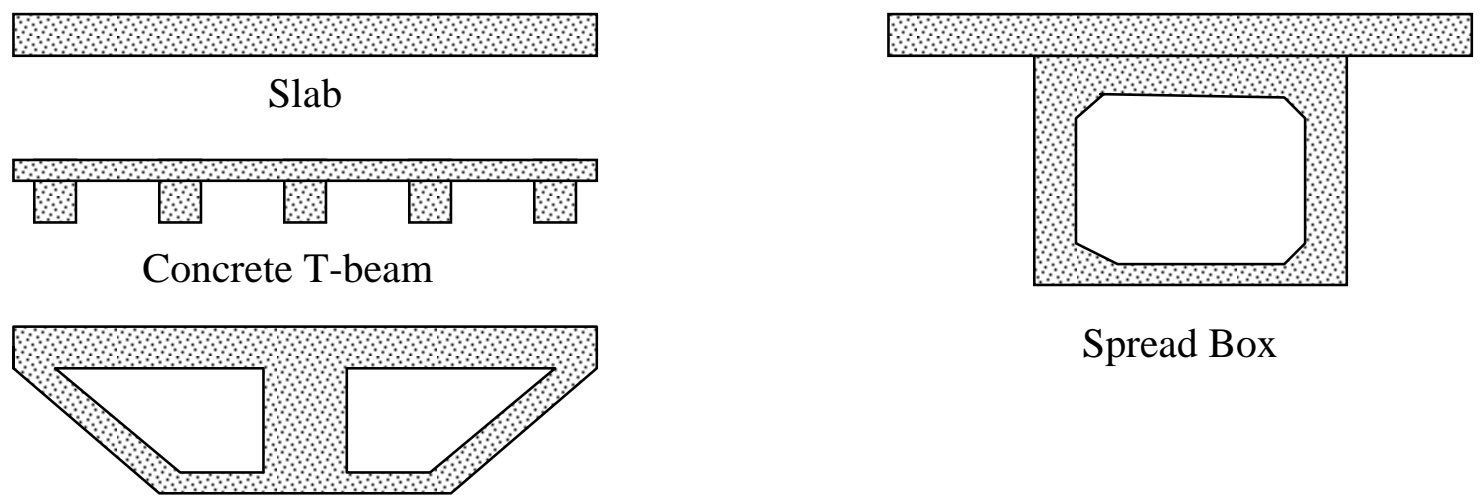

Spread Box

\section{Concrete box girder}
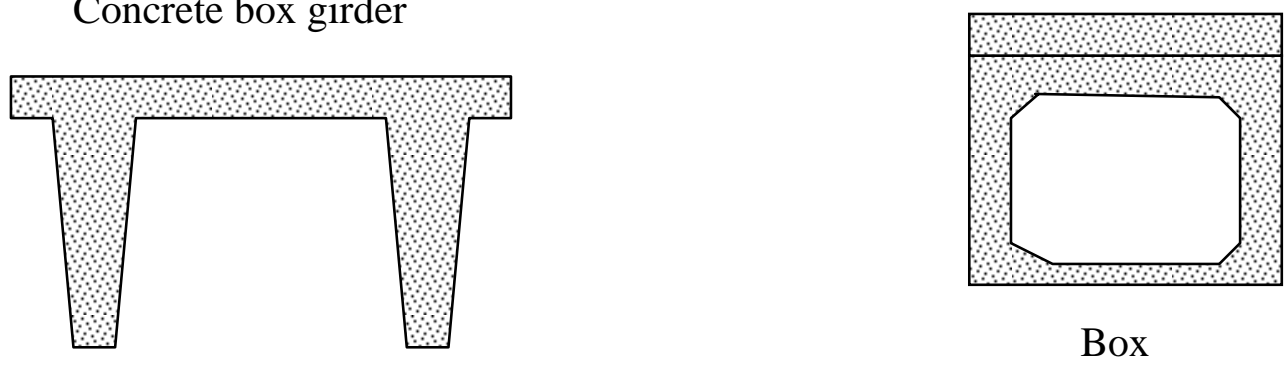

Channel

Figure 4: Typical Concrete Sections

Concrete deck girder bridges are divided into three main types according to the interaction between the girder and the slab. They are: 1) girder-and-slab systems, where the slab spans transversely between longitudinal girders providing a typical T-beam action; 2) girder, floor beam, and one-way slab supported on the floor beam, and 3) girder, floor beam, and two way slab supported along four edges. 